\title{
Pre-emptive and preventive opioids for postoperative pain in adults undergoing all types of surgery (Review)
}

Doleman B, Leonardi-Bee J, Heinink TP, Bhattacharjee D, Lund JN, Williams JP

Doleman B, Leonardi-Bee J, Heinink TP, Bhattacharjee D, Lund JN, Williams JP.

Pre-emptive and preventive opioids for postoperative pain in adults undergoing all types of surgery.

Cochrane Database of Systematic Reviews 2018, Issue 12. Art. No.: CD012624.

DOI: 10.1002/14651858.CD012624.pub2.

www.cochranelibrary.com 
TABLE OF CONTENTS

HEADER 1

ABSTRACT

PLAIN LANGUAGE SUMMARY ....

SUMMARY OF FINDINGS

BACKGROUND

OBJECTIVES

METHODS

RESULTS

Figure 1.

Figure 2.

Figure 3.

Figure 4.

Figure 5.

DISCUSSION

AUTHORS' CONCLUSIONS

ACKNOWLEDGEMENTS

REFERENCES

CHARACTERISTICS OF STUDIES

DATA AND ANALYSES

Analysis 1.1. Comparison 1 Preventive versus postincision opioids for postoperative pain, Outcome 1 Early acute postoperative pain (within 6 hours postoperatively).

Analysis 1.2. Comparison 1 Preventive versus postincision opioids for postoperative pain, Outcome 2 Nausea and vomiting (long term).

Analysis 1.3. Comparison 1 Preventive versus postincision opioids for postoperative pain, Outcome 3 Late acute postoperative pain (24 to 48 hours postoperatively).

Analysis 1.4. Comparison 1 Preventive versus postincision opioids for postoperative pain, Outcome 4 24-hour morphine consumption (mg).

Analysis 1.5. Comparison 1 Preventive versus postincision opioids for postoperative pain, Outcome 5 Time to first analgesic request (minutes).

Analysis 1.6. Comparison 1 Preventive versus postincision opioids for postoperative pain, Outcome 6 Pruritus (long term). .... Analysis 1.7. Comparison 1 Preventive versus postincision opioids for postoperative pain, Outcome 7 Bradycardia (incidence).

Analysis 1.8. Comparison 1 Preventive versus postincision opioids for postoperative pain, Outcome 8 Bradycardia (mean dose of chronotrope in $\mathrm{mcg}$ ).

Analysis 1.9. Comparison 1 Preventive versus postincision opioids for postoperative pain, Outcome 9 Hypotension (incidence).

ADDITIONAL TABLES

APPENDICES

CONTRIBUTIONS OF AUTHORS

DECLARATIONS OF INTEREST

DIFFERENCES BETWEEN PROTOCOL AND REVIEW

INDEX TERMS 
[Intervention Review]

\section{Pre-emptive and preventive opioids for postoperative pain in adults undergoing all types of surgery}

Brett Doleman¹, Jo Leonardi-Bee², Thomas P Heinink³ ${ }^{3}$ Debamita Bhattacharjee ${ }^{4}$, Jon N Lund5 ${ }^{5}$ John P Williams ${ }^{1}$

1Department of Surgery and Anaesthesia, Division of Medical Sciences and Graduate Entry Medicine, School of Medicine, University of Nottingham, Derby, UK. 2Division of Epidemiology and Public Health, The University of Nottingham, Nottingham, UK. ${ }^{3}$ Department of Anaesthesia, Frimley Health NHS Foundation Trust, Frimley Park Hospital, Frimley, UK. ${ }^{4}$ Department of Respiratory Medicine, Royal Derby Hospital, Derby, UK. ${ }^{5}$ Division of Health Sciences, School of Medicine, University of Nottingham, Derby, UK

Contact address: Brett Doleman, Department of Surgery and Anaesthesia, Division of Medical Sciences and Graduate Entry Medicine, School of Medicine, University of Nottingham, Uttoxeter New Road, Derby, DE22 3DT, UK. brett.doleman@nhs.net.

Editorial group: Cochrane Anaesthesia, Critical and Emergency Care Group.

Publication status and date: New, published in Issue 12, 2018.

Citation: Doleman B, Leonardi-Bee J, Heinink TP, Bhattacharjee D, Lund JN, Williams JP. Pre-emptive and preventive opioids for postoperative pain in adults undergoing all types of surgery. Cochrane Database of Systematic Reviews 2018, Issue 12. Art. No.: CD012624. DOI: 10.1002/14651858.CD012624.pub2.

Copyright @ 2018 The Cochrane Collaboration. Published by John Wiley \& Sons, Ltd.

\section{A B S T R A C T}

\section{Background}

Postoperative pain is a common consequence of surgery and can have deleterious effects. It has been suggested that the administration of opioid analgesia before a painful stimulus may improve pain control. This can be done in two ways. We defined 'preventive opioids' as opioids administered before incision and continued postoperatively, and 'pre-emptive opioids' as opioids given before incision but not continued postoperatively. Both pre-emptive and preventive analgesia involve the initiation of an analgesic agent prior to surgical incision with the aim of reducing intraoperative nociception and therefore postoperative pain.

\section{Objectives}

To assess the efficacy of preventive and pre-emptive opioids for reducing postoperative pain in adults undergoing all types of surgery.

\section{Search methods}

We searched the following electronic databases: CENTRAL, MEDLINE, Embase, AMED, and CINAHL (up to 18 March 2018). In addition, we searched for unpublished studies in three clinical trial databases, conference proceedings, grey literature databases, and reference lists of retrieved articles. We did not apply any restrictions on language or date of publication.

\section{Selection criteria}

We included parallel-group randomized controlled trials (RCTs) only. We included participants aged over 15 years old undergoing any type of surgery. We defined postincision opioids as the same intervention administered after incision whether single dose (as comparator with pre-emptive analgesia) or continued postoperatively (as comparator with preventive analgesia) (control group). We considered studies that did and did not use a double-dummy placebo (e.g. intervention group received active drug before incision and placebo after incision; control group received placebo before incision and active drug after incision).

\section{Data collection and analysis}

We used the standard methodological procedures expected by Cochrane. Our primary outcomes were: early acute postoperative pain (measured within six hours and reported on a 0-to-10 scale) and respiratory depression. Our secondary outcomes included: late acute postoperative pain ( 24 to 48 hours and reported on a 0-to-10 scale), 24-hour morphine consumption, and adverse events (intraoperative bradycardia and hypotension). We used GRADE to assess the quality of the evidence for each outcome. 


\section{Main results}

We included 20 RCTs, including one unpublished study with 1343 participants. Two studies were awaiting classification as the full text for these studies was not available. One study evaluated pre-emptive opioids, and 19 studies evaluated preventive opioids. We considered only one study to be at low risk of bias for most domains. The surgeries and opioids used varied, although roughly half of the included studies were conducted in abdominal hysterectomy, and around a quarter used morphine as the intervention. All studies were conducted in secondary care.

\section{Pre-emptive opioids compared to postincision opioids}

For pre-emptive opioids in dental surgery, there may be a reduction in early acute postoperative pain (mean difference (MD) -1.20, 95\% confidence interval ( $\mathrm{Cl})-1.75$ to $-0.65 ; 40$ participants; 1 study; low-quality evidence). This study did not report on adverse events (respiratory depression, bradycardia, or hypotension). There may be a reduction in late acute postoperative pain (MD $-2.10,95 \% \mathrm{Cl}-2.57$ to -1.63; 40 participants; 1 study; low-quality evidence). This study did not report 24-hour morphine consumption.

\section{Preventive opioids compared to postincision opioids}

For preventive opioids, there was probably no reduction in early acute postoperative pain (MD $0.11,95 \% \mathrm{Cl}-0.32$ to 0.53 ; 706 participants; 10 studies; $1^{2}=61 \%$; moderate-quality evidence). There were no events of respiratory depression in four studies (433 participants). There was no important reduction in late acute postoperative pain (MD $-0.06,95 \% \mathrm{Cl}-0.13$ to $0.01 ; 668$ participants; 9 studies; $12=0 \%$; moderatequality evidence). There may be a small reduction in 24-hour morphine consumption (MD $-4.91 \mathrm{mg}, 95 \% \mathrm{Cl}-9.39 \mathrm{mg}$ to $-0.44 \mathrm{mg} ; 526$ participants; 11 studies; $\mathrm{I}^{2}=82 \%$; very low-quality evidence). There may be similar rates of bradycardia (risk ratio (RR) $0.33,95 \% \mathrm{Cl} 0.01$ to 7.88; 112 participants; 2 studies; $\mathrm{I}^{2}=0 \%$; low-quality evidence) and hypotension (RR $1.08,95 \% \mathrm{Cl} 0.25$ to 4.73 ; 88 participants; 2 studies; $12=0 \%$; low-quality evidence).

\section{Authors' conclusions}

Due to the low quality of the evidence, we are uncertain whether pre-emptive opioids reduce postoperative pain. Based on the trials conducted thus far, there was no clear evidence that preventive opioids result in reductions in pain scores. It was unclear if there was a reduction in morphine consumption due to very low-quality of evidence. Too few studies reported adverse events to be able to draw any definitive conclusions. Once assessed, the two studies awaiting classification may alter the conclusions of the review.

\section{PLAIN LANGUAGE SUMMARY}

\section{Pre-emptive and preventive opioids for postoperative pain in adults undergoing all types of surgery}

To assess the ability of a single dose of opioid given before making the first cut during surgery (pre-emptive opioids) and preventive opioids that are given before the first cut and continued after surgery for reducing pain due to surgery in adults.

\section{Review question}

We reviewed the evidence for opioid painkillers (strong painkillers) when given before surgery, compared to the same painkiller given only after the surgeon has cut the skin.

\section{Background}

Most people experience pain after surgery that requires strong opioid painkillers. These medications are associated with a number of side effects including depressed breathing, a slow heart rate, and low blood pressure, as well as vomiting, drowsiness, itching, and constipation. Reducing the amount of opioid needed can limit these side effects and improve the patient experience. Compared to starting painkillers later, beginning painkillers before making the first cut for surgery may reduce pain sensitivity, and so lessen the postoperative pain experienced. We wanted to find out whether giving opioid painkillers before surgery was more effective than giving the same painkiller after surgery.

\section{Study characteristics}

We searched the medical literature for randomized controlled trials (a type of study in which participants are assigned to a treatment group using a random method) in March 2018. Participants were randomly allocated to one of two groups. One group was treated with opioids before the surgeon cut the skin, whilst the other group was given the same medication after the surgeon cut the skin. We identified 20 trials involving a total of 1343 participants aged over 15 years who were undergoing a variety of surgeries. In all but one trial, participants received general anaesthetic. Nearly all participants were low-risk patients. Only one of the trials used a pre-emptive dose of opioid.

\section{Key results}


In one small trial (40 participants) involving people undergoing dental surgery, use of pre-emptive opioids resulted in a small reduction in pain experienced in the first six hours after surgery and at 24 to 48 hours based on low-quality evidence. This study did not report on adverse events or 24-hour morphine consumption.

For preventive opioids started before the first cut was made and continued over the first day after surgery, pain in the first six hours after surgery was similar to when the first opioid dose was given after the first cut to the skin (10 studies; 706 participants). Postoperative pain 24 to 48 hours after surgery was similar between groups ( 9 studies; 668 participants). The evidence for both these findings was of moderate quality. The following findings were supported by low- or very low-quality evidence. A reduction in 24-hour morphine consumption was too small to be clinically relevant (11 studies; 526 participants). Not all studies reported on adverse events, but the numbers of participants with respiratory depression (4 studies; 433 participants), low heart rate (2 studies; 112 participants), or low blood pressure ( 2 studies; 88 participants) were similar between groups.

\section{Quality of the evidence}

The quality of the evidence ranged from very low to moderate. The main issues concerning the included trials were high risk of bias due to limitations in how the findings were presented, the design and conduct of the studies, and wide variations in the findings, which led to uncertainty in the results. Consequently, we found no convincing evidence that starting opioids before the beginning of surgery reduces levels of pain after surgery or the need for continuing opioids. 


\section{SUMMARY OF FINDINGS}

\section{Summary of findings for the main comparison. Pre-emptive opioids compared with postincision opioids for postoperative pain}

Pre-emptive opioids compared with postincision opioids for postoperative pain

Patient or population: adults undergoing dental surgery

Settings: secondary care in Mexico

Intervention: pre-emptive opioids: opioids initiated before incision but not continued postoperatively

Comparison: postincision opioids: the same analgesic intervention initiated after surgical incision

\begin{tabular}{|c|c|c|c|c|c|c|}
\hline \multirow[t]{3}{*}{ Outcomes } & \multicolumn{2}{|c|}{$\begin{array}{l}\text { Illustrative comparative risks* }(95 \% \\
\mathrm{CI})\end{array}$} & \multirow[t]{3}{*}{$\begin{array}{l}\text { Relative effect } \\
(95 \% \mathrm{Cl})\end{array}$} & \multirow{3}{*}{$\begin{array}{l}\text { No. of partici- } \\
\text { pants } \\
\text { (studies) }\end{array}$} & \multirow{3}{*}{$\begin{array}{l}\text { Quality of the } \\
\text { evidence } \\
\text { (GRADE) }\end{array}$} & \multirow[t]{3}{*}{ Comments } \\
\hline & Assumed risk & $\begin{array}{l}\text { Corresponding } \\
\text { risk }\end{array}$ & & & & \\
\hline & $\begin{array}{l}\text { Risk with postin- } \\
\text { cision opioids }\end{array}$ & $\begin{array}{l}\text { Risk with pre- } \\
\text { emptive opioids }\end{array}$ & & & & \\
\hline $\begin{array}{l}\text { Respiratory depression (defined as } \mathrm{SaO}_{2}<92 \% \text {; } \\
\text { yes/no during the postoperative period) }\end{array}$ & $\mathrm{N} / \mathrm{A}$ & $\mathrm{N} / \mathrm{A}$ & $\mathrm{N} / \mathrm{A}$ & $\mathrm{N} / \mathrm{A}$ & $\mathrm{N} / \mathrm{A}$ & $\begin{array}{l}\text { Study did not } \\
\text { report this out- } \\
\text { come. }\end{array}$ \\
\hline $\begin{array}{l}\text { Late acute postoperative pain (measured at } 24 \\
\text { to } 48 \text { hours postoperatively using a validated pain } \\
\text { scale, } 0 \text { no pain to } 10 \text { maximum pain) }\end{array}$ & $\begin{array}{l}\text { The mean pain } \\
\text { was } 3.39 \text { in the } \\
\text { postincision } \\
\text { group. }\end{array}$ & $\begin{array}{l}\text { The mean pain } \\
\text { was } 1.29 \text { in the } \\
\text { pre-emptive } \\
\text { group. }\end{array}$ & $\begin{array}{l}\text { The mean pain } \\
\text { was } 2.10(-2.57 \\
\text { to }-1.63) \text { lower. }\end{array}$ & $\begin{array}{l}40 \\
\text { (1 study) }\end{array}$ & $\begin{array}{l}\oplus \oplus \ominus \ominus \\
\text { low } \mathbf{1}\end{array}$ & \\
\hline $\begin{array}{l}\text { 24-hour morphine consumption ( } \mathrm{mg} \text { ) (if alternative } \\
\text { opioids were used, we converted these to morphine } \\
\text { equivalents using standard conversion factors) }\end{array}$ & $\mathrm{N} / \mathrm{A}$ & $\mathrm{N} / \mathrm{A}$ & $\mathrm{N} / \mathrm{A}$ & $\mathrm{N} / \mathrm{A}$ & $\mathrm{N} / \mathrm{A}$ & $\begin{array}{l}\text { Study did not } \\
\text { report this out- } \\
\text { come. }\end{array}$ \\
\hline Intraoperative bradycardia (yes/no) & $\mathrm{N} / \mathrm{A}$ & $\mathrm{N} / \mathrm{A}$ & $\mathrm{N} / \mathrm{A}$ & $\mathrm{N} / \mathrm{A}$ & $\mathrm{N} / \mathrm{A}$ & $\begin{array}{l}\text { Study did not } \\
\text { report this out- } \\
\text { come. }\end{array}$ \\
\hline
\end{tabular}




\begin{tabular}{|c|c|c|c|c|c|c|c|c|}
\hline 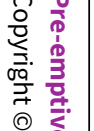 & \multicolumn{2}{|l|}{ Intraoperative hypotension (yes/no) } & $\mathrm{N} / \mathrm{A}$ & N/A & $\mathrm{N}$ & & & $\begin{array}{l}\text { Study did not } \\
\text { report this out- } \\
\text { come. }\end{array}$ \\
\hline 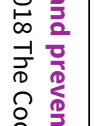 & \multicolumn{8}{|c|}{$\begin{array}{l}{ }^{*} \text { The basis for the assumed risk (e.g. the median control group risk across studies) is provided in footnotes. The corresponding risk (and its } 95 \% \text { confidence interval) is } \\
\text { based on the assumed risk in the comparison group and the relative effect of the intervention (and its } 95 \% \mathrm{CI} \text { ). } \\
\text { Cl: confidence interval; N/A: not applicable }\end{array}$} \\
\hline 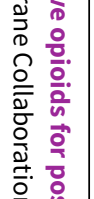 & \multicolumn{8}{|c|}{$\begin{array}{l}\text { GRADE Working Group grades of evidence } \\
\text { High quality: Further research is very unlikely to change our confidence in the estimate of effect. } \\
\text { Moderate quality: Further research is likely to have an important impact on our confidence in the estimate of effect and may change the estimate. } \\
\text { Low quality: Further research is very likely to have an important impact on our confidence in the estimate of effect and is likely to change the estimate. } \\
\text { Very low quality: We are very uncertain about the estimate. }\end{array}$} \\
\hline 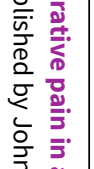 & \multicolumn{8}{|c|}{ Summary of findings 2. Preventive opioids compared with postincision opioids for postoperative pain } \\
\hline 离 & \multicolumn{8}{|c|}{ Preventive opioids compared with postincision opioids for postoperative pain } \\
\hline 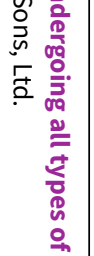 & \multicolumn{8}{|c|}{$\begin{array}{l}\text { Patient or population: adults undergoing all types of surgery } \\
\text { Settings: secondary care in Greece, Germany, the UK, Ireland, Turkey, Croatia, Singapore, Poland, China, the Czech Republic, and Iran } \\
\text { Intervention: preventive opioids: opioids initiated before surgical incision and continued postoperatively } \\
\text { Comparison: postincision opioids: the same analgesic intervention initiated after surgical incision }\end{array}$} \\
\hline 尊 & \multirow[t]{3}{*}{ Outcomes } & \multicolumn{2}{|c|}{$\begin{array}{l}\text { Illustrative comparative risks* } \\
(95 \% \mathrm{CI})\end{array}$} & \multirow[t]{3}{*}{$\begin{array}{l}\text { Relative effect } \\
(95 \% \mathrm{Cl})\end{array}$} & \multirow{3}{*}{$\begin{array}{l}\text { No. of partici- } \\
\text { pants } \\
\text { (studies) }\end{array}$} & \multirow{3}{*}{$\begin{array}{l}\text { Quality of the } \\
\text { evidence } \\
\text { (GRADE) }\end{array}$} & \multirow[t]{3}{*}{ Comments } & \\
\hline$\stackrel{\frac{s}{0}}{\underline{0}}$ & & Assumed risk & $\begin{array}{l}\text { Corresponding } \\
\text { risk }\end{array}$ & & & & & \\
\hline & & $\begin{array}{l}\text { Risk with } \\
\text { postincision } \\
\text { opioids }\end{array}$ & $\begin{array}{l}\text { Risk with pre- } \\
\text { ventive opi- } \\
\text { oids }\end{array}$ & & & & & \\
\hline & $\begin{array}{l}\text { Early acute postoperative pain } \\
\text { (measured within } 6 \text { hours postop- } \\
\text { eratively using a validated pain } \\
\text { scale, } 0 \text { no pain to } 10 \text { maximum } \\
\text { pain) }\end{array}$ & $\begin{array}{l}\text { The mean pain } \\
\text { was } 4.37 \text { ( } 2.94 \\
\text { to } 5.79) .\end{array}$ & $\begin{array}{l}\text { The mean pain } \\
\text { was } 4.53 \text { ( } 3.13 \\
\text { to } 5.93) \text {. }\end{array}$ & $\begin{array}{l}\text { The mean pain in the } \\
\text { intervention groups } \\
\text { was } 0.11 \text { higher ( } 0.32 \\
\text { lower to } 0.53 \text { higher). }\end{array}$ & $\begin{array}{l}706 \\
\text { (10 studies) }\end{array}$ & $\begin{array}{l}\oplus \oplus \oplus \ominus \\
\text { moderate }^{1}\end{array}$ & $\begin{array}{l}\text { From studies } \\
\text { comes as me } \\
\text { reported no } \\
\text { scores and } 1\end{array}$ & $\begin{array}{l}\text { reporting out- } \\
\text { dians, } 6 \text { studies } \\
\text { difference in pain } \\
\text { reported lower }\end{array}$ \\
\hline
\end{tabular}




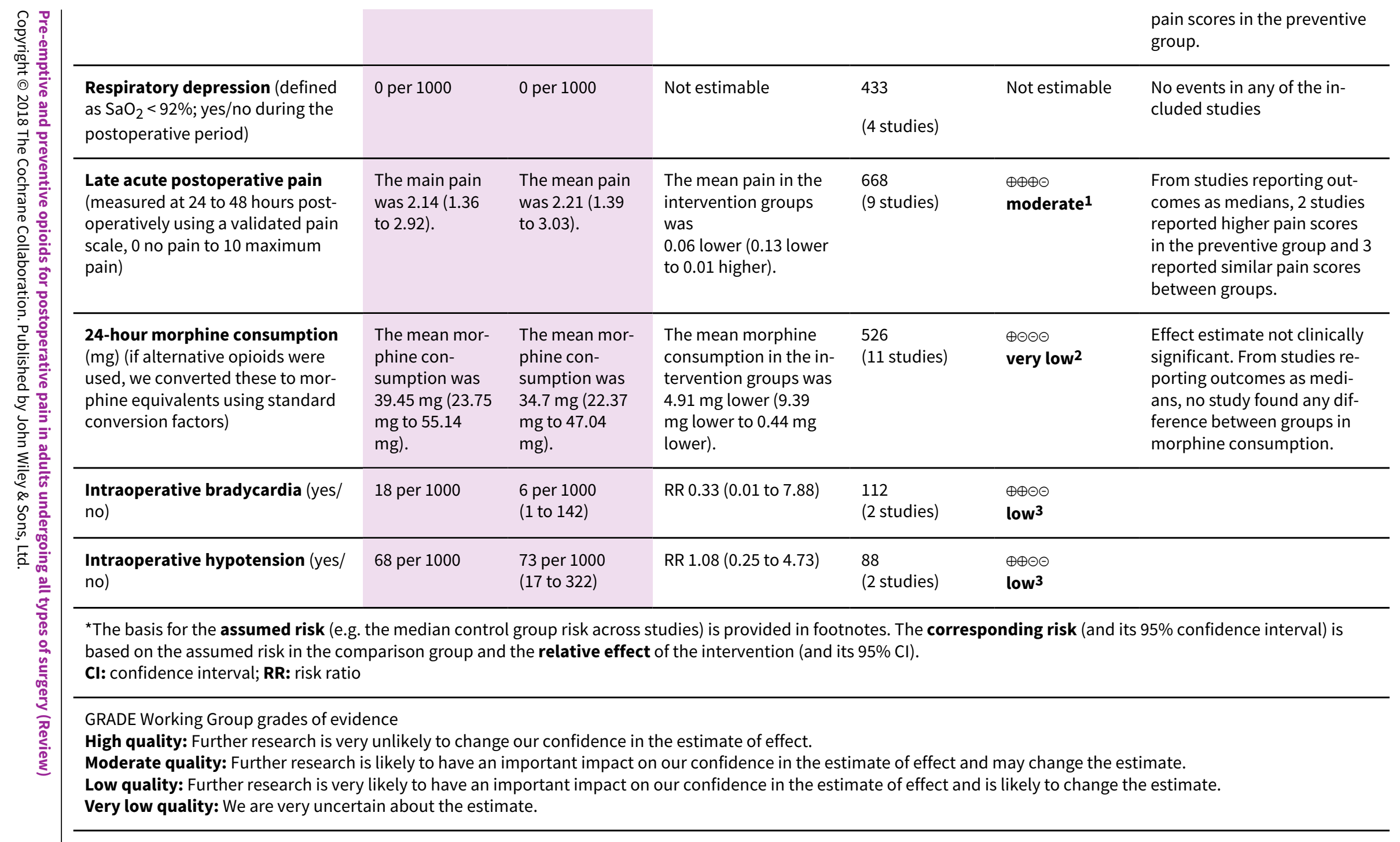

1Downgraded one level due to concerns over risk of bias.

2Downgraded three levels due to concerns over risk of bias, possible publication bias, and unexplained heterogeneity.

${ }^{3}$ Downgraded two levels due to concerns over risk of bias and imprecision. 


\section{B A C K G R O U N D}

\section{Description of the condition}

Postoperative pain is a common consequence of surgery that affects around $80 \%$ of patients. The severity of postoperative pain varies, with $18 \%$ of patients suffering extreme pain in one study (Apfelbaum 2003), and around 25\% of participants having severe pain in a more recent study of 22,963 German patients (Gerbershagen 2014). Pain can have deleterious effects during the postoperative period, including patient dissatisfaction (Myles 2000), interference with daily activities (Strassels 2002), pulmonary complications (Desai 1999), increases in the stress response to surgery (Desborough 2000), and an increased risk of chronic postsurgical pain (Kehlet 2006). Risk factors for severe postoperative pain include the presence of preoperative pain, preoperative anxiety, and the type of surgery (Ip 2009). Intravenous opioids are commonly used to treat pain in the postoperative period (Benhamou 2008). However, their use is associated with many side effects such as vomiting, pruritus (itching), sedation (drowsiness), and patient concerns over addiction (Apfelbaum 2003). Alternative strategies to manage both postoperative pain and reduce postoperative opioid consumption may therefore have important benefits for people undergoing surgery.

\section{Description of the intervention}

Multimodal or balanced analgesia is the gold standard for perioperative pain. However, opioids are still used in the majority of patients undergoing surgery (Benhamou 2008), despite an association between higher opioid use and lower patient satisfaction (Mhuircheartaigh 2009). The mechanism of action of opioids involves binding to mu opioid receptors within the central nervous system, which produces analgesia (Pathan 2012). Although the efficacy of opioids is well established, recent studies have highlighted concerns over the administration of opioids during the perioperative period (Fletcher 2014). Opioid use is associated with a range of adverse effects such as hypotension, bradycardia, vomiting, constipation, respiratory depression, and suppression of immune function (Wheeler 2002; Williams 2007). Furthermore, opioid use may be associated with a paradoxical increase in postoperative pain, a phenomenon known as opioid-induced hyperalgesia. One meta-analysis found that higher intraoperative doses of opioids resulted in both higher postoperative pain scores and opioid consumption (Fletcher 2014).

Pre-emptive analgesia involves the initiation of an analgesic agent (painkiller) prior to surgical incision (before the surgeon cuts the skin). It is thought that by initiating analgesic interventions before surgical injury, the analgesic can provide reductions in intraoperative nociception to the central nervous system and therefore provide superior pain relief compared with the same analgesic given postincision (after the surgeon has cut the skin) (Kissin 2000). Preventive analgesia extends this definition to include increasing the intensity and duration of pre-emptive analgesic interventions until final wound healing (Dahl 2011). The first review to examine the clinical effects of pre-emptive analgesia showed that pre-emptive opioids increased postoperative pain scores when compared to postincision opioids (Møiniche 2002). A second review published a few years later also showed a possible increase in postoperative pain with pre-emptive opioids when compared to postincision opioids (Ong 2005). However, as these reviews were performed over a decade ago, new evidence may have changed these conclusions. Furthermore, these reviews did not evaluate reductions in postoperative opioid side effects and potential adverse events.

\section{How the intervention might work}

Surgical incision promotes changes in both the central and peripheral nervous system known as sensitization. Such sensitization can cause biochemical changes that manifest as hyperalgesia (the same pain stimulus causing increased pain) and allodynia (normally non-painful stimuli causing pain). It is thought that by initiating analgesia before surgical incision, both peripheral and central sensitization can be reduced, resulting in reductions in intraoperative nociception and later both acute and chronic postoperative pain. Preventive analgesia extends this reduction in sensitization to include the postoperative period. This enhanced definition came from an increased understanding of the development of persistent postsurgical pain, which is associated with postoperative sensitization and may only be reduced by continuing analgesia longer into the postoperative period (Dahl 2011). As opioids are commonly used to treat pain postoperatively (Benhamou 2008), any reductions in opioid use may also result in a reduction in opioid adverse events and improve the patient experience. Opioids are known to induce analgesia by binding to $\mathrm{mu}$ opioid receptors within the central nervous system, therefore if these are initiated before surgical incision, this may reduce sensitization and thus lead to lower postoperative pain when compared to postincision administration. Conversely, the use of intraoperative opioids has been associated with the phenomenon of opioid-induced hyperalgesia, which may paradoxically increase postoperative pain (Fletcher 2014; Ong 2005). Exposure to opioids is thought to increase sensitivity to pain via the glutaminergic system, which may manifest as increased pain scores following surgery (Lee 2011).

\section{Why it is important to do this review}

Due to both its common occurrence and potential deleterious effects during the postoperative period (Apfelbaum 2003), reducing postoperative pain is an important clinical issue. A simple adjustment in clinical practice, such as changing the timing of administration of analgesics, could have important implications for postoperative pain management. Moreover, such a change is costneutral and therefore may benefit both anaesthetists in low-income countries and those working within healthcare systems with finite resources (such as the National Health Service (NHS) in the UK). A previous review has highlighted an increase in postoperative pain with pre-emptive opioids (Ong 2005), although most of the data were published over a decade ago, which mandates an updated review of the evidence.

\section{O B JECTIVES}

To assess the effects of preventive and pre-emptive opioids for reducing postoperative pain in adults undergoing all types of surgery (Doleman 2017b). 


\section{METHODS}

\section{Criteria for considering studies for this review}

\section{Types of studies}

We included parallel-group randomized controlled trials only. We also considered studies that did not use a double-dummy placebo (e.g. intervention group received active drug before incision and placebo after incision; control group received placebo before incision and active drug after incision). We excluded studies that included paediatric participants and pharmacokinetic studies not reporting any clinical outcomes. We excluded no studies on the basis of language or publication status. We included participants undergoing general, regional, and local anaesthesia.

\section{Types of participants}

We included adults (aged 15 years and older) undergoing any type of surgery.

We did not include studies that included both participants aged over 15 years and paediatric participants.

\section{Types of interventions}

We compared both preventive opioids and pre-emptive opioids (intervention groups) with postincision opioids (control group). We used the following definitions.

1. Preventive opioids: opioids initiated before surgical incision and continued postoperatively.

2. Pre-emptive opioids: opioids initiated before incision and not continued postoperatively.

3. Postincision opioids: the same analgesic intervention initiated after surgical incision, whether single dose (as comparator with pre-emptive analgesia) or continued postoperatively (as comparator with preventive analgesia) (control group).

However, we acknowledged that most studies including opioids would be preventive by definition (with opioids continued postoperatively).

We only compared interventions if identical analgesics with identical dosages were used. In addition, we only included studies if concurrent use of other multimodal analgesic agents during the perioperative period was identical to avoid confounding. If the studies reported multiple intervention subgroups that had comparable control groups (identical interventions), we combined these into one group using methods described in the Cochrane Handbook for Systematic Reviews of Interventions (Higgins 2011a). We included all types of opioid, at any dose, via any route of administration (oral and parenteral), and all types of regimen (preemptive or preventive) in the analysis.

\section{Types of outcome measures}

\section{Primary outcomes}

1. Early acute postoperative pain (measured within six hours postoperatively using a validated pain scale, converted to a 0 to- 10 scale where a 0-to-100 scale was used; where multiple time points were reported we included the earliest reported time point).
2. Respiratory depression (defined as oxygen saturation $\left(\mathrm{SaO}_{2}\right)<$ $92 \%$; yes/no).

\section{Secondary outcomes}

1. Nausea and vomiting (yes/no).

2. Late acute postoperative pain (measured at 24 to 48 hours postoperatively using a validated pain scale, converted to a 0 to-10 scale where a 0-to-100 scale was used; where multiple time points were reported we included the earliest reported time point).

3. 24-hour morphine consumption (mg) (if alternative opioids were used, we converted these to morphine equivalents using conversion factors) (Table 1) (Doleman 2017a).

4. Time to first analgesic request (minutes).

5. Pruritus (yes/no).

6. Sedation (measured on a continuous scale).

7. Patient satisfaction (converted to a 0-to-10 scale where a 0to-100 scale was used).

8. Chronic pain (yes/no, measured three to six months postoperatively; we included the earliest time point closest to three months).

9. Time to first bowel movement (hours).

10.Intraoperative bradycardia (yes/no and mean dose of chronotrope in $\mathrm{mg} / \mathrm{mcg}$ to assess severity).

11.Intraoperative hypotension (yes/no and mean dose of inotrope/ vasopressor in $\mathrm{mg} / \mathrm{mcg}$ to assess severity).

For the secondary outcomes where time points were not specified, we used the endpoint closest to two hours (one to six hours) to assess immediate short-term effects, and the endpoint closest to 24 hours (six to 48 hours) to assess longer-term effects. We considered a reduction in pain score of 1.5 (on a 0 -to-10 scale) (Gallagher 2001), a reduction in the time to first analgesic request of one hour, a time to first bowel movement of 12 hours, a $10 \mathrm{mg}$ reduction in morphine consumption, and a number needed to treat for an additional beneficial/harmful outcome (NNTB/NNTH) of 10 as clinically significant (Doleman 2015a).

Outcomes did not form part of the study eligibility assessment so studies that met the participant, intervention, and comparison criteria were included in the review even if they reported no relevant outcomes.

\section{Search methods for identification of studies}

\section{Electronic searches}

We did not apply any restrictions on the basis of language or publication status. We translated non-English language studies where necessary. We searched the following electronic databases via the Healthcare Databases Advanced Search (HDAS) from the UK National Institute for Health and Care Excellence: MEDLINE (1946 to 18 March 2018) (Appendix 1); MEDLINE (In-Process \& Other NonIndexed Citations); Embase (1974 to 18 March 2018) (Appendix 2); EBSCO Cumulative Index to Nursing and Allied Health Literature (CINAHL) (1982 to 18 March 2018) (Appendix 2); and the Allied and Complementary Medicine Database (AMED) (1985 to 18 March 2018) (Appendix 3). We also searched the Cochrane Central Register of Controlled Trials (CENTRAL) (the Cochrane Library, Issue 2, February 2018). 
We used the Cochrane Highly Sensitive Search Strategy (sensitivity maximizing version) for identifying randomized controlled trials in MEDLINE (Lefebvre 2011). We searched the following databases for unpublished clinical trials:

1. US National Institutes of Health Ongoing Trials Register ClinicalTrials.gov (www.clinicaltrials.gov);

2. World Health Organization International Clinical Trials Registry Platform (apps.who.int/trialsearch/Default.aspx);

3. European Union Clinical Trials Registry (www.clinicaltrialsregister.eu/).

\section{Searching other resources}

We conducted a search of the OpenGrey database to identify grey literature sources (18 March 2018). We searched reference lists of identified studies and reviews for further studies. We utilized Google Scholar to identify studies that have cited the included studies. In addition, we searched the following conference proceedings to identify further unpublished studies (all years considered):

1. World Congress on Pain (International Association for the Study of Pain);

2. Anaesthetic Research Society Meetings;

3. Association of Anaesthetists of Great Britain and Ireland Winter Symposium and Annual Congress;

4. American Society of Anesthesiologists Annual Meeting;

5. European Society of Anaesthesiologists Euroanaesthesia Conference.

\section{Data collection and analysis}

\section{Selection of studies}

Two review authors (BD and JPW) independently screened the titles and abstracts of studies identified by the search to determine their potential relevance based on the inclusion criteria. We retrieved the full texts of those studies deemed potentially relevant, and BD and JPW assessed the full-text articles for eligibility. Any disagreements were resolved by consensus or by consulting a third review author (JLB) if necessary. BD and JPW used the information from the retrieved reports, such as author name, study centre, type and dose of interventions used, and study dates, to help identify any duplicate publications and linked any duplicate publications.

\section{Data extraction and management}

Two review authors (BD and $\mathrm{TH}$ ) independently extracted data into an electronic database using standardized data extraction forms (Appendix 4; Appendix 5), resolving any disagreements by consensus or by consulting a third review author (DB) if necessary. One review author (BD) performed the analysis. We translated nonEnglish language studies, and extracted data following translation. If data were missing from the original research report, we contacted the corresponding author irrespective of the age of publication. We extracted the following information:

1. bibliographic data including date of completion/publication;

2. country;

3. publication status;

4. source of funding;

5. trial design, e.g. parallel;
6. study setting;

7. number of participants randomized to each trial arm and number included in final analysis;

8. eligibility criteria and key baseline participant data including sex and age;

9. details of treatment regimen received by each group;

10. details of any co-interventions;

11.primary and secondary outcome(s) (with definitions and time points, where applicable);

12.outcome data for primary and secondary outcomes (by group);

13.duration of follow-up;

14.number of withdrawals (by group) and number of withdrawals (by group) due to adverse events;

15.adverse events.

\section{Assessment of risk of bias in included studies}

We assessed risk of bias in the included studies using the Cochrane 'Risk of bias' tool (Higgins 2011b). Two review authors (BD and JPW) independently undertook assessment of risk of bias, and reached agreement by consensus, consulting a third review author (JLB) if disagreement persisted. We assessed risk of bias for the domains of sequence generation; allocation concealment; blinding of participants, study personnel, and outcome assessors; incomplete outcome data; selective outcome reporting; and other sources of bias (Appendix 4). We assessed each domain as low, unclear, or high risk of bias (Higgins 2011b). We presented the results in both a 'Risk of bias' summary and a 'Risk of bias' graph. We interpreted risk of bias across studies by reducing the quality of evidence if there was potential risk of bias in the studies included in each analysis.

\section{Measures of treatment effect}

The treatment effects of dichotomous outcomes are presented as risk ratios (RR) and NNTB/NNTH. We calculated the NNTB/NNTH from the reciprocal of the risk difference if significant differences were observed. Continuous outcomes are presented as mean differences (MD), or if non-comparable scales were used across studies but still presented as continuous data, as standardized mean differences (SMD). The outcomes of time to first analgesic and time to first bowel movement are presented as hazard ratios (HR) where reported. We planned to aggregate reported log hazard ratios, and their associated standard errors, using the generic inverse variance method, but no studies reported data in this format. The precision of effect estimates is reported using $95 \%$ confidence intervals $(\mathrm{Cl})$.

\section{Unit of analysis issues}

As we included parallel-group randomized controlled trials only, unit of analysis issues were not expected (Higgins 2011c). For the main results, we combined different subgroups into one treatment group as suggested in the Cochrane Handbook for Systematic Reviews of Interventions (Higgins 2011a). When conducting metaregression, if a study reported multiple treatment groups for each covariate, we treated these as separate studies and distributed the control group participants between the treatment groups to avoid analysing them twice (Higgins 2011c).

Pre-emptive and preventive opioids for postoperative pain in adults undergoing all types of surgery (Review)

Copyright $\odot 2018$ The Cochrane Collaboration. Published by John Wiley \& Sons, Ltd. 


\section{Dealing with missing data}

We contacted corresponding authors for any data missing from the original publication irrespective of publication date. If we received no response, we extracted data from published graphs. If standard deviations were not reported, we attempted to calculate these from other reported statistics. If this was not possible, we estimated standard deviations from other studies within the meta-analysis (Higgins 2011c). We did not attempt to calculate standard deviations from other measures of dispersion such as the interquartile range.

\section{Assessment of heterogeneity}

We assessed clinical heterogeneity by examining study characteristics such as the type of population, type of surgery, and intervention used, and considered when pooling of results was clinically appropriate. We assessed statistical heterogeneity using the $1^{2}$ statistic. We used the following recommended cut-off values in the interpretation of the $\mathrm{I}^{2}$ statistic (Deeks 2011):

1. $0 \%$ to $40 \%$ might not be important;

2. $30 \%$ to $60 \%$ may represent moderate heterogeneity;

3. $50 \%$ to $90 \%$ may represent substantial heterogeneity;

4. $75 \%$ to $100 \%$ considerable heterogeneity.

For analyses with substantial or considerable statistical heterogeneity, we considered investigating the heterogeneity using meta-regression.

\section{Assessment of reporting biases}

We assessed selective outcome reporting by examining the original study protocol or methods section and comparing these with the reported results. We reported this as part of the Cochrane 'Risk of bias' tool (Higgins 2011b). If 10 or more studies were included in the meta-analysis, we assessed publication bias graphically using funnel plots and quantitatively using Egger's linear regression test (Egger 1997). Due to the low power of this test, we regarded $\mathrm{P}<$ 0.1 as evidence of imprecise study effects and possible publication bias.

\section{Data synthesis}

We used Review Manager 5 to aggregate study data (Review Manager 2014). We conducted separate analyses for pre-emptive and preventive interventions. We aggregated data using a DerSimonian and Laird random-effects model, as we expected the treatment effect to vary with respect to the different populations within each study, and therefore there is no single underlying effect to estimate. For continuous outcomes, we inputted mean, standard deviation, and sample size data from the individual studies, and combined these using the generic inverse variance method. Where raw data could not be extracted from the studies (and the authors did not reply to our request for data), but mean differences were reported, we would use the generic inverse variance method to combine effect measures from studies, although no studies required this. We combined dichotomous outcomes using the Mantel-Haenszel method.

\section{Subgroup analysis and investigation of heterogeneity}

We conducted a priori subgroup analysis for the type of opioid (remifentanil, rapidly short-acting, short-acting, intermediateacting, and long-acting). We grouped these as follows:
1. rapidly short-acting: alfentanil;

2. short-acting: fentanyl, sufentanil;

3. intermediate-acting: pethidine, morphine;

4. long-acting: tramadol.

If we included 10 or more studies in a meta-analysis, we explored reasons for heterogeneity by performing a restricted maximum likelihood, random-effects meta-regression using the covariates type of opioid, dose of opioid (different opioids converted to morphine equivalents), type of anaesthesia, and type of surgery (Thompson 2002). For dummy variables, we used the least effective subgroup as the reference category. We present the $\mathrm{R}^{2}$ analogue with a corresponding $P$ value for each covariate. Due to the expected low number of studies, we only performed univariate analysis for each covariate. We used the Knapp-Hartung method to calculate $P$ values (as this method more appropriately uses the $t$ distribution for the between-study variance). We performed this analysis using the software Stata Version 15 (metan and metareg command).

\section{Sensitivity analysis}

We performed sensitivity analysis by restricting the analysis to studies at low risk of bias (defined as low risk for randomization, allocation concealment, blinding, and incomplete outcome data, and not judged as high risk for any other domain). As we judged studies that did not use a double-dummy design as at high risk of bias for blinding, we assessed the impact of excluding these studies from the analysis. We also performed sensitivity analysis by excluding studies where standard deviations were estimated. Furthermore, for dichotomous outcomes, if it was unclear if all randomized participants had been analysed using intention-totreat, we assumed that any missing participants did not suffer an event in the main analysis (best-case scenario). During sensitivity analysis, we also assumed missing participants did suffer an event (worst-case scenario). We did not use any other forms of imputation for missing values. For continuous outcomes, we analysed only the participants whose outcomes were measured (available-case analysis).

\section{'Summary of findings' table and GRADE}

We have presented outcomes in a 'Summary of findings' table. We produced two 'Summary of findings' tables, one for each comparison:

1. pre-emptive opioids versus postincision opioids (Summary of findings for the main comparison);

2. preventive opioids versus postincision opioids (Summary of findings 2).

The outcomes for each comparison included early acute postoperative pain, adverse events (respiratory depression, bradycardia, and hypotension), late acute postoperative pain, and 24-hour morphine consumption. We presented these using the GRADE approach (Schünemann 2011). We downgraded the quality of evidence from high to moderate, low, or very low. Two review authors (BD and JPW) independently undertook the downgrading of evidence, reaching agreement by consensus. Characteristics of the evidence that resulted in downgrading included:

Pre-emptive and preventive opioids for postoperative pain in adults undergoing all types of surgery (Review) 
1. limitations in the design and implementation of available studies suggesting a high likelihood of bias (e.g. studies not using a double-dummy placebo design);

2. indirectness of evidence (indirect population, intervention, control, or outcomes);

3. unexplained heterogeneity $(12>50 \%)$ or inconsistency of results not explained through meta-regression or sensitivity analyses;

4. imprecision of results (wide confidence intervals);

5. evidence of publication bias ( $P<0.1$ on Egger's linear regression test).

\section{RE S U L T S}

\section{Description of studies}

\section{Results of the search}

Our search of the electronic databases identified 3728 studies (Figure 1). We identified no ongoing unpublished studies from the clinical trial databases or grey literature searching. We identified two further studies from conference proceedings (Espi 2004; Kurzova 2005). We found one further study from searching of reference lists, and those studies that had cited the included studies. We assessed 23 full-text articles, three of which we excluded. We excluded one because it did not meet our inclusion criteria, Collis 1995, and two for which only abstracts were available and there was not enough information to extract data (Espi 2004; Nagasaka 1996). We contacted the authors of 11 studies (Gerlach 2003; Koprulu 2015; Lenz 2008; Mansfield 1996; Millar 1998; PozosGuillen 2007; Sert 2012; Shen 2008; Wilson 1994; Wordliczek 2002; Zand 2012). We received replies from three of these (Lenz 2008; Millar 1998; Wilson 1994), but unfortunately no further data were available. Of the three studies available in abstract form only, we attempted to contact the authors (Espi 2004; Kurzova 2005; Nagasaka 1996), receiving a response from only one who provided enough information for inclusion (Kurzova 2005). Given the possibility of receiving further data in future reviews, we categorized two of these abstracts to studies awaiting classification (see Characteristics of studies awaiting classification) (Espi 2004; Nagasaka 1996). 
Figure 1. Study flow diagram.

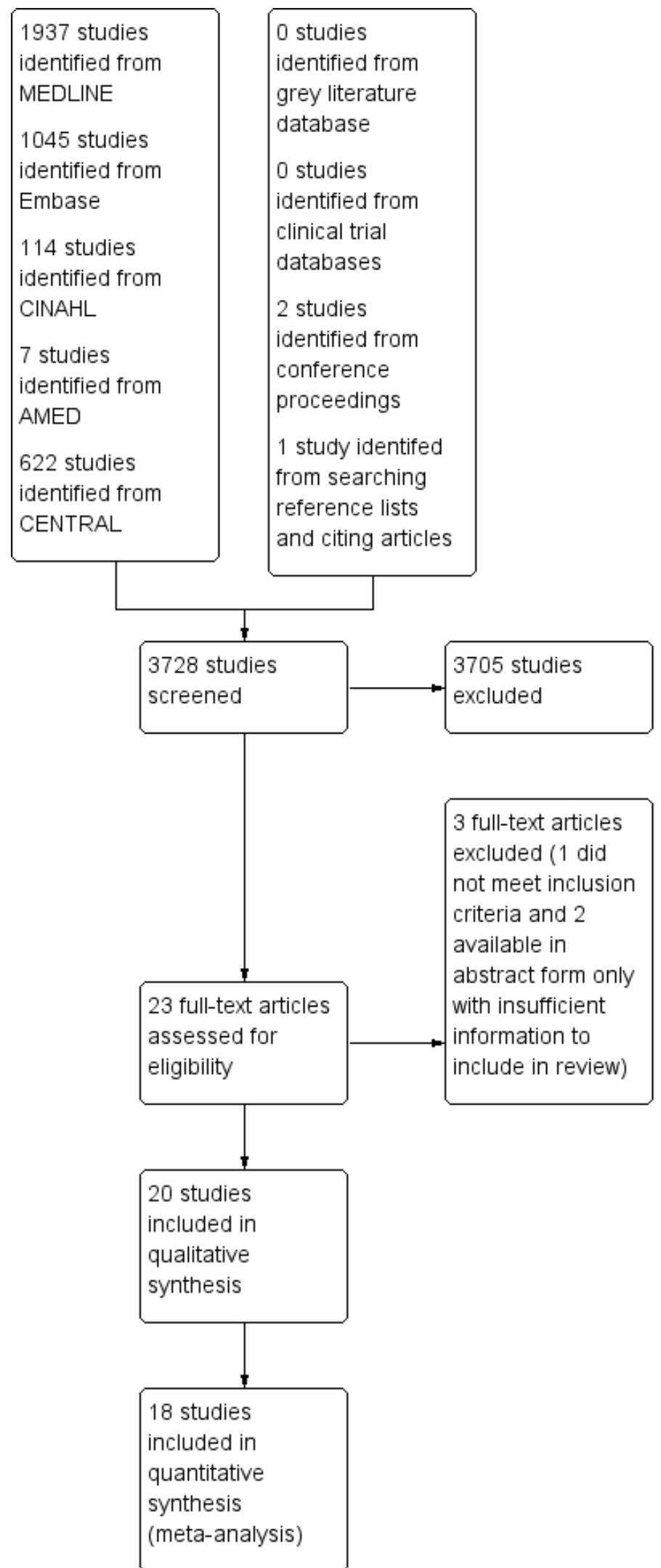




\section{Included studies}

Following full-text review, we included 20 studies with a total of 1343 participants.

\section{Participants}

The types of surgery conducted in studies were diverse: abdominal hysterectomy in 10 studies (Fassoulaki 1995; Griffin 1997; Kiliçkan 2001; Kurzova 2005; Mansfield 1994; Mansfield 1996; Millar 1998; Richmond 1993; Sarantopoulos 1996; Wilson 1994); dental surgery in two studies (Chew 1997; Pozos-Guillen 2007); lumbar spinal surgery in one study (Gerlach 2003); varicose vein surgery in one study (Koprulu 2015); arthroscopic anterior cruciate ligament repair in one study (Lenz 2008); open cholecystectomy in one study (Pjevic 1999); thyroid and breast surgery in one study (Sert 2012); lumpectomy in one study (Shen 2008); hemicolectomy in one study (Wordliczek 2002); and open nephrolithomy in one study (Zand 2012). All studies included participants undergoing general anaesthesia, except one that was performed under local anaesthesia (Pozos-Guillen 2007). Due to the nature of the surgery, 10 studies included female participants only (Fassoulaki 1995; Griffin 1997; Kiliçkan 2001; Kurzova 2005; Mansfield 1994; Mansfield 1996; Millar 1998; Richmond 1993; Sarantopoulos 1996; Wilson 1994). Nearly all studies included low-risk patients (American Society of Anesthesiologists (ASA) 1 or 2), and common exclusion criteria included participants with systemic disease (especially liver and renal disease) and participants with chronic pain or chronic use of analgesics and allergies to study medications.

\section{Settings}

All studies were conducted in secondary care (Chew 1997; Fassoulaki 1995; Gerlach 2003; Griffin 1997; Kiliçkan 2001; Koprulu 2015; Kurzova 2005; Lenz 2008; Mansfield 1994; Mansfield 1996; Millar 1998; Pjevic 1999; Pozos-Guillen 2007; Richmond 1993; Sarantopoulos 1996; Sert 2012; Shen 2008; Wilson 1994; Wordliczek 2002; Zand 2012). Five studies were conducted in the UK (Mansfield 1994; Mansfield 1996; Millar 1998; Richmond 1993; Wilson 1994), one in Singapore (Chew 1997), two in Greece (Fassoulaki 1995; Sarantopoulos 1996), one in Ireland (Griffin 1997), three in Turkey (Kiliçkan 2001; Koprulu 2015; Sert 2012), one in the Czech Republic (Kurzova 2005), one in Norway (Lenz 2008), one in Croatia (Pjevic 1999), one in Mexico (Pozos-Guillen 2007), one in China (Shen 2008), one in Poland (Wordliczek 2002), one in Iran (Zand 2012), and one in Germany (Gerlach 2003).

\section{Interventions}

Opioids studied included: morphine in six studies (Kiliçkan 2001; Kurzova 2005; Mansfield 1996; Millar 1998; Richmond 1993; Zand 2012); tramadol in four studies (Koprulu 2015; Pozos-Guillen 2007; Shen 2008; Wordliczek 2002); pethidine in three studies (Chew 1997; Pjevic 1999; Sert 2012); alfentanil in three studies (Griffin 1997; Mansfield 1994; Wilson 1994); fentanyl in one study (Lenz 2008); sufentanil in one study (Sarantopoulos 1996); fentanyl and sufentanil (different subgroups within the same study) in one study (Fassoulaki 1995); and remifentanil in one study (Gerlach 2003). Nearly all studies evaluated preventive opioids, with only one study evaluating pre-emptive interventions (Pozos-Guillen 2007).

\section{Comparators}

All of the included studies gave identical postincision doses (Chew 1997; Fassoulaki 1995; Gerlach 2003; Griffin 1997; Kiliçkan 2001;
Koprulu 2015; Kurzova 2005; Lenz 2008; Mansfield 1994; Mansfield 1996; Millar 1998; Pjevic 1999; Pozos-Guillen 2007; Richmond 1993; Sarantopoulos 1996; Sert 2012; Shen 2008; Wilson 1994; Wordliczek 2002; Zand 2012). Timing of the postincision dosing varied and included 15 studies that gave the dose after incision but intraoperatively (Fassoulaki 1995; Gerlach 2003; Griffin 1997; Kiliçkan 2001; Koprulu 2015; Mansfield 1994; Mansfield 1996; Millar 1998; Pjevic 1999; Richmond 1993; Sarantopoulos 1996; Sert 2012; Shen 2008; Wilson 1994; Zand 2012), and five that gave the dose after surgery (Chew 1997; Kurzova 2005; Lenz 2008; Pozos-Guillen 2007; Wordliczek 2002).

\section{Funding sources}

Twelve studies did not report whether or not they received any funding (Chew 1997; Fassoulaki 1995; Kiliçkan 2001; Mansfield 1994; Mansfield 1996; Millar 1998; Pjevic 1999; Sarantopoulos 1996; Sert 2012; Shen 2008; Wilson 1994; Zand 2012). Five studies reported receiving funding from non-commercial entities (Gerlach 2003; Griffin 1997; Lenz 2008; Pozos-Guillen 2007; Wordliczek 2002); one study reported receiving no funding (Koprulu 2015); one study reported receiving funding, although it was unclear whether this was commercial or not (Kurzova 2005), and one study author received funding from a commercial entity, although it was unclear what role the funder had in the study (Richmond 1993).

\section{Postoperative opioids and concurrent analgesia}

Most of the included studies used patient-controlled analgesia (PCA) (Gerlach 2003; Griffin 1997; Kiliçkan 2001; Kurzova 2005; Lenz 2008; Mansfield 1994; Mansfield 1996; Millar 1998; Richmond 1993; Sert 2012; Shen 2008; Wilson 1994; Wordliczek 2002; Zand 2012). Postoperative opioids used (on demand) included pethidine (Chew 1997; Koprulu 2015; Sarantopoulos 1996), propoxyphene and pethidine (Fassoulaki 1995), piritramide (Gerlach 2003; Pjevic 1999), morphine (Griffin 1997; Kiliçkan 2001; Kurzova 2005; Mansfield 1994; Mansfield 1996; Millar 1998; Richmond 1993; Shen 2008; Wilson 1994; Zand 2012), fentanyl and oxycodone (Lenz 2008), and tramadol (Sert 2012; Wordliczek 2002). Concurrent postoperative analgesia included paracetamol (Fassoulaki 1995; Koprulu 2015), paracetamol and diclofenac (Lenz 2008), metamizole (Pjevic 1999), dexamethasone, paracetamol, and diclofenac (Pozos-Guillen 2007), propoxyphene and paracetamol (Sarantopoulos 1996), and many reported no concurrent analgesia or did not mention any in the methods (Chew 1997; Gerlach 2003; Griffin 1997; Kiliçkan 2001; Kurzova 2005; Mansfield 1994; Mansfield 1996; Millar 1998; Richmond 1993; Sert 2012; Shen 2008; Wilson 1994; Wordliczek 2002; Zand 2012).

\section{Excluded studies}

We excluded one study because part of the postincision dosing was given before incision, therefore it did not satisfy the inclusion criteria as a true postincision intervention (control) (see Characteristics of excluded studies) (Collis 1995).

\section{Studies awaiting classification}

Given the possibility of acquiring further data in future reviews, we categorized two further studies as awaiting classification (see Characteristics of studies awaiting classification) (Espi 2004; Nagasaka 1996). We did not include these studies because they were only available in abstract format with not enough information 
to extract data, and our attempts to contact the study authors went unanswered.

\section{Ongoing studies}

We did not identify any ongoing studies.

\section{Risk of bias in included studies}

We have presented an overview of the risk of bias in the included studies in Figure 2 and Figure 3.

Figure 2. Risk of bias graph: review authors' judgements about each risk of bias item presented as percentages across all included studies.

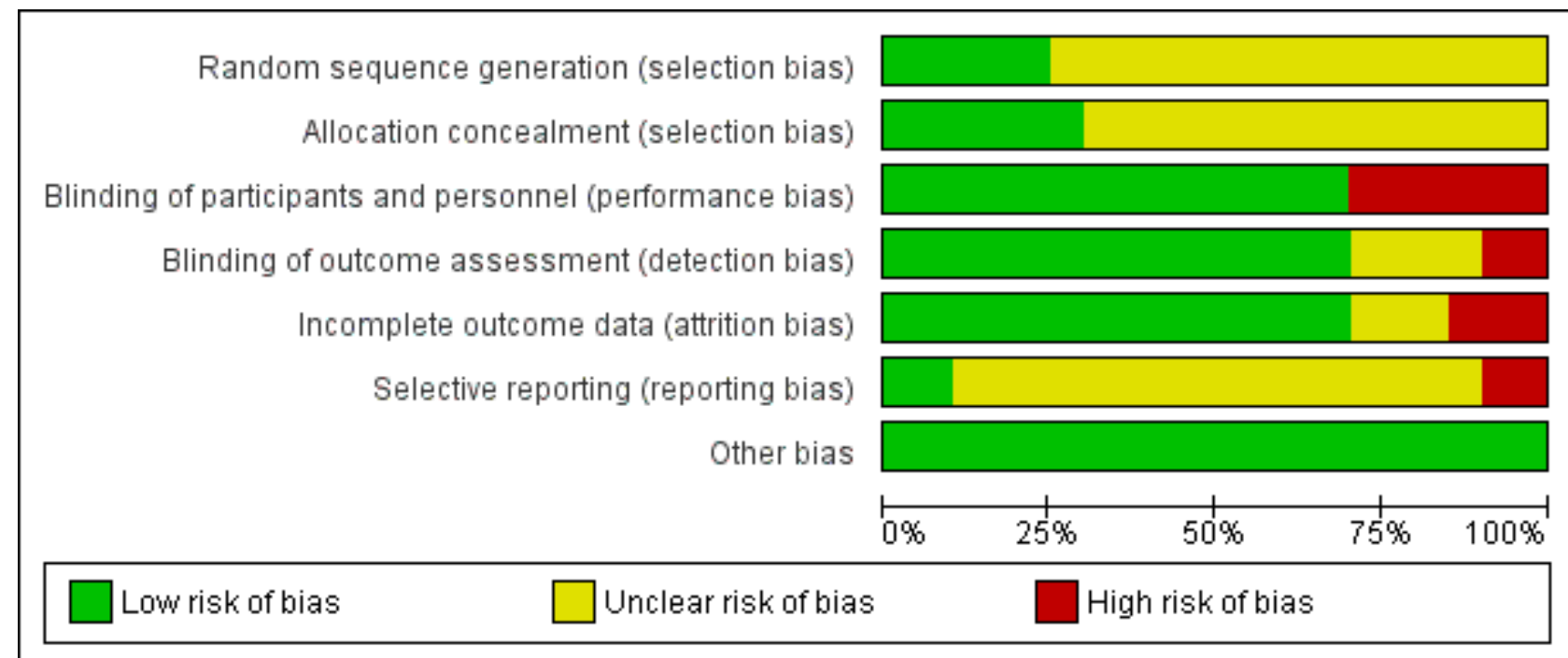


Figure 3. Risk of bias summary: review authors' judgements about each risk of bias item for each included study.

\begin{tabular}{|c|c|c|c|c|c|c|c|}
\hline & 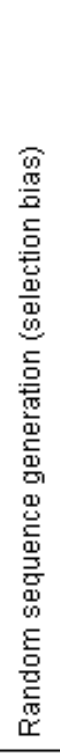 & 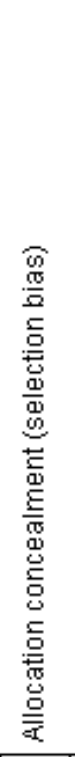 & 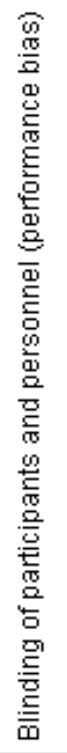 & 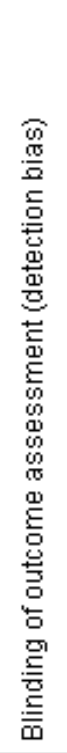 & 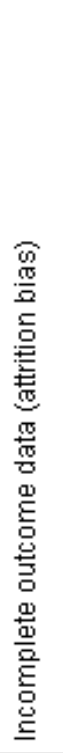 & 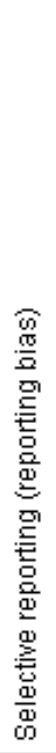 & 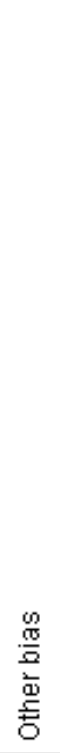 \\
\hline Chew 1997 & $?$ & $?$ & + & + & + & $?$ & + \\
\hline Fassoulaki 1995 & + & $?$ & $\odot$ & $\oplus$ & $\odot$ & $?$ & + \\
\hline Gerlach 2003 & $?$ & $?$ & $\odot$ & + & + & $?$ & + \\
\hline Griffin 1997 & $?$ & $?$ & $\odot$ & $\odot$ & $\odot$ & $?$ & 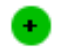 \\
\hline Kiliçkan 2001 & $?$ & + & + & + & $?$ & $?$ & + \\
\hline Koprulu 2015 & ? & ? & + & $?$ & + & ? & + \\
\hline Kurzova 2005 & $?$ & $?$ & $\oplus$ & + & + & $?$ & + \\
\hline Lenz 2008 & + & $\odot$ & $\odot$ & $\odot$ & $\odot$ & + & + \\
\hline Mansfield 1994 & $?$ & $?$ & $\Theta$ & $\odot$ & $\odot$ & ? & + \\
\hline Mansfield 1996 & $?$ & + & + & + & $\odot$ & $?$ & + \\
\hline Millar 1998 & $?$ & + & + & $?$ & $\odot$ & $\odot$ & + \\
\hline Pjevic 1999 & $?$ & $?$ & + & $?$ & + & ? & + \\
\hline Pozos-Guillen 2007 & $?$ & $?$ & $\Theta$ & $\Theta$ & $\odot$ & $\Theta$ & + \\
\hline Richmond 1993 & $?$ & + & $\odot$ & $\odot$ & $\Theta$ & ? & + \\
\hline Sarantopoulos 1996 & + & $?$ & + & + & + & ? & + \\
\hline Sert 2012 & $\odot$ & $?$ & $\Theta$ & ? & + & ? & + \\
\hline Shen 2008 & $?$ & + & + & + & + & ? & + \\
\hline Wilson 1994 & $?$ & $?$ & $\odot$ & $\odot$ & ? & ? & + \\
\hline Wordliczek 2002 & ? & ? & - & - & $?$ & ? & + \\
\hline Zand 2012 & + & $?$ & $\odot$ & + & $\odot$ & + & + \\
\hline
\end{tabular}


Figure 3. (Continued)

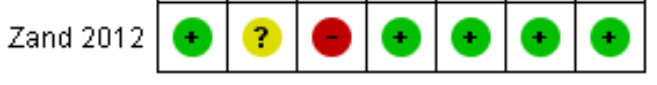

\section{Allocation}

For random sequence generation, we judged 15 studies as at unclear risk of bias as they did not include enough information to be judged as low risk (Chew 1997; Gerlach 2003; Griffin 1997; Kiliçkan 2001; Koprulu 2015; Kurzova 2005; Mansfield 1994; Mansfield 1996; Millar 1998; Pjevic 1999; Pozos-Guillen 2007; Richmond 1993; Shen 2008; Wilson 1994; Wordliczek 2002). The remainder of the studies used computer-generated randomization and were therefore assessed as at low risk of bias for this domain (Fassoulaki 1995; Lenz 2008; Sarantopoulos 1996; Sert 2012; Zand 2012). For allocation concealment, 11 studies did not include enough information to enable a judgement of low risk and were therefore assessed as at unclear risk of bias (Chew 1997; Gerlach 2003; Koprulu 2015; Kurzova 2005; Mansfield 1994; Pjevic 1999; PozosGuillen 2007; Sert 2012; Wilson 1994; Wordliczek 2002; Zand 2012). Three studies used sealed envelopes with no further details provided and so were judged as at unclear risk of bias (Fassoulaki 1995; Griffin 1997; Sarantopoulos 1996), and two studies used sequentially numbered, sealed envelopes that were either opaque or administered by a third party not involved in the study, and so were judged as at low risk of bias (Lenz 2008; Shen 2008). In four studies participants were pharmacy allocated (Kiliçkan 2001; Mansfield 1996; Millar 1998; Richmond 1993), therefore these studies were assessed as at low risk of bias for this domain. No studies were judged as at high risk of bias for either random sequence generation or allocation concealment.

\section{Blinding}

Due to both intervention and control groups receiving an active intervention, in order for a study to be judged as at low risk of performance bias it needed to use a double-dummy placebo that was described as similar or identical in appearance (see Types of studies). Fourteen studies satisfied the criteria to be judged as at low risk of bias for this domain (Chew 1997; Fassoulaki 1995; Griffin 1997; Kiliçkan 2001; Koprulu 2015; Kurzova 2005; Lenz 2008; Mansfield 1996; Millar 1998; Pjevic 1999; Richmond 1993; Sarantopoulos 1996; Shen 2008; Wilson 1994). Six studies did not use a double-dummy placebo that was similar in appearance and were therefore judged as at high risk of performance bias (Gerlach 2003; Mansfield 1994; Pozos-Guillen 2007; Sert 2012; Wordliczek 2002; Zand 2012). For detection bias, we assessed studies as at low risk of bias if they described outcome assessment as blinded or if it was likely blinded due to masked allocation concealment and identical placebo used. We assessed 14 studies as at low risk of detection bias (Chew 1997; Fassoulaki 1995; Gerlach 2003; Griffin 1997; Kiliçkan 2001; Kurzova 2005; Lenz 2008; Mansfield 1994; Mansfield 1996; Richmond 1993; Sarantopoulos 1996; Shen 2008; Wilson 1994; Zand 2012). Four studies included insufficient information to be judged as either low or high risk for this domain (Koprulu 2015; Millar 1998; Pjevic 1999; Sert 2012). We judged two studies as at high risk of detection bias, one because no placebo was used (Pozos-Guillen 2007), and the other because the interventions were administered at different times (Wordliczek 2002).

\section{Incomplete outcome data}

We judged 14 studies as at low risk of attrition bias due to complete follow-up or dropouts that were similar in numbers (Chew 1997; Fassoulaki 1995; Gerlach 2003; Koprulu 2015; Kurzova 2005; Lenz 2008; Mansfield 1994; Mansfield 1996; Pjevic 1999; Pozos-Guillen 2007; Sarantopoulos 1996; Sert 2012; Shen 2008; Zand 2012). Three studies did not include enough information to permit a judgement of low or high risk of bias and were therefore judged as at unclear risk of bias (Kiliçkan 2001; Wilson 1994; Wordliczek 2002). We judged three studies as at high risk of attrition bias as participants were excluded for adverse effects that could have been caused by excess morphine consumption, which introduced bias into the study (Griffin 1997; Millar 1998; Richmond 1993).

\section{Selective reporting}

Sixteen studies did not report registration on a clinical trial database or have a published protocol and so were judged as at unclear risk of bias for this domain (Chew 1997; Fassoulaki 1995; Gerlach 2003; Griffin 1997; Kiliçkan 2001; Koprulu 2015; Kurzova 2005; Mansfield 1994; Mansfield 1996; Pjevic 1999; Richmond 1993; Sarantopoulos 1996; Sert 2012; Shen 2008; Wilson 1994; Wordliczek 2002). Two studies were registered on a clinical trial database and reported prespecified outcomes and so were judged as at low risk of reporting bias (Lenz 2008; Zand 2012). Two studies did not report adverse events that were prespecified on a clinical trial registration and therefore were judged as at high risk of bias for this domain (Millar 1998; Pozos-Guillen 2007).

\section{Other potential sources of bias}

We judged all of the included studies as at low risk of other bias as they had groups with similar baseline characteristics and received no industry funding, or industry had no clear involvement in the study (Chew 1997; Fassoulaki 1995; Gerlach 2003; Griffin 1997; Kiliçkan 2001; Koprulu 2015; Kurzova 2005; Lenz 2008; Mansfield 1994; Mansfield 1996; Millar 1998; Pjevic 1999; Pozos-Guillen 2007; Richmond 1993; Sarantopoulos 1996; Sert 2012; Shen 2008; Wilson 1994; Wordliczek 2002; Zand 2012).

\section{Effects of interventions}

See: Summary of findings for the main comparison Pre-emptive opioids compared with postincision opioids for postoperative pain; Summary of findings 2 Preventive opioids compared with postincision opioids for postoperative pain

\section{Pre-emptive opioids versus postincision opioids Primary outcomes}

1. Early acute postoperative pain (measured within six hours postoperatively)

One study evaluated pre-emptive opioids versus postincision opioids in dental surgery (Pozos-Guillen 2007). There may be a reduction in early acute postoperative pain with pre-emptive opioids (mean difference (MD) $-1.20,95 \%$ confidence interval (CI) -1.75 to $-0.65 ; 40$ participants; Table 2 ). We downgraded the quality 
of the evidence (by two levels) to low due to concerns over risk of bias and imprecision.

\section{Respiratory depression (defined as $\mathrm{SaO}_{2}<92 \%$; yes/no)}

No studies reported respiratory depression for pre-emptive versus postincision opioids.

\section{Secondary outcomes}

\section{Nausea and vomiting (yes/no)}

No studies reported nausea and vomiting for pre-emptive versus postincision opioids.

\section{Late acute postoperative pain (measured at $\mathbf{2 4}$ to $\mathbf{4 8}$ hours postoperatively)}

One study evaluated pre-emptive opioids versus postincision opioids in dental surgery (Pozos-Guillen 2007). There may be lower pain scores in the pre-emptive opioid group (MD -2.10, 95\% Cl -2.57 to $-1.63 ; 40$ participants; Table 2 ). We downgraded the quality of the evidence (by two levels) to low due to concerns over risk of bias and imprecision.

\section{24-hour morphine consumption (mg)}

This outcome does not apply to this comparison, as by definition pre-emptive opioids were not given during the postoperative period.

\section{Time to first analgesic request (minutes)}

No studies reported time to first analgesic for pre-emptive versus postincision opioids.

\section{Pruritus (yes/no)}

No studies reported pruritus for pre-emptive versus postincision opioids.

\section{Sedation (measured on a continuous scale)}

No studies reported sedation for pre-emptive versus postincision opioids.

\section{Patient satisfaction (converted to a 0-to-10 scale where a 0-to-100 scale was used)}

No studies reported patient satisfaction for pre-emptive versus postincision opioids.

\section{Chronic pain (yes/no, measured three to six months postoperatively; we included the earliest time point closest to three months)}

No studies reported chronic pain for pre-emptive opioids versus postincision opioids.

\section{Time to first bowel movement (hours)}

No studies reported time to first bowel movement for pre-emptive versus postincision opioids.

10. Intraoperative bradycardia (yes/no and mean dose of chronotrope in $\mathrm{mg} / \mathrm{mcg}$ to assess severity)

No studies reported intraoperative bradycardia or mean dose of chronotrope for pre-emptive versus postincision opioids.

\section{Intraoperative hypotension (yes/no and mean dose of inotrope/} vasopressor in $\mathrm{mg} / \mathrm{mcg}$ to assess severity)

No studies reported intraoperative hypotension or mean dose of inotrope for pre-emptive versus postincision opioids.

\section{Preventive opioids versus postincision opioids}

\section{Primary outcomes}

1. Early acute postoperative pain (measured within six hours postoperatively)

Ten studies evaluated preventive opioids versus postincision opioids (Fassoulaki 1995; Gerlach 2003; Griffin 1997; Kiliçkan 2001; Koprulu 2015; Pjevic 1999; Richmond 1993; Sarantopoulos 1996; Shen 2008; Wordliczek 2002). There was probably no important reduction in early postoperative pain with preventive opioids (MD $0.11,95 \% \mathrm{Cl}-0.32$ to $0.53 ; 706$ participants; $\mathrm{I}^{2}=61 \%$; Analysis 1.1 ). There was no evidence of publication bias on visual inspection of funnel plots (Figure 4), or Egger's linear regression test $(P=0.27)$. The quality of evidence was moderate (downgraded one level due to concerns over risk of bias). On meta-regression analysis, type of opioid predicted nearly all of the observed heterogeneity $\left(\mathrm{R}^{2}=\right.$ $98 \% ; P=0.05 ; 12$ residual $=0 \%)$, with longer-acting opioids the most effective (MD - 0.94 for intermediate-acting and MD - 0.55 for longacting). Type of surgery was not a significant predictor $\left(R^{2}=0 \% ; P=\right.$ $0.8 ; 12$ residual $=66 \%$ ). Excluding studies where standard deviations had been estimated did not change the results (MD $0.36,95 \% \mathrm{CI}$ -0.20 to 0.93 ). 
Figure 4. Funnel plot of comparison: 1 Preventive versus postincision, outcome: 1.1 Early acute postoperative pain.

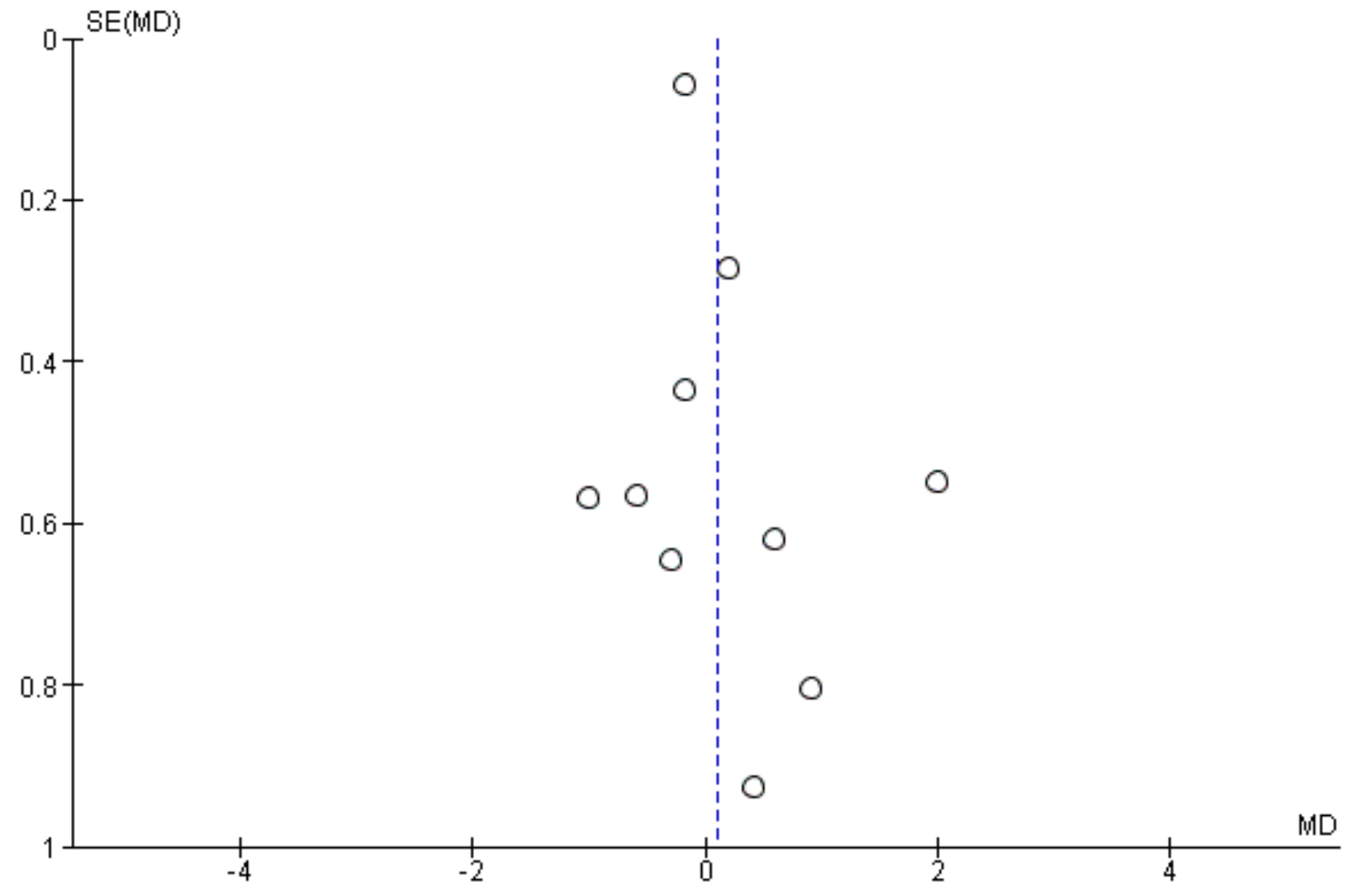

The following studies reported continuous outcomes as medians and were therefore included in a narrative synthesis. Most studies found no difference in pain scores, although one study did report lower pain scores in the preventive versus postincision group (2 versus 3 , respectively; $P=0.01$ ) (Sert 2012). Of the other studies reporting similar pain scores, one study reported no difference recorded at 0.5 hours postoperatively (preventive 2 versus postincision $1 ; \mathrm{P}=0.17$ ) (Lenz 2008). Another study reported no difference in pain scores at 2 hours on a 0 -to-100millimetre visual analogue scale (VAS) (preventive $45.5 \mathrm{~mm}$ versus postincision $38 \mathrm{~mm}$; $\mathrm{P}>0.05$ ) (Mansfield 1994). A study by the same authors found no significant difference between preventive and postincision groups on a 0-to-100-millimetre VAS $(48.2 \mathrm{~mm}$ versus $58.7 \mathrm{~mm}$, respectively; $P>0.05$ ) (Mansfield 1996). A study conducted in dental surgery also found no difference at 0.5 hours between groups (preventive 1.2 versus postincision 1.1; $\mathrm{P}=0.9$ ) (Chew 1997). We could not use data from one study because the graphs contained contradictory legends, although they reported no difference in the results text (Millar 1998); each graph contained a main title of "pain scores at rest" or "pain scores on movement", whilst the text underneath the graph explained the opposite condition. One study reported similar median pain scores in both preventive and postincision groups ( 8 versus $8 ; \mathrm{P}=0.38$ ) (Zand 2012).

\section{Respiratory depression (defined as $\mathrm{SaO}_{2}<92 \%$; yes/no)}

Four studies (433 participants) reported on respiratory depression for preventive versus postincision opioids (Griffin 1997; Koprulu
2015; Sert 2012; Shen 2008). However, none of the studies reported any events.

\section{Secondary outcomes}

\section{Nausea and vomiting (yes/no)}

Three studies evaluated long-term outcomes for preventive opioids for the composite outcome of nausea and vomiting (Gerlach 2003; Griffin 1997; Mansfield 1996). On meta-analysis there was probably no difference between groups (risk ratio (RR) $0.90,95 \% \mathrm{Cl} 0.58$ to $1.39 ; 121$ participants; 3 studies; $1^{2}=0 \%$; Analysis 1.2 ). The quality of evidence was moderate (downgraded one level due to concerns over risk of bias). Inputting data assuming that excluded participants suffered an event did not change the results for this outcome (RR $0.80,95 \% \mathrm{Cl} 0.54$ to 1.18 ).

\section{Late acute postoperative pain (measured at 24 to 48 hours postoperatively)}

Nine studies evaluated late acute postoperative pain for preventive versus postincision opioids (Fassoulaki 1995; Gerlach 2003; Griffin 1997; Kiliçkan 2001; Koprulu 2015; Pjevic 1999; Richmond 1993; Sarantopoulos 1996; Shen 2008). On meta-analysis, we found no difference between groups in pain scores (MD $-0.06,95 \% \mathrm{Cl}-0.13$ to $0.01 ; 668$ participants; $\left.\right|^{2}=0 \%$; Analysis 1.3 ). The quality of evidence was moderate (downgraded one level due to concerns over risk of bias). Some studies reported data in graphs that were either bar charts at each time point or line graphs of pain scores ( $y$ axis) and time (x axis). Excluding studies where standard deviations had been 
estimated did not change the results (MD $-0.06,95 \% \mathrm{Cl}-0.13$ to 0.01).

The following studies reported continuous outcomes as medians and were therefore included in a narrative synthesis. Studies found either higher pain scores in the preventive group, Lenz 2008; Wilson 1994, or similar pain scores (Mansfield 1994; Mansfield 1996; Sert 2012). One study reported higher pain scores on postoperative day one in the preventive group compared with the postincision group (2 versus 1; $P=0.02$ ) (Lenz 2008). Another study also reported higher pain scores in the preventive group at 24 hours on a 0 to-100-millimetre VAS (34 mm versus $23 \mathrm{~mm}$; $\mathrm{P}<0.05$ ) (Wilson 1994). A further study reported no difference in pain scores at 24 hours using a 0-to-100-millimetre VAS (preventive $28.5 \mathrm{~mm}$ versus postincision $21 \mathrm{~mm} ; \mathrm{P}>0.05$ ) (Mansfield 1994). A study by the same authors found no significant difference on a 0-to-100-millimetre VAS (preventive $23.4 \mathrm{~mm}$ versus postincision $31.5 \mathrm{~mm}$; $\mathrm{P}>0.05$ ) (Mansfield 1996). Another study reported pain scores on a graph, although it was unclear what measure of central tendency these represented. There was no difference in pain scores between the preventive and postincision group ( 0 versus 1 , respectively; $P>0.05$ ) (Sert 2012). One study did not report 24-hour pain scores on the graph and so the results could not be included (Zand 2012). We could not use data from one study because the graphs contained contradictory legends, although they reported no difference in the results text (Millar 1998).

\section{24-hour morphine consumption (mg)}

Eleven studies evaluated this outcome for preventive versus postincision opioids (Gerlach 2003; Griffin 1997; Kiliçkan 2001; Koprulu 2015; Kurzova 2005; Lenz 2008; Pjevic 1999; Richmond 1993; Sarantopoulos 1996; Wilson 1994; Zand 2012). However, in one study no participant received postoperative opioids, thus this study did not contribute data to the meta-analysis (Pjevic 1999). There may be a small reduction in 24-hour morphine consumption in the preventive group (MD $-4.91 \mathrm{mg}, 95 \% \mathrm{Cl}-9.39 \mathrm{mg}$ to -0.44 mg; 526 participants; $1^{2}=82 \%$; Analysis 1.4 ). The quality of the evidence was very low. There was evidence of possible publication bias $(P=0.07)$ (Figure 5). We downgraded the evidence by three levels due to concerns over risk of bias, possible publication bias, and unexplained heterogeneity. On meta-regression analysis for 24-hour morphine consumption, although both type of opioid ( $\mathrm{R}^{2}$ $=45 \% ; \mathrm{P}=0.24 ; \mathrm{I}^{2}$ residual $\left.=49 \%\right)$ and type of surgery $\left(\mathrm{R}^{2}=42 \%\right.$; $P=0.29 ; I^{2}$ residual $=46 \%$ ) explained some of the heterogeneity, neither was statistically significant $(P>0.1)$. Excluding studies where standard deviations had been estimated did not change the results (MD $-6.99 \mathrm{mg}, 95 \% \mathrm{Cl}-14.25 \mathrm{mg}$ to $0.28 \mathrm{mg}$ ). When we restricted the analysis to studies at low risk of bias, only one study remained (Lenz 2008); 24-hour morphine consumption in this study was similar between groups (MD $-1.76 \mathrm{mg}, 95 \% \mathrm{Cl}-7.64 \mathrm{mg}$ to 4.12 $\mathrm{mg})$. No other results differed from the main analysis.

\section{Figure 5. Funnel plot of comparison: 1 Preventive versus postincision, outcome: 1.5 24-hour morphine consumption} (mg).

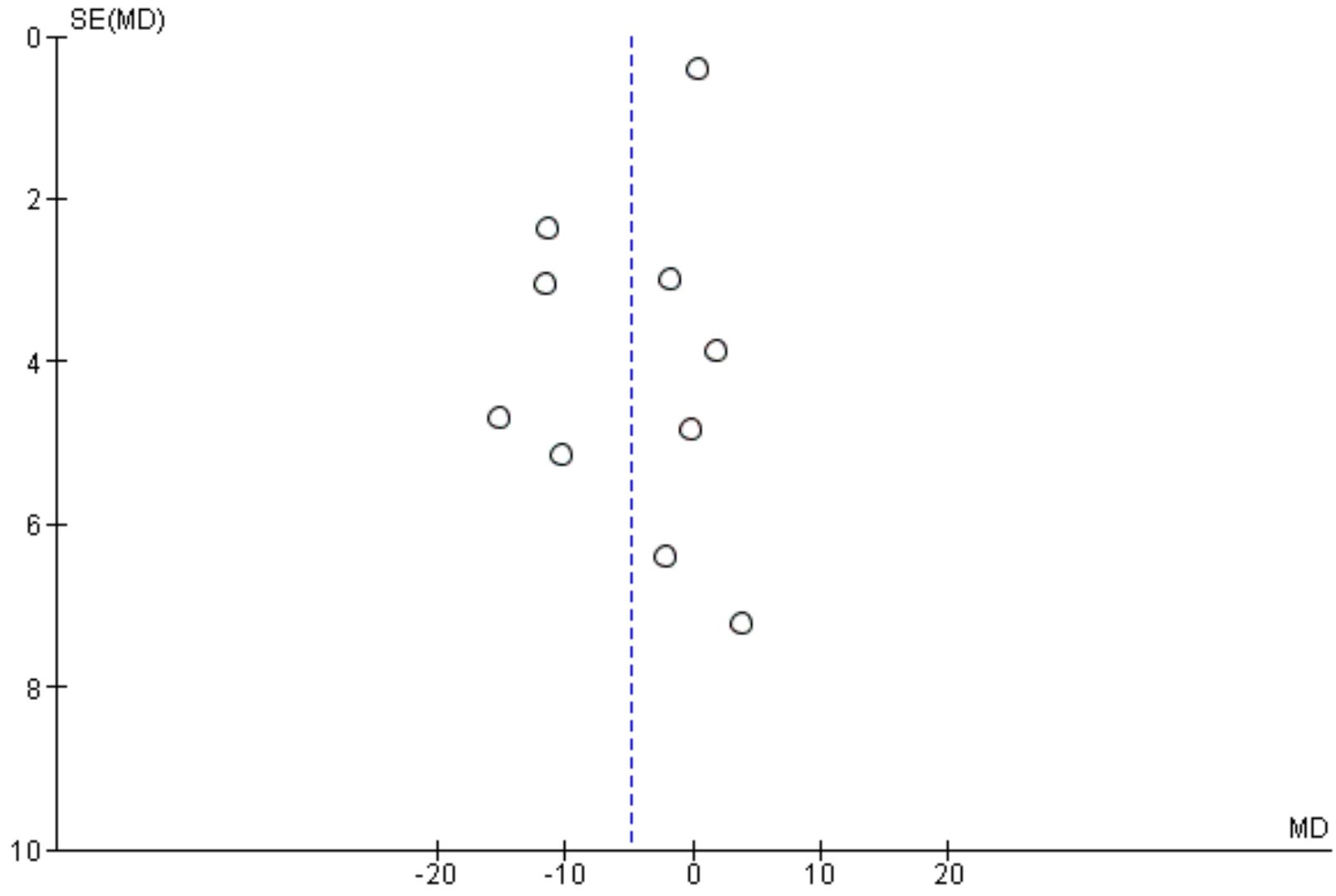

Pre-emptive and preventive opioids for postoperative pain in adults undergoing all types of surgery (Review) 
The following studies reported data as medians and were therefore included in a narrative synthesis. None of the studies found any difference in postoperative opioid consumption (Mansfield 1994; Mansfield 1996; Millar 1998; Shen 2008; Sert 2012). One study reported similar morphine consumption in the preventive and postincision group ( $53.5 \mathrm{mg}$ versus $52 \mathrm{mg}$, respectively; $\mathrm{P}>$ 0.05) (Mansfield 1994). Another study by the same authors found no difference in morphine consumption, although the difference included a clinically significant effect (preventive $56 \mathrm{mg}$ versus postincision $68 \mathrm{mg} ; \mathrm{P}>0.05$ ) (Mansfield 1996). Another study reported similar morphine consumption between the preventive and postincision groups (58 mg versus $57.5 \mathrm{mg}$, respectively; $\mathrm{P}$ > 0.05) (Millar 1998). Similarly, a further study found no difference in morphine consumption between the preventive and postincision group (4.6 mg versus $4.1 \mathrm{mg}$, respectively; $\mathrm{P}=0.81$ ) (Shen 2008). One study reported no difference in 24-hour tramadol consumption between the preventive and postincision group (95 mg versus 86 $\mathrm{mg}$, respectively; $\mathrm{P}=0.95$ ) (Sert 2012).

\section{Time to first analgesic request (minutes)}

No studies reported outcomes as time to event and instead used continuous scales. Six studies evaluated time to first analgesic request (minutes) for preventive versus postincision opioids (Fassoulaki 1995; Griffin 1997; Koprulu 2015; Pjevic 1999; Sarantopoulos 1996; Wordliczek 2002). There may be no difference between groups, and the effect estimate confidence intervals did not contain our predefined clinically significant threshold of one hour (MD -8.15 minutes, $95 \% \mathrm{Cl}-19.45$ minutes to 3.14 minutes; 298 participants; $1^{2}=63 \%$; Analysis 1.5$)$. The quality of evidence was low (downgraded two levels due to concerns over risk of bias and unexplained heterogeneity). Excluding studies where standard deviations had been estimated did not change the results (MD -6.52 minutes, $95 \% \mathrm{Cl}-20.50$ minutes to 7.45 minutes).

Two studies reported outcomes as medians and could not be included in the meta-analysis; both studies found no difference between groups (Chew 1997; Sert 2012). One study reported no difference in time to first analgesic when reported as median (preventive 279.4 minutes versus postincision 231.6 minutes; $P=$ 0.74) (Chew 1997). Another study found no difference between the preventive and postincision groups (45 minutes versus 45 minutes, respectively; $\mathrm{P}=0.8$ ) (Sert 2012).

\section{Pruritus (yes/no)}

Three studies evaluated long-term pruritus for preventive versus postincision opioids (Griffin 1997; Sert 2012; Shen 2008). There was probably no difference between groups on meta-analysis (RR 0.75 , $95 \% \mathrm{Cl} 0.40$ to $1.43 ; 383$ participants; $1^{2}=0 \%$; Analysis 1.6). The quality of evidence was moderate (downgraded one level due to concerns over risk of bias). Inputting data assuming that excluded participants suffered an event did not change the results (RR 0.84 , $95 \% \mathrm{Cl} 0.52$ to 1.36$)$.

\section{Sedation (measured on a continuous scale)}

One study evaluated both short- and long-term sedation measured on a 0-to-100-millimetre VAS (Kiliçkan 2001). There may be no important difference between groups for either short-term (MD $0.60 \mathrm{~mm}, 95 \% \mathrm{Cl}-2.22 \mathrm{~mm}$ to $3.42 \mathrm{~mm} ; 40$ participants; Table 3) or long-term sedation (MD $1.40 \mathrm{~mm}, 95 \% \mathrm{Cl}-3.19 \mathrm{~mm}$ to 5.99 $\mathrm{mm} ; 40$ participants; Table 3). The quality of evidence was low (downgraded two levels due to concerns over risk of bias and imprecision).

\section{Patient satisfaction (converted to a 0-to-10 scale where a 0-to-100 scale was used)}

One study evaluated long-term patient satisfaction on a 0-to-100millimetre VAS (Shen 2008). There was probably no difference between groups (MD $-0.22 \mathrm{~mm}, 95 \% \mathrm{Cl}-0.53 \mathrm{~mm}$ to $0.09 \mathrm{~mm}$; 299 participants; Table 3). The quality of evidence was moderate (downgraded one level due to concerns over risk of bias).

\section{Chronic pain (yes/no, measured three to six months postoperatively; we included the earliest time point closest to three months)}

No studies reported chronic pain for preventive versus postincision opioids.

\section{Time to first bowel movement (hours)}

No studies reported time to first bowel movement for preventive versus postincision opioids.

\section{Intraoperative bradycardia (yes/no and mean dose of chronotrope in $\mathrm{mg} / \mathrm{mcg}$ to assess severity)}

Two studies measured intraoperative bradycardia (incidence) for preventive versus postincision opioids (Mansfield 1994; Sert 2012). One study reported no events in either group (Sert 2012). There was only one event in the other study (Mansfield 1994), in the postincision group (RR $0.33,95 \% \mathrm{Cl} 0.01$ to 7.88 ; 112 participants; Analysis 1.7). The quality of evidence was low (downgraded two levels due to concerns over risk of bias and imprecision). Two studies evaluated mean dose of chronotrope (atropine) (Mansfield 1994; Sert 2012). No participant required atropine in one study (Sert 2012). The mean dose of atropine required may not differ between groups in one study (MD $-9.68 \mathrm{mcg}, 95 \% \mathrm{Cl}-28.65 \mathrm{mcg}$ to 9.29 mcg; 112 participants; Analysis 1.8) (Mansfield 1994). The quality of evidence was low (downgraded two levels due to concerns over risk of bias and imprecision).

\section{Intraoperative hypotension (yes/no and mean dose of inotrope/ vasopressor in $\mathrm{mg} / \mathrm{mcg}$ to assess severity)}

Two studies reported the incidence of intraoperative hypotension for preventive versus postincision opioids (Griffin 1997; Sert 2012). There may be no difference between groups (RR 1.08, 95\% Cl 0.25 to 4.73 ; 88 participants; $12=0 \%$; Analysis 1.9 ). The quality of evidence was low (downgraded two levels due to concerns over risk of bias and imprecision). One study evaluated the mean dose of chronotrope/inotrope (ephedrine) (Sert 2012). There was no difference between groups (MD $-0.20 \mathrm{mg}, 95 \% \mathrm{Cl}-0.59 \mathrm{mg}$ to $0.19 \mathrm{mg} ; 50$ participants; Table 3). The quality of evidence was low (downgraded two levels due to concerns over risk of bias and imprecision). Inputting data assuming that excluded participants suffered an event did not change the results (RR $0.72,95 \% \mathrm{Cl} 0.24$ to 2.13$)$.

\section{DISCUSSION}

\section{Summary of main results}

There were too few studies to enable us to evaluate the effects of pre-emptive opioids versus postincision opioids, as only one study satisfied our inclusion criteria (Pozos-Guillen 2007). In this trial there may be a reduction in early acute postoperative pain (MD 
$-1.20,95 \% \mathrm{Cl}-1.75$ to $-0.65 ; 40$ participants; 1 study; low-quality evidence). This study did not report adverse events (respiratory depression, hypotension, or bradycardia). There may also be a reduction in late acute postoperative pain (MD -2.10, 95\% Cl -2.57 to -1.63 ; 40 participants; 1 study; low-quality evidence). This study did not report 24-hour morphine consumption. However, this study was conducted in dental surgery under local anaesthesia.

For preventive versus postincision opioids, there was probably no difference between groups in early acute postoperative pain (MD $0.11,95 \% \mathrm{Cl}-0.32$ to $0.53 ; 706$ participants; 10 studies; $\mathrm{I}^{2}=$ $61 \%$; moderate-quality evidence). There were no events in the four studies that reported rates of respiratory depression. There was probably no difference between groups in late acute postoperative pain (MD $-0.06,95 \% \mathrm{Cl}-0.13$ to $0.01 ; 668$ participants; 9 studies; $\mathrm{R}^{2}=0 \%$; moderate-quality evidence). There was a possible small clinically insignificant reduction in 24-hour morphine consumption (MD -4.91 mg, 95\% Cl $-9.39 \mathrm{mg}$ to $-0.44 \mathrm{mg} ; 526$ participants; 11 studies; $12=82 \%$; very low-quality evidence), although this finding was not supported by most of the other studies that reported outcome data as medians. There may be no difference between groups in bradycardia (RR $0.33,95 \% \mathrm{Cl} 0.01$ to 7.88 ; 112 participants; 2 studies; $12=0 \%$; low-quality evidence) and hypotension (RR $1.08,95 \% \mathrm{Cl} 0.25$ to 4.73 ; 88 participants; 2 studies; $\mathrm{I}^{2}=0 \%$; low-quality evidence). The quality of evidence ranged from moderate to very low, mainly due to concerns over risk of bias and imprecision related to the low number of included studies. Consequently, we could find no convincing evidence that opioids administered before surgical incision improve postoperative pain or opioid adverse events.

\section{Overall completeness and applicability of evidence}

We undertook a wide-ranging search strategy of both published and unpublished studies. We identified two unpublished studies from conference proceedings (Espi 2004; Kurzova 2005), and one study that was unavailable in full text despite our attempts to retrieve it from the British Library (Nagasaka 1996). We attempted to contact the authors of these studies, but received a reply from only one study author who provided further information that permitted inclusion of the study in the review (Kurzova 2005). Of the unavailable studies, one study concluded that participants administered preventive pentazocine had similar analgesic consumption to those given postincision pentazocine (Nagasaka 1996), and the other study stated that morphine consumption was higher in the preventive group, although the difference was not significant (Espi 2004). It is therefore unlikely that the addition of these two studies would influence the conclusions of the present review. None of the included studies reported chronic pain, although a lack of efficacy for acute pain makes reductions in chronic pain unlikely.

Another issue that affected the completeness of our evidence relates to the widespread reporting of central tendency values as median rather than means. At the protocol stage, we did not plan to estimate means from medians due to the high likelihood of nonnormal data (Doleman 2017b). Despite this, we found that most of these studies reported negative results, in keeping with the main analysis findings, therefore it seems unlikely that this would affect the conclusions of the review. In addition, no study reported the outcome of time to first analgesic request as time to event, which is a more appropriate analysis for this type of outcome. This limits any conclusions derived from this analysis.

In terms of the applicability of evidence, most studies were conducted in women undergoing hysterectomy, so it is unclear whether the results can be extrapolated to other forms of surgery (Fassoulaki 1995; Griffin 1997; Kiliçkan 2001; Kurzova 2005; Mansfield 1994; Mansfield 1996; Millar 1998; Richmond 1993; Sarantopoulos 1996; Wilson 1994). However, a previous review has shown that type of surgery is not a significant independent predictor of heterogeneity in meta-analyses of postoperative analgesics (Doleman 2017a). This is also true for the only study that evaluated pre-emptive interventions (Pozos-Guillen 2007), as this was conducted in dental surgery under local anaesthetic. It is therefore unclear if this evidence can be applied to both more extensive surgeries where pain levels would be higher, or surgeries conducted under general anaesthesia. In addition, all studies were conducted in low-risk patients, so it unclear whether use in higherrisk patients may influence outcomes, especially adverse events. Furthermore, many of the studies excluded individuals with chronic pain and those currently using analgesics, although it is unlikely that inclusion of such participants would influence the conclusions of the present review.

\section{Quality of the evidence}

The overall quality of the evidence ranged from moderate to very low, mainly due to concerns over risk of bias and imprecision related to the low number of included studies for some outcomes. The quality of the evidence for the main analgesic outcomes of early and late acute postoperative pain, 24-hour morphine consumption, and time to first analgesic request also ranged from moderate to very low (mainly secondary to concerns over risk of bias). However, as the results from our review are negative and issues with risk of bias are more likely to have exaggerated effect estimates (Doleman 2017a), higher-quality evidence is unlikely to alter the conclusions of this review.

We also found issues of clinical heterogeneity in the included studies. Firstly, the timing of the pre-emptive/preventive dosing varied in the different studies, with most administering it at induction. This may have affected the results, as earlier preoperative dosing may have allowed therapeutic levels to be achieved earlier before incision and therefore been more effective (especially for morphine), although dosing closer to incision may be more appropriate for faster-acting opioids (alfentanil). This issue may also be relevant to postincision dosing. Secondly, the opioids used in the studies varied, with differing durations of action. Indeed, our meta-regression analysis suggested that longer-acting opioids may be more effective in reducing early acute postoperative pain and could be the focus of future studies. Thirdly, the variation in baseline pain/opioid consumption may have contributed to clinical heterogeneity. Studies including participants with higher baseline pain levels may have shown greater effect sizes, whilst those with low baseline levels may not have been able to detect a difference between groups (Doleman 2017a). For example, two studies for early acute postoperative pain, Pozos-Guillen 2007; Shen 2008, and seven studies for late acute postoperative pain, Griffin 1997; Kiliçkan 2001; Koprulu 2015; Pjevic 1999; Richmond 1993; Sarantopoulos 1996; Shen 2008, included groups with mean pain scores of three or less, which may limit their ability to detect differences between groups. 


\section{Potential biases in the review process}

None of the review authors were involved in any of the included studies, making any related bias unlikely. Three review authors (BD, JPW, and JL) have received funding for an ongoing trial of preventive paracetamol (not yet unpublished), although this is unlikely to bias the current review. In terms of the included studies, many were at unclear or high risk of bias in at least one domain, which may have introduced bias. This is reflected in the quality of evidence being moderate to very low. The review authors have recently developed novel methodology for presenting effect estimates, and are currently developing methods for publication bias assessment for outcomes such as morphine consumption and pain scores (which are dependent on baseline risk) (Doleman 2017a). However, although our work indicates bias with the use of traditional methods, we have used these methods in this review as they are stipulated by the Cochrane Handbook for Systematic Reviews of Interventions (Deeks 2011).

\section{Agreements and disagreements with other studies or reviews}

There have been two previous reviews of pre-emptive/preventive opioids versus postincision opioids (Møiniche 2002; Ong 2005). One of these reviews included eight studies and found on metaanalysis that pre-incisional opioids were associated with increases in postoperative pain $(5 \mathrm{~mm}$ on a 0 -to-100-millimetre VAS, $95 \% \mathrm{Cl} 1$ $\mathrm{mm}$ to $9 \mathrm{~mm}$ ), although analgesic consumption was reduced in two trials, similar to our findings (Møiniche 2002). These results contrast with the results of our review, where we found no difference between groups in pain scores. The other review found that pre-incisional opioids increased pain scores (standardised mean difference (SMD) $0.24,95 \% \mathrm{Cl} 0.46$ to 0.01 ), but there was no difference in analgesic consumption (SMD $-0.23,95 \% \mathrm{Cl} 0.06$ to -0.52 ) (Ong 2005). Again, we found no difference in pain scores. It is important to note that our review includes many studies that have been published since these previous reviews were undertaken. Based on both our results and those from these previous reviews, it appears that preventive opioids are not efficacious in reducing pain scores following surgery.

In comparison with other analgesics used around the perioperative period (Doleman 2017a), the 24-hour morphine reductions observed in this review are similar to lidocaine $(5 \mathrm{mg})$ and dexamethasone $(4 \mathrm{mg})$ but less effective than gabapentinoids $(8 \mathrm{mg})$, paracetamol $(8 \mathrm{mg})$, alpha-2 agonists $(11 \mathrm{mg})$, and non-steroidal anti-inflammatory drugs $(11 \mathrm{mg})$. However, these comparisons do not take into account variable baseline risk and should be interpreted with caution (Doleman 2017a).

\section{AUTHORS' CONCLUSIONS}

\section{Implications for practice}

We found no evidence from the trials conducted thus far that preventive opioids result in clinically significant reductions in pain scores, morphine consumption, or time to first analgesic request. Furthermore, there were probably little or no differences in postoperative opioid complications. Data were insufficient to draw any conclusions regarding adverse events. We included only one study evaluating pre-emptive opioids, which was conducted in dental surgery, limiting any conclusions on this analgesic strategy. The two studies awaiting classification may alter the conclusions of the review once assessed (see Characteristics of studies awaiting classification). The results of this review indicate that the current practice of using long-acting opioids as pre-medication may not have a strong evidence base. There may not be any clinically significant effect in reducing pain or opioid consumption after surgery. In addition, too few studies assessed adverse events such as bradycardia and hypotension, which may be affected by preoperative administration, to permit any conclusions. Such intraoperative haemodynamic effects may be associated with significant adverse events such as stroke (Bijker 2012). Conversely, preoperative opioids may reduce haemodynamic responses to intubation, which may benefit high-risk patients (Doleman 2016).

\section{Implications for research}

If further studies are to be undertaken despite a lack of efficacy shown in this review, they would need to use methodology that ensures adequate randomization, allocation concealment, and blinding to improve the quality of evidence (Doleman 2017a). In addition, future studies may wish to focus on analgesics with a longer duration of action as indicated on meta-regression analysis, although the inherent limitations of these analyses and small sample sizes limit any conclusions. Finally, if future studies are performed, they may wish to be conducted in surgeries with higher postoperative morphine consumption to improve absolute benefits, if benefits exist (Doleman 2017a).

\section{ACKNOWLEDGEMENTS}

We would like to acknowledge the editorial comments of Marialena Trivella, Anna Lee, Arash Afshari, Bronagh Blackwood, Asieh Golozar, Nathan Pace, Jane Cracknell, and Nuala Livingstone (editorial screening of protocol) (Doleman 2017b).

We would also like to thank Mike Bennett (Content Editor), Asieh Golozar (Statistical Editor), Andrew Smith (Co-ordinating Editor), Liz Bickerdike (Cochrane Editorial Unit), and David Dickerson and R Andrew Moore (Peer Referees) for their help and editorial advice during the preparation of the protocol for the systematic review (Doleman 2017b). In addition, we would like to thank Michael Bennett (Content Editor), Vibeke Horstmann (Statistical Editor), David Dickerson, Jean-Pierre C Estebe, Ole Mathiesen (Peer Reviewers), and Janet Wale (Consumer Editor) for their help and editorial advice during the preparation of this systematic review. 
R E F E R E N C E S

\section{References to studies included in this review}

Chew 1997 \{published data only\}

Chew ST, Low TC. Preoperative versus postoperative pethidine for extraction of impacted third molars. Annals of the Academy of Medicine, Singapore 1997;26(4):426-9. [PUBMED: 9395803]

Fassoulaki 1995 \{published data only\}

Fassoulaki A, Sarantopoulos C, Zotou M, Papoulia D. Preemptive opioid analgesia does not influence pain after abdominal hysterectomy. Canadian Journal of Anaesthesia 1995;42(2):109-13. [PUBMED: 7720151]

Gerlach 2003 \{published data only (unpublished sought but not used)\}

Gerlach K, Uhlig T, Hppe M, Khirt T, Saager L, Schmucker P. Postoperative analgesia after preincisional administration of remifentanil. Minerva Anestesiologica 2003;69(6):563-9. [PUBMED: 14564253]

\section{Griffin 1997 \{published data only\}}

Griffin MJ, Hughes D, Knaggs A, Donnelly MB, Boylan JF. Lateonset preemptive analgesia associated with preincisional largedose alfentanil. Anesthesia and Analgesia 1997;85(6):1317-21. [PUBMED: 9390601]

\section{Kiliçkan 2001 \{published data only\}}

Kiliçkan L, Toker K. The effect of preemptive intravenous morphine on postoperative analgesia and surgical stress response. Revista Brasileira de Anestesiologia 2001;51(6):503-10. [DOI: 10.1590/S0034-70942001000600005]

Koprulu 2015 \{published data only (unpublished sought but not used)\}

Köprülü AS, Sener T, Gül YG, Haspolat A, Neymen B. Comparison between the effects of preoperative (preemptive) and intraoperative use of tramadol on post-operative pain. Haseki Tip Bulteni 2015;53(3):220-4. [DOI: 10.4274/haseki.2389]

\section{Kurzova 2005 \{unpublished data only\}}

Kurzova A, Malek J, Noskova P, Bendova M, Strunova M. Pre-emptive analgesia with combination of morphine and ketamine: A-724. European Journal of Anaesthesiology 2005;22:187 [unpublished].

Lenz 2008 \{published data only (unpublished sought but not used)\} Lenz H, Raeder J, Hoymork SC. Administration of fentanyl before remifentanil-based anaesthesia has no influence on post-operative pain or analgesic consumption. Acta Anaesthesiologica Scandinavica 2008;52(1):149-54. [PUBMED: 17996006]

\section{Mansfield 1994 \{published data only\}}

Mansfield M, Meikle R, Miller C. A trial of pre-emptive analgesia. Influence of timing of peroperative alfentanil on postoperative pain and analgesic requirements. Anaesthesia 1994;49(12):1091-3. [PUBMED: 7864328]
Mansfield 1996 \{published data only (unpublished sought but not used)\}

Mansfield MD, James KS, Kinsella J. Influence of dose and timing of administration of morphine on postoperative pain and analgesic requirements. British Journal of Anaesthesia 1996;76(3):358-61. [PUBMED: 8785133]

Millar 1998 \{published data only (unpublished sought but not used)\}

Millar AY, Mansfield MD, Kinsella J. Influence of timing of morphine administration on postoperative pain and analgesic consumption. British Journal of Anaesthesia 1998;81(3):373-6. [PUBMED: 9861123]

Pjevic 1999 \{published data only\}

Pjević M, Komarcević M, Kovacević S, Jovanović L, Gajić S. Preemptive analgesia in cholecystectomy using pethidine. Medicinski Pregled 1999;52(11-12):485-8. [PUBMED: 10748772]

Pozos-Guillen 2007 \{published data only (unpublished sought but not used)\}

Pozos-Guillen A, Martinez-Rider R, Aguirre-Banuelos P, PerezUrizar J. Pre-emptive analgesic effect of tramadol after mandibular third molar extraction: a pilot study. Journal of Oral and Maxillofacial Surgery 2007;65(7):1315-20. [PUBMED: 17577495]

Richmond 1993 \{published data only\}

Richmond CE, Bromley LM, Woolf CJ. Preoperative morphine pre-empts postoperative pain. Lancet 1993;342(8863):73-5. [PUBMED: 8100911]

\section{Sarantopoulos 1996 \{published data only\}}

Sarantopoulos C, Fassoulaki A. Sufentanil does not preempt pain after abdominal hysterectomy. Pain 1996;65(2-3):273-6. [PUBMED: 8826517]

Sert 2012 \{published data only (unpublished sought but not used)\} Sert H, Demırcıoğlu Ri, Usta B, Muslu B, Yazici Ü, Gözdemır M, et al. A comparative study of preoperative versus intraoperative meperidine administration in patients receiving general anesthesia: a prospective, randomized double-blind study. Turkish Journal of Medical Sciences 2012;42(1):47-54. [DOI: 10.3906/sag-1010-1226]

Shen 2008 \{published data only (unpublished sought but not used)\} Shen X, Wang F, Xu S, Ma L, Liu Y, Feng S, et al. Comparison of the analgesic efficacy of preemptive and preventive tramadol after lumpectomy. Pharmacological Reports 2008;60(3):415-21. [PUBMED: 18622068]

Wilson 1994 \{published data only (unpublished sought but not used)\}

Wilson RJ, Leith S, Jackson IJ, Hunter D. Pre-emptive analgesia from intravenous administration of opioids. No effect with alfentanil. Anaesthesia 1994;49(7):591-3. [PUBMED: 8042723] 
Wordliczek 2002 \{published data only (unpublished sought but not used)\}

Wordliczek J, Banach M, Garlicki J, Jakowicka-Wordliczek J, Dobrogowski J. Influence of pre- or intraoperational use of tramadol (preemptive or preventive analgesia) on tramadol requirement in the early postoperative period. Polish Journal of Pharmacology 2002;54(6):693-7. [PUBMED: 12866726]

Zand 2012 \{published data only (unpublished sought but not used)\} Zand F, Amini A, Hamidi SA. Effect of timing of morphine administration during propofol-remifentanil anesthesia on the requirements of post-operative analgesia. Korean Journal of Anesthesiology 2012;63(3):233-7. [PUBMED: 23060980]

\section{References to studies excluded from this review}

Collis 1995 \{published data only\}

Collis R, Brandner B, Bromley LM, Woolf CJ. Is there any clinical advantage of increasing the pre-emptive dose of morphine or combining pre-incisional with postoperative morphine administration?. British Journal of Anaesthesia 1995;74(4):396-9. [PUBMED: 7734257]

\section{References to studies awaiting assessment}

Espi 2004 \{unpublished data only\}

Espí C, Vila P, Muñoz S, Monerris M, Lopez M, Canet J. Morphine requirements during early recovery from remifentanilbased anaesthesia for gynecological surgery: A-770. European Journal of Anaesthesiology 2004;21:189. [DOI: 10.1097/00003643-200406002-00687]

\section{Nagasaka 1996 \{published data only\}}

Nagasaka H, Taguchi M, Mizumoto Y, Hori K, Hayashi K, Sugai M, et al. Pre-emptive analgesia from intravenous administration of opioid: no effect with pentazocine. Masui. The Japanese Journal of Anesthesiology 1996;45(6):750-5. [PUBMED: 8752779]

\section{Additional references}

\section{Apfelbaum 2003}

Apfelbaum JL, Chen C, Mehta SS, Gan TJ. Postoperative pain experience: results from a national survey suggest postoperative pain continues to be undermanaged. Anesthesia and Analgesia 2003;97(2):534-40. [PUBMED: 12873949]

\section{Benhamou 2008}

Benhamou D, Berti M, Brodner G, Andres JD, Draisci G, MorenoAzcoita M, et al. Postoperative Analgesic THerapy Observational Survey (PATHOS): a practice pattern study in 7 central/southern European countries. Pain 2008;136(1-2):134-41. [PUBMED: 17703887]

\section{Bijker 2012}

Bijker JB, Persoon S, Peelen LM, Moons KG, Kalkman CJ, Kappelle LJ, et al. Intraoperative hypotension and perioperative ischemic stroke after general surgery: a nested case-control study. Anesthesiology 2012;116(3):658-64. [PUBMED: 22277949]
Dahl 2011

Dahl JB, Kehlet H. Preventive analgesia. Current Opinion in Anaesthesiology 2011;24(3):331-8. [PUBMED: 21478742]

\section{Deeks 2011}

Deeks JJ, Higgins JP, Altman DG. Chapter 9: Analysing data and undertaking meta-analyses. In: Higgins JP, Green S (editors). Cochrane Handbook for Systematic Reviews of Interventions Version 5.1.0 (updated March 2011). The Cochrane Collaboration, 2011. Available from handbook.cochrane.org.

\section{Desai 1999}

Desai PM. Pain management and pulmonary dysfunction. Critical Care Clinics 1999;15(1):151-66. [PUBMED: 9929792]

\section{Desborough 2000}

Desborough JP. The stress response to trauma and surgery. British Journal of Anaesthesia 2000;85(1):109-17. [PUBMED: 10927999]

\section{Doleman 2015a}

Doleman B, Heinink TP, Read DJ, Faleiro RJ, Lund JN, Williams JP. A systematic review and meta-regression analysis of prophylactic gabapentin for postoperative pain. Anaesthesia 2015;70(10):1186-204. [PUBMED: 26300519]

\section{Doleman 2015b}

Doleman B, Read D, Lund JN, Williams JP. Preventive acetaminophen reduces postoperative opioid consumption, vomiting, and pain scores after surgery: systematic review and meta-analysis. Regional Anesthesia and Pain Medicine 2015;40(6):706-12. [PUBMED: 26469366]

\section{Doleman 2016}

Doleman B, Sherwin M, Lund JN, Williams JP. Gabapentin for the hemodynamic response to intubation: systematic review and meta-analysis. Canadian Journal of Anesthesia 2016;63(9):1042-58. [PUBMED: 27206565]

\section{Doleman 2017a}

Doleman B, Sutton AJ, Sherwin M, Lund JN, Williams JP. Baseline morphine consumption may explain between-study heterogeneity in meta-analyses of adjuvant analgesics and improve precision and accuracy of effect estimates. Anesthesia and Analgesia 2017;126(2):648-60. [PUBMED: 28682950]

\section{Egger 1997}

Egger M, Smith GD, Schneider M, Minder C. Bias in meta-analysis detected by a simple, graphical test. $B M J$ 1997;315(7109):629-34. [PUBMED: 9310563]

\section{Fletcher 2014}

Fletcher D, Martinez V. Opioid-induced hyperalgesia in patients after surgery: a systematic review and a meta-analysis. British Journal of Anaesthesia 2014;112(6):991-1004. [PUBMED: 24829420]

\section{Gallagher 2001}

Gallagher EJ, Liebman M, Bijur PE. Prospective validation of clinically important changes in pain severity measured 
on a visual analog scale. Annals of Emergency Medicine 2001;38(6):633-8. [PUBMED: 11719741]

\section{Gerbershagen 2014}

Gerbershagen HJ, Pogatzki-Zahn E, Aduckathil S, Peelen LM, Kappen TH, van Wijck AJ, et al. Procedure-specific risk factor analysis for the development of severe postoperative pain. Anesthesiology 2014;120(5):1237-45. [PUBMED: 24356102]

\section{Higgins 2011a}

Higgins JP, Deeks JJ. Chapter 7: Selecting studies and collecting data. In: Higgins JP, Green S editor(s). Cochrane Handbook for Systematic Reviews of Interventions Version 5.1.0 (updated March 2011). The Cochrane Collaboration, 2011. Available from handbook.cochrane.org.

\section{Higgins 2011b}

Higgins JP, Altman DG, Sterne JAC. Chapter 8: Assessing risk of bias in included studies. In: Higgins JP, Green $S$ editor(s). Cochrane Handbook for Systematic Reviews of Interventions Version 5.1.0 (updated March 2011). The Cochrane Collaboration, 2011. Available from handbook.cochrane.org.

\section{Higgins 2011c}

Higgins JP, Deeks JJ, Altman DG. Chapter 16: Special topics in statistics. In: Higgins JP, Green S editor(s). Cochrane Handbook for Systematic Reviews of Interventions Version 5.1.0 (updated March 2011). The Cochrane Collaboration, 2011. Available from handbook.cochrane.org.

\section{Ip 2009}

Ip HYV, Abrishami A, Peng PW, Wong J, Chung F. Predictors of postoperative pain and analgesic consumption: a qualitative systematic review. Anesthesiology 2009;111(3):657-77.

[PUBMED: 19672167]

\section{Kehlet 2006}

Kehlet H, Jensen TS, Woolf CJ. Persistent postsurgical pain: risk factors and prevention. Lancet 2006;367(9522):1618-25. [PUBMED: 16698416]

\section{Kissin 2000}

Kissin I. Preemptive analgesia. Anesthesiology 2000;93(4):1138-43. [PUBMED: 11020772]

\section{Lee 2011}

Lee M, Silverman S, Hansen H, Patel V, Manchikanti L. A comprehensive review of opioid-induced hyperalgesia. Pain Physician 2011;14(2):145-61. [PUBMED: 21412369]

\section{Lefebvre 2011}

Lefebvre C, Manheimer E, Glanville J. Chapter 6: Searching for studies. In: Higgins JP, Green S editor(s). Cochrane Handbook for Systematic Reviews of Interventions Version 5.1.0 (updated March 2011). The Cochrane Collaboration, 2011. Available from handbook.cochrane.org.

\section{Mhuircheartaigh 2009}

Mhuircheartaigh RN, Moore RA, McQuay HJ. Analysis of individual patient data from clinical trials: epidural morphine for postoperative pain. British Journal of Anaesthesia 2009;103(6):874-81. [PUBMED: 19889750]

\section{Myles 2000}

Myles PS, Williams DL, Hendrata M, Anderson H, Weeks AM. Patient satisfaction after anaesthesia and surgery: results of a prospective survey of 10,811 patients. British Journal of Anaesthesia 2000;84(1):6-10. [PUBMED: 10740539]

\section{Møiniche 2002}

Møiniche S, Kehlet H, Dahl JB. A qualitative and quantitative systematic review of preemptive analgesia for postoperative pain relief: the role of timing of analgesia. Anesthesiology 2002;96(3):725-41. [PUBMED: 11873051]

\section{Ong 2005}

Ong CKS, Lirk P, Seymour RA, Jenkins BJ. The efficacy of preemptive analgesia for acute postoperative pain management: a meta-analysis. Anesthesia and Analgesia 2005;100(3):757-73. [PUBMED: 15728066]

\section{Pathan 2012}

Pathan H, Williams J. Basic opioid pharmacology: an update. British Journal of Pain 2012;6(1):11-6. [PUBMED: 26516461]

\section{Review Manager 2014 [Computer program]}

Nordic Cochrane Centre, The Cochrane Collaboration. Review Manager 5 (RevMan 5). Version 5.3. Copenhagen: Nordic Cochrane Centre, The Cochrane Collaboration, 2014.

\section{Schünemann 2011}

Schünemann HJ, Oxman AD, Vist GE, Higgins JP, Deeks JJ, Glasziou $P$, et al. Chapter 12: Interpreting results and drawing conclusions. In: Higgins JP, Green S (editors). Cochrane Handbook for Systematic Reviews of Interventions Version 5.1.0 (updated March 2011). The Cochrane Collaboration, 2011. Available from handbook.cochrane.org.

\section{Stata Version 15 [Computer program]}

StataCorp. Stata Statistical Software: Release 15. Version Accessed June 2017. College Station, TX: StataCorp LLC, 2017.

\section{Strassels 2002}

Strassels SA, Chen C, Carr DB. Postoperative analgesia: economics, resource use, and patient satisfaction in an urban teaching hospital. Anesthesia and Analgesia 2002;94(1):130-7. [PUBMED: 11772815]

\section{Thompson 2002}

Thompson SG, Higgins JP. How should meta-regression analyses be undertaken and interpreted?. Statistics in Medicine 2002;21 (11):1559-73. [PUBMED: 12111920]

\section{Wheeler 2002}

Wheeler M, Oderda GM, Ashburn MA, Lipman AG. Adverse events associated with postoperative opioid analgesia: a systematic review. Journal of Pain 2002;3(3):159-80. [PUBMED: 14622770]

\section{Williams 2007}

Williams JP, Thompson JP, McDonald J, Barnes TA, Cote T, Rowbotham DJ, et al. Human peripheral blood mononuclear

Pre-emptive and preventive opioids for postoperative pain in adults undergoing all types of surgery (Review) 
cells express nociceptin/orphanin FQ, but not $\mu, \delta$, or $\mathrm{k}$ opioid receptors. Anesthesia and Analgesia 2007;105(4):998-1005. [PUBMED: 17898379]

\section{References to other published versions of this review}

\section{Doleman 2017b}

Doleman B, Leonardi-Bee J, Heinink TP, Lund J, Williams JP. Preventive opioids for postoperative pain. Cochrane Database of Systematic Reviews 2017, Issue 4. [DOI: 10.1002/14651858.CD012624]

\section{CHARACTERISTICS OF STUDIES}

Characteristics of included studies [ordered by study ID]

Chew 1997

Methods Study design: parallel-group randomized controlled trial

Sample size: 40

Country: Singapore

Setting: secondary care hospital

Dates conducted: not reported

Postoperative opioid used and delivery: pethidine $50 \mathrm{mg}$ intramuscularly if VAS $>50 \mathrm{~mm}$

Pain score collection: recorded by blinded nursing staff

Concurrent postoperative analgesics: none reported

\section{Participants}

\section{Inclusion criteria}

1. ASA 1 only

2. No systemic disease

3. Undergoing removal of bilateral impacted third molars under general anaesthesia

\section{Exclusion criteria}

1. Known allergy to opioids

2. Systemic illnesses

Interventions

Group 1 (20 participants): intramuscular pethidine $50 \mathrm{mg} 1$ to 2 hours before surgery and $1 \mathrm{~mL}$ saline placebo immediately after surgery

Group 2 (20 participants): $1 \mathrm{~mL}$ saline placebo 1 to 2 hours before surgery and intramuscular pethidine $50 \mathrm{mg}$ immediately after surgery

Outcomes 1. Postoperative pain (0-to-100-millimetre VAS at 30 minutes, 1, 3, and 6 hours)

2. Pethidine consumption ( $\mathrm{mg}$, time point not reported)

Notes

Funding: none reported

Declarations of interest: none declared

Authors contacted: no

Other: postoperative pain reported as median so included in narrative synthesis. Pethidine consumption not included, as time point not reported and study follow-up only 6 hours.

\section{Risk of bias}

\section{Bias}

Authors' judgement Support for judgement

Pre-emptive and preventive opioids for postoperative pain in adults undergoing all types of surgery (Review) 
Chew 1997 (Continued)

Random sequence genera- Unclear risk No details. Quote: "participants were allocated randomly to two groups" tion (selection bias)

\begin{tabular}{|c|c|c|}
\hline $\begin{array}{l}\text { Allocation concealment } \\
\text { (selection bias) }\end{array}$ & Unclear risk & Not mentioned \\
\hline $\begin{array}{l}\text { Blinding of participants } \\
\text { and personnel (perfor- } \\
\text { mance bias) }\end{array}$ & Low risk & $\begin{array}{l}\text { Double-dummy placebo of saline intramuscularly and described as identical. } \\
\text { Quote: "during the study, each patient received two identical, coded } 1 \mathrm{ml} \text { in- } \\
\text { jections; one containing pethidine } 50 \mathrm{mg} \text {, the other containing normal saline" }\end{array}$ \\
\hline
\end{tabular}

\begin{tabular}{|c|c|c|}
\hline $\begin{array}{l}\text { Blinding of outcome as- } \\
\text { sessment (detection bias) } \\
\text { All outcomes }\end{array}$ & Low risk & $\begin{array}{l}\text { Blinded. Quote: "these values were recorded by the nursing staff who were un- } \\
\text { aware of the sequence of administration of the injections" }\end{array}$ \\
\hline $\begin{array}{l}\text { Incomplete outcome data } \\
\text { (attrition bias) } \\
\text { All outcomes }\end{array}$ & Low risk & $\begin{array}{l}\text { All participants analysed, and numbers in table match the number random- } \\
\text { ized. }\end{array}$ \\
\hline $\begin{array}{l}\text { Selective reporting (re- } \\
\text { porting bias) }\end{array}$ & Unclear risk & No protocol or trial registration \\
\hline Other bias & Low risk & Similar baseline characteristics. No industry funding reported. \\
\hline
\end{tabular}

\section{Fassoulaki 1995}

Study design: parallel-group randomized controlled trial
Sample size: 85
Country: Greece
Setting: secondary care hospital
Dates conducted: not reported
Postoperative opioid used and delivery: (see below)
Pain score collection: collected by independent observer
Concurrent postoperative analgesics: propoxyphene 75 mg with paracetamol 1600 mg intramuscularly
6 hourly supplemented by meperidine 50 mg given intramuscularly 12 hours postoperatively

\section{Participants}

\section{Inclusion criteria}

1. Female participants

2. ASA 1 and 2

3. Scheduled for elective abdominal hysterectomy via a midline subumbilical incision

\section{Exclusion criteria}

1. History of chronic pain

2. Regular intake of analgesic drugs

3. History of psychiatric disease

Interventions

Group FA (17 participants): intravenous fentanyl $10 \mathrm{mcg} / \mathrm{kg} 5$ minutes before induction and equal volume of normal saline after incision and removal of the uterus 
Group SA (17 participants): intravenous sufentanil $1 \mathrm{mcg} / \mathrm{kg} 5$ minutes before induction and equal volume of normal saline after incision and removal of the uterus

Group FB (17 participants): intravenous fentanyl $10 \mathrm{mcg} / \mathrm{kg}$ after incision and normal saline before induction and on removal of the uterus

Group SB (17 participants): intravenous sufentanil $1 \mathrm{mcg} / \mathrm{kg}$ after incision and normal saline before induction and removal of the uterus

Group FC (17 participants): intravenous fentanyl $10 \mathrm{mcg} / \mathrm{kg}$ after removal of the uterus and normal saline before induction and after incision

\begin{tabular}{ll}
\hline Outcomes & $\begin{array}{l}\text { 1. Postoperative pain (0-to-10-centimetre VAS and 1-to- } 6 \text { VRS at } 30 \text { minutes, 1, 1.5, 2, 2.5, and 24 hours } \\
\text { postoperatively) }\end{array}$ \\
2. Tme to analgesic request (minutes) \\
Notes \\
Funding: not reported \\
Declarations of interest: not reported \\
Authors contacted: no \\
$\begin{array}{l}\text { Other: once participant requested analgesia, their pain was no longer assessed until } 24 \text { hours, so some } \\
\text { participants not included in early acute postoperative pain outcome. Groups combined for the main } \\
\text { analysis. }\end{array}$
\end{tabular}

\section{Risk of bias}

\begin{tabular}{|c|c|c|}
\hline Bias & Authors' judgement & Support for judgement \\
\hline $\begin{array}{l}\text { Random sequence genera- } \\
\text { tion (selection bias) }\end{array}$ & Low risk & $\begin{array}{l}\text { Table of random numbers by computerized statistical package. Quote: "ac- } \\
\text { cording to a randomization schedule generated by a table of random numbers } \\
\text { by means of a computerized statistical package" }\end{array}$ \\
\hline $\begin{array}{l}\text { Allocation concealment } \\
\text { (selection bias) }\end{array}$ & Unclear risk & $\begin{array}{l}\text { Sealed envelope. No further details. Quote: "the contents of a sealed envelope } \\
\text { indicated the patient's group, determined by the opioid and the timing of its } \\
\text { administration" }\end{array}$ \\
\hline $\begin{array}{l}\text { Blinding of participants } \\
\text { and personnel (perfor- } \\
\text { mance bias) } \\
\text { All outcomes }\end{array}$ & Low risk & $\begin{array}{l}\text { Double-dummy placebo used, which sounds similar in appearance. Quote: } \\
\text { "the study was double-blind. Three syringes, one with fentanyl or sufentanil, } \\
\text { and two with normal saline of equal volume as that containing opioid were } \\
\text { prepared by an anaesthetist, who was involved in the patient randomization } \\
\text { (opening of the envelopes) but not in its anaesthesia, pain assessment or data } \\
\text { collection" }\end{array}$ \\
\hline $\begin{array}{l}\text { Blinding of outcome as- } \\
\text { sessment (detection bias) } \\
\text { All outcomes }\end{array}$ & Low risk & $\begin{array}{l}\text { Blinded. Quote: "all other anaesthetists, anaesthetic nurses and patients were } \\
\text { unaware of the group to which the patient was assigned. Postoperative pain } \\
\text { was assessed by an independent observer, who was not involved in patient } \\
\text { randomization or anaesthesia administration" }\end{array}$ \\
\hline $\begin{array}{l}\text { Incomplete outcome data } \\
\text { (attrition bias) } \\
\text { All outcomes }\end{array}$ & Low risk & $\begin{array}{l}\text { All participants analysed. Some participants missing from early pain score da- } \\
\text { ta but numbers similar between groups. }\end{array}$ \\
\hline $\begin{array}{l}\text { Selective reporting (re- } \\
\text { porting bias) }\end{array}$ & Unclear risk & No protocol or trial registration \\
\hline Other bias & Low risk & Sufentanil groups had longer surgery but should cancel out on analysis. \\
\hline
\end{tabular}


Gerlach 2003

Study design: parallel-group randomized controlled trial
Sample size: 48
Country: Germany
Setting: secondary care hospital
Dates conducted: not reported
Postoperative opioid used and delivery: PCA piritramide
Pain score collection: blinded interviewer
Concurrent postoperative analgesics: none reported

\section{Participants}

\section{Inclusion criteria}

1. ASA 1 or 2 undergoing lumbar spinal surgery

\section{Exclusion criteria}

1. Individuals aged over 60 years

2. Liver disorder or renal disease

3. Known drug or alcohol abuse

4. Current administration of opioid analgesics

5. Known allergies to study drugs

Group R5 (16 participants): intravenous remifentanil $0.2 \mathrm{mcg} / \mathrm{kg} / \mathrm{min}$ administered over a 5-minute period before induction. After a 15-minute break, anaesthesia was started with an infusion of $0.25 \mathrm{mcg} /$ $\mathrm{kg} / \mathrm{min}$ remifentanil followed by a continuous infusion of $0.25 \mathrm{mcg} / \mathrm{kg} / \mathrm{min}$ until the end of anaesthesia.

Group R20 (16 participants): intravenous remifentanil $0.05 \mathrm{mcg} / \mathrm{kg} / \mathrm{min}$ was administered over a period of 20 minutes before induction and then same regimen as R5.

Group RL (15 participants): 10 minutes after skin incision intravenous remifentanil $0.2 \mathrm{mcg} / \mathrm{kg} / \mathrm{min}$ was administered for 5 minutes followed by an infusion of $0.5 \mathrm{mcg} / \mathrm{kg} / \mathrm{min}$ for 50 minutes. The infusion was then reduced to $0.25 \mathrm{mcg} / \mathrm{kg} / \mathrm{min}$ and continued until the end of anaesthesia.

All groups had similar total doses of remifentanil.

1. Postoperative pain (NRS 0 to 15 at $1,2,3,4,5,6$, and 24 hours)
2. Piritramide consumption ( $\mathrm{mg}$, reported at $2,4,6$, and 24 hours)
3. Adverse events (blood pressure ( $\mathrm{mmHg}$ ), heart rate (beats per minute), sedation (Ramsey sedation
scale), intraoperative awareness (yes/no), nausea and vomiting (yes/no) at 1 hourly intervals up to 6
hours and again at 24 hours)

\section{Notes}

Funding: departmental funds

Declarations of interest: not reported

Authors contacted: yes, although no reply

Other: postoperative pain converted to a 0-to-10 scale. Data extracted from graphs using computer software. R5 and R20 groups combined for main analysis. We contacted authors for further information but received no response.

\section{Risk of bias}

Pre-emptive and preventive opioids for postoperative pain in adults undergoing all types of surgery (Review) 
Gerlach 2003 (Continued)

\begin{tabular}{|c|c|c|}
\hline Bias & Authors' judgement & Support for judgement \\
\hline $\begin{array}{l}\text { Random sequence genera- } \\
\text { tion (selection bias) }\end{array}$ & Unclear risk & $\begin{array}{l}\text { No details. Quote: "participants were randomly assigned to } 1 \text { of } 3 \text { study } \\
\text { groups" }\end{array}$ \\
\hline $\begin{array}{l}\text { Allocation concealment } \\
\text { (selection bias) }\end{array}$ & Unclear risk & No mention \\
\hline $\begin{array}{l}\text { Blinding of participants } \\
\text { and personnel (perfor- } \\
\text { mance bias) } \\
\text { All outcomes }\end{array}$ & High risk & No double-dummy placebo used. \\
\hline $\begin{array}{l}\text { Blinding of outcome as- } \\
\text { sessment (detection bias) } \\
\text { All outcomes }\end{array}$ & Low risk & $\begin{array}{l}\text { Blinded. Quote: "the assessment was performed by a single interviewer, who } \\
\text { was unaware of the study medication" }\end{array}$ \\
\hline $\begin{array}{l}\text { Incomplete outcome data } \\
\text { (attrition bias) } \\
\text { All outcomes }\end{array}$ & Low risk & $\begin{array}{l}1 \text { participant dropped out of postincision group due to protocol violation, } \\
\text { which was unlikely to cause bias. Quote: "of the } 48 \text { patients enrolled in the } \\
\text { study, } 1 \text { had to be excluded because the study protocol was violated: the } \\
\text { surgery lasted less than } 50 \text { minutes, and thus the patient could not receive the } \\
\text { complete remifentanil infusion as described for group RL" }\end{array}$ \\
\hline $\begin{array}{l}\text { Selective reporting (re- } \\
\text { porting bias) }\end{array}$ & Unclear risk & No protocol or trial registration \\
\hline Other bias & Low risk & $\begin{array}{l}\text { Longer surgery in postincision group, although this was of little clinical signifi- } \\
\text { cance. Quote: "there were no significant differences between the groups with } \\
\text { respect to demographic data, duration of surgery and anaesthesia and type of } \\
\text { surgical procedure" }\end{array}$ \\
\hline
\end{tabular}

Griffin 1997

Study design: parallel-group randomized controlled trial
Sample size: 38
Country: Ireland
Setting: secondary care hospital
Dates conducted: not reported
Postoperative opioid used and delivery: 2 mg intravenous morphine in recovery then PCA morphine on
ward
Pain score collection: blinded assessor
Concurrent postoperative analgesics: no other analgesia used

Participants

\section{Inclusion criteria}

1. ASA 1 or 2 and admitted for elective total abdominal hysterectomy

Interventions

Group PRE (18 participants): intravenous alfentanil $70 \mathrm{mcg} / \mathrm{kg} 15$ minutes before surgical incision and intravenous saline 15 minutes postincision 
Griffin 1997 (Continued)

Group POST (16 participants): saline 15 minutes before incision and intravenous alfentanil $70 \mathrm{mcg} / \mathrm{kg}$ 15 minutes after incision

Outcomes
2. Postoperative pain (0-to-200-millimetre VAS at 6, 12, 24, 48, and 72 hours)
3. Intraoperative hypotension (yes/no)
4. Nausea and vomiting (yes/no)
5. Pruritus (yes/no)
6. Respiratory depression (yes/no)

Notes $\quad$ Funding: supported by Abbott Research Endowment (Royal College of Surgeons, Ireland)

Declarations of interest: not reported

Authors contacted: no

Other: pain score data extracted from graphs using computer software. Pain score data presented in graphs as 0-to-10-centimetre VAS. Standard deviation for morphine consumption estimated.

\section{Risk of bias}

\begin{tabular}{|c|c|c|}
\hline Bias & Authors' judgement & Support for judgement \\
\hline $\begin{array}{l}\text { Random sequence genera- } \\
\text { tion (selection bias) }\end{array}$ & Unclear risk & $\begin{array}{l}\text { Unclear how sequence was generated. Quote: "participants were allocated us- } \\
\text { ing sealed envelopes to one of two groups" }\end{array}$ \\
\hline $\begin{array}{l}\text { Allocation concealment } \\
\text { (selection bias) }\end{array}$ & Unclear risk & $\begin{array}{l}\text { No details. Quote: "participants were allocated using sealed envelopes to one } \\
\text { of two groups" }\end{array}$ \\
\hline $\begin{array}{l}\text { Blinding of participants } \\
\text { and personnel (perfor- } \\
\text { mance bias) } \\
\text { All outcomes }\end{array}$ & Low risk & $\begin{array}{l}\text { Placebo sounds similar in appearance based on description. Quote: "a ran- } \\
\text { domized double-blind design was used with both patients and postoperative } \\
\text { assessors blinded to intraoperative management" }\end{array}$ \\
\hline $\begin{array}{l}\text { Blinding of outcome as- } \\
\text { sessment (detection bias) } \\
\text { All outcomes }\end{array}$ & Low risk & $\begin{array}{l}\text { Postoperative assessors blinded. Quote: "a randomized double-blind design } \\
\text { was used with both patients and postoperative assessors blinded to intraoper- } \\
\text { ative management" }\end{array}$ \\
\hline $\begin{array}{l}\text { Incomplete outcome data } \\
\text { (attrition bias) } \\
\text { All outcomes }\end{array}$ & High risk & $\begin{array}{l}4 \text { participants excluded, some for reasons that could have influenced out- } \\
\text { come. Quote: "of the } 38 \text { randomized patients, } 4 \text { were withdrawn from the } \\
\text { study ( } 1 \text { from Group PRE and } 3 \text { from Group POST). } 2 \text { patients were withdrawn } \\
\text { because of nausea and vomiting and two because of surgical complications } \\
\text { necessitating return to the operating room" }\end{array}$ \\
\hline $\begin{array}{l}\text { Selective reporting (re- } \\
\text { porting bias) }\end{array}$ & Unclear risk & No protocol or trial registration \\
\hline Other bias & Low risk & $\begin{array}{l}\text { Similar baseline characteristics and no industry funding. Quote: "this work } \\
\text { was supported in part by the Abbott Research Endowment, Faculty of Anaes- } \\
\text { thetists, Royal College of Surgeons in Ireland" }\end{array}$ \\
\hline
\end{tabular}

\section{Kiliçkan 2001}

Methods

Study design: parallel-group randomized controlled trial

Sample size: 60 
Kiliçkan 2001 (Continued)
Country: Turkey
Setting: secondary care hospital
Dates conducted: not reported
Postoperative opioid used and delivery: $2 \mathrm{mg}$ morphine bolus in recovery then PCA morphine
Pain score collection: no mention
Concurrent postoperative analgesics: none reported

Inclusion criteria
1. Female participants
2. ASA 1 or 2
3. Aged 20 to 60 years
4. Undergoing total abdominal hysterectomy, with or without salpingo-opherectomy
Exclusion criteria
1. Chronic pain
2. Chronic analgesic use
3. Unco-operative individuals

Interventions

Group I (20 participants): received $0.15 \mathrm{mg} / \mathrm{kg}$ of morphine following induction and placebo during peritoneal closure

Group II (20 participants): received placebo following induction and $0.15 \mathrm{mg} / \mathrm{kg}$ of morphine during peritoneal closure

Group III (20 participants): received placebo both during induction and peritoneal closure

Outcomes
2. Morphine consumption (mg at 24 hours)
3. Sedation (0-to-100-millimetre VAS at 4,24 , and 48 hours)
4. Nausea and vomiting (0-to-100-millimetre VAS at 4,24 , and 48 hours)
5. Plasma cortisol (nmol/L at preoperative afternoon and morning, 4 hours, and 1st day postoperatively)
6. Plasma leukocytes (preoperatively and at 30 minutes, $4,8,24$ hours after surgery)
7. Plasma glucose (preoperatively and at 30 minutes, $4,8,24$ hours after surgery)

Notes

Funding: not reported

Declarations of interest: not reported

Authors contacted: no

Other: only data from Group I versus II included in review. Pain data extracted from graph using computer software.

\begin{tabular}{lll}
\hline Risk of bias & \\
\hline Bias & Authors' judgement & Support for judgement \\
\hline $\begin{array}{l}\text { Random sequence genera- } \\
\text { tion (selection bias) }\end{array}$ & Unclear risk & No mention \\
\hline $\begin{array}{l}\text { Allocation concealment } \\
\text { (selection bias) }\end{array}$ & Low risk & $\begin{array}{l}\text { Pharmacy controlled. Quote: "before starting the study our hospital pharma- } \\
\text { cy prepared 120 pairs of ampoules, each ampoule containing 10 ml of colour- } \\
\text { less solution. Each pair of ampoules was boxed and numbered consecutively, } 1\end{array}$ \\
\hline
\end{tabular}


Kiliçkan 2001 (Continued)

to 120 , and comprised one ampoule labelled 'induction' and one labelled 'closure"

\begin{tabular}{|c|c|c|}
\hline $\begin{array}{l}\text { Blinding of participants } \\
\text { and personnel (perfor- } \\
\text { mance bias) }\end{array}$ & Low risk & $\begin{array}{l}\text { Similar ampoules and double-dummy placebo used. Quote: "the researchers } \\
\text { did not know the content two pairs of ampules; only the pharmacy knew the } \\
\text { random distribution" }\end{array}$ \\
\hline
\end{tabular}

Blinding of outcome as- Low risk Likely blinded due to above information
sessment (detection bias)

All outcomes

Incomplete outcome data Unclear risk No mention

(attrition bias)

All outcomes

\begin{tabular}{lll}
\hline $\begin{array}{l}\text { Selective reporting (re- } \\
\text { porting bias) }\end{array}$ & Unclear risk & No protocol or trial registration \\
\hline Other bias & Low risk & $\begin{array}{l}\text { Similar baseline characteristics. Quote: "there was no difference in demo- } \\
\text { graphics, type and duration between groups" }\end{array}$ \\
\hline
\end{tabular}

Koprulu 2015

Study design: parallel-group randomized controlled trial
Sample size: 50
Country: Turkey
Setting: secondary care hospital
Dates conducted: 2012 to 2014
Postoperative opioid used and delivery: pethidine $1 \mathrm{mg} / \mathrm{kg}$ when VAS $>4$
Pain score collection: not reported
Concurrent postoperative analgesics: paracetamol $15 \mathrm{mg} / \mathrm{kg}$

Inclusion criteria
Participants Elective lower limb varicose vein surgery (saphenous vein stripping)
2. Aged 25 to 64 years of age

\section{Exclusion criteria}

1. History of chronic alcohol abuse

2. Regular analgesic use within 6 months

3. Chronic pain

4. Other systemic illness

Interventions Group 1 (25 participants): intravenous tramadol $1.5 \mathrm{mg} / \mathrm{kg} 15$ minutes before induction and saline placebo after incision

Group 2 (25 participants): intravenous tramadol $1.5 \mathrm{mg} / \mathrm{kg}$ after incision and saline placebo $15 \mathrm{~min}$ utes before induction 
Koprulu 2015 (Continued)

Outcomes
1. Postoperative pain (on a 0-to-10-centimetre VAS at extubation, before first analgesic request, 6,12 , 18 , and 24 hours)

2. Pethidine and paracetamol consumption ( $\mathrm{mg}$ at 24 hours)

3. Time to first analgesic request (minutes)

4. Complications (arrhythmia, respiratory depression, convulsions, hypotension, headache, dizziness, nausea, vomiting, and urinary retention (yes/no) at 24 hours)
Funding: not reported

Declarations of interest: not reported

Authors contacted: yes, although no response received

Other: time to first analgesic request not reported as time to event. Turkish article that was translated before data extraction. We contacted authors for further information but received no response.

\section{Risk of bias}

\begin{tabular}{|c|c|c|}
\hline Bias & Authors' judgement & Support for judgement \\
\hline $\begin{array}{l}\text { Random sequence genera- } \\
\text { tion (selection bias) }\end{array}$ & Unclear risk & No details. Quote: "two divided into equal groups" \\
\hline $\begin{array}{l}\text { Allocation concealment } \\
\text { (selection bias) }\end{array}$ & Unclear risk & No mention \\
\hline $\begin{array}{l}\text { Blinding of participants } \\
\text { and personnel (perfor- } \\
\text { mance bias) } \\
\text { All outcomes }\end{array}$ & Low risk & $\begin{array}{l}\text { Double-dummy placebo of identical saline. Quote: "the same volume of physi- } \\
\text { ological saline" }\end{array}$ \\
\hline $\begin{array}{l}\text { Blinding of outcome as- } \\
\text { sessment (detection bias) } \\
\text { All outcomes }\end{array}$ & Unclear risk & No mention \\
\hline $\begin{array}{l}\text { Incomplete outcome data } \\
\text { (attrition bias) } \\
\text { All outcomes }\end{array}$ & Low risk & All participants analysed. Numbers in tables match those randomized. \\
\hline $\begin{array}{l}\text { Selective reporting (re- } \\
\text { porting bias) }\end{array}$ & Unclear risk & No protocol or trial registration \\
\hline Other bias & Low risk & $\begin{array}{l}\text { Similar groups and no industry funding. Quote: "demographic differences be- } \\
\text { tween the two groups statistical significance in terms of findings and duration } \\
\text { of operation no difference was found" }\end{array}$ \\
\hline
\end{tabular}

\section{Kurzova 2005}

Study design: parallel-group randomized controlled trial
Sample size: 63
Country: Czech Republic
Setting: secondary care hospital
Dates conducted: not reported


Kurzova 2005 (Continued)

Postoperative opioid used and delivery: PCA morphine

Pain score collection: not reported

Concurrent postoperative analgesics: none reported

Inclusion criteria
Participants ASA 1 to 3 individuals undergoing abdominal hysterectomy with adnexectomy
Exclusion criteria
1. Known allergy to the drugs used
2. Unable to use PCA

$\begin{array}{ll}\text { Interventions } & \text { Group M (21 participants): morphine } 0.1 \mathrm{mg} / \mathrm{kg} 10 \text { minutes before induction and ketamine } 0.6 \mathrm{mg} / \mathrm{kg} \\ & 10 \text { minutes after laparotomy }\end{array}$

Group K (21 participants): ketamine $0.6 \mathrm{mg} / \mathrm{kg} 10$ minutes before induction and morphine $0.1 \mathrm{mg} / \mathrm{kg}$ 10 minutes after laparotomy

Group MK (21 participants): morphine $0.1 \mathrm{mg} / \mathrm{kg}$ and ketamine $0.6 \mathrm{mg} / \mathrm{kg} 10$ minutes before induction and normal saline 10 minutes after laparotomy

\begin{tabular}{ll}
\hline Outcomes & $\begin{array}{l}\text { 1. Morphine consumption (mg at } 24 \text { and } 48 \text { hours) } \\
\text { 2. Postoperative pain (0-to-100 NRS for } 48 \text { hours) }\end{array}$ \\
\hline Notes & Funding: supported by grant IGA NL 7682-3 (source unclear) \\
& Declarations of interest: not reported \\
& Authors contacted: yes, and further information provided \\
& Other: authors contacted and provided further information necessary for inclusion as study unpub- \\
lished. Although ketamine given, Group MK qualifies as preventive and Group K as postincision. Time \\
point for pain scores unclear so not included.
\end{tabular}

Risk of bias

\begin{tabular}{lll}
\hline Bias & Authors' judgement & Support for judgement \\
\hline $\begin{array}{l}\text { Random sequence genera- } \\
\text { tion (selection bias) }\end{array}$ & Unclear risk & States that "the patients were randomly divided" but no details provided \\
\hline $\begin{array}{l}\text { Allocation concealment } \\
\text { (selection bias) }\end{array}$ & Unclear risk & No mention \\
\hline $\begin{array}{l}\text { Blinding of participants } \\
\text { and personnel (perfor- } \\
\text { mance bias) }\end{array}$ & Low risk & $\begin{array}{l}\text { Stl outcomes that participants were blinded and drugs were in coded syringes, and } \\
\text { normal saline given as double-dummy placebo. Quote: "the patients and the } \\
\text { staff were blinded to the study group" }\end{array}$ \\
\hline $\begin{array}{l}\text { Blinding of outcome as- } \\
\text { sessment (detection bias) } \\
\text { All outcomes }\end{array}$ & Low risk & $\begin{array}{l}\text { Staff were blinded. Quote: "the patients and the staff were blinded to the study } \\
\text { group" }\end{array}$ \\
\hline $\begin{array}{l}\text { Incomplete outcome data } \\
\text { (attrition bias) } \\
\begin{array}{l}\text { All outcomes } \\
\hline\end{array}\end{array}$ & Low risk & All participants analysed \\
\hline
\end{tabular}


Kurzova 2005 (Continued)

Selective reporting (re- $\quad$ Unclear risk $\quad$ No protocol or trial registration
porting bias)

Other bias Low risk Similar groups

Lenz 2008

\begin{tabular}{|c|c|}
\hline Methods & $\begin{array}{l}\text { Study design: parallel-group randomized controlled trial } \\
\text { Sample size: } 100 \\
\text { Country: Norway } \\
\text { Setting: secondary care hospital } \\
\text { Dates conducted: not reported } \\
\text { Postoperative opioid used and delivery: PCA fentanyl (first } 4 \text { hours) then oxycodone } 5 \mathrm{mg} \text { after } \\
\text { Pain score collection: not reported } \\
\text { Concurrent postoperative analgesics: paracetamol } 2 \mathrm{~g} \text { pre-medication then paracetamol } 1 \mathrm{~g} \text { and di- } \\
\text { clofenac } 50 \text { mg } 6 \text { hours after pre-medication, evening, and next morning }\end{array}$ \\
\hline Participants & $\begin{array}{l}\text { Inclusion criteria } \\
\text { 1. Adults ( } 18 \text { to } 70 \text { years) } \\
\text { 2. Scheduled for endoscopic reconstruction of the anterior cruciate ligament } \\
\text { 3. ASA } 1 \text { or } 2 \\
\text { Exclusion criteria } \\
\text { 1. Regular use of paracetamol, NSAIDs, corticosteroids, antiemetics, or opioids } \\
\text { 2. Contraindications for NSAIDs } \\
\text { 3. Obesity } \\
\text { 4. Pregnancy }\end{array}$ \\
\hline
\end{tabular}

Interventions Group Pre (50 participants): $1.5 \mathrm{mcg} / \mathrm{kg}$ IV fentanyl before remifentanil infusion (at induction) and 10 minutes before the end of surgery $(3 \mathrm{mcg} / \mathrm{kg}$ in total)

Group Post (50 participants): saline placebo at induction and $3 \mathrm{mcg} / \mathrm{kg}$ IV fentanyl 10 minutes before the end of surgery

\begin{tabular}{ll}
\hline Outcomes & $\begin{array}{l}\text { 1. Opioid consumption (mcg fentanyl } 0 \text { to } 4 \text { hours then mg oxycodone } 4 \text { to } 24 \text { hours) } \\
\text { 2. Postoperative pain ( } 0 \text {-to- } 4 \text { VRS at } 1,2,3 \text {, and } 4 \text { hours after surgery) } \\
\text { 3. Nausea and vomiting (yes/no, both } 0 \text { to } 4 \text { hours and } 4 \text { to } 24 \text { hours) }\end{array}$ \\
\hline Fotes & Funding: departmental funding \\
Authors contacted: we contacted authors for further information and received a response, however no \\
further data were available. \\
Other: opioid consumption data extracted from graph using computer software. Pain reported as medi- \\
an so included in narrative synthesis.
\end{tabular}

\section{Risk of bias}

Pre-emptive and preventive opioids for postoperative pain in adults undergoing all types of surgery (Review) 
Lenz 2008 (Continued)

Bias Authors' judgement Support for judgement

$\begin{array}{ll}\begin{array}{l}\text { Random sequence genera- } \\ \text { tion (selection bias) }\end{array} & \begin{array}{l}\text { Computer-generated codes. Quote: "randomization was based on comput- } \\ \text { er-generated codes" }\end{array}\end{array}$

\begin{tabular}{|c|c|c|}
\hline $\begin{array}{l}\text { Allocation concealment } \\
\text { (selection bias) }\end{array}$ & Low risk & $\begin{array}{l}\text { Quote: "stored in sequentially numbered, sealed envelopes. A nurse not partic- } \\
\text { ipating in the handling or the evaluation of the participant was responsible for } \\
\text { opening the envelopes and preparing the two coded syringes" }\end{array}$ \\
\hline $\begin{array}{l}\text { Blinding of participants } \\
\text { and personnel (perfor- } \\
\text { mance bias) } \\
\text { All outcomes }\end{array}$ & Low risk & $\begin{array}{l}\text { Quote: "Group Pre, both syringes contained fentanyl } 1.5 \mathrm{mg} / \mathrm{kg} \text { for partici- } \\
\text { pant's weight. In Group Post, syringe no. } 1 \text { contained } 0.9 \% \text { saline (placebo) } \\
\text { and syringe no. } 2 \text { contained fentanyl } 3.0 \mathrm{mg} / \mathrm{kg} \text { based on participant's weight. } \\
\text { Saline was used for dilution so that the syringes contained the same volume } \\
\text { for participants with the same weight" }\end{array}$ \\
\hline $\begin{array}{l}\text { Blinding of outcome as- } \\
\text { sessment (detection bias) } \\
\text { All outcomes }\end{array}$ & Low risk & Likely blinded based on above information \\
\hline $\begin{array}{l}\text { Incomplete outcome data } \\
\text { (attrition bias) } \\
\text { All outcomes }\end{array}$ & Low risk & $\begin{array}{l}\text { Exclusions unlikely to cause bias. Quote: "from } 112 \text { participants, } 12 \text { were ex- } \\
\text { cluded because the surgical procedure did not proceed to repair as planned" }\end{array}$ \\
\hline $\begin{array}{l}\text { Selective reporting (re- } \\
\text { porting bias) }\end{array}$ & Low risk & $\begin{array}{l}\text { NCT00241332. Primary outcomes pre-stated. Quote: "the study was reported } \\
\text { to ClinicalTrials.gov ID: NCT00241332" }\end{array}$ \\
\hline Other bias & Low risk & $\begin{array}{l}\text { Similar groups and no industry funding. Quote: "the demographic characteris- } \\
\text { tics of these } 100 \text { patients were similar in the two groups" }\end{array}$ \\
\hline
\end{tabular}

Mansfield 1994

\begin{tabular}{|c|c|}
\hline Methods & $\begin{array}{l}\text { Study design: parallel-group randomized controlled trial } \\
\text { Sample size: } 62 \\
\text { Country: UK } \\
\text { Setting: secondary care hospital } \\
\text { Dates conducted: not reported } \\
\text { Postoperative opioid used and delivery: PCA morphine } \\
\text { Pain score collection: ward nurses } \\
\text { Concurrent postoperative analgesics: none reported }\end{array}$ \\
\hline Participants & $\begin{array}{l}\text { Inclusion criteria } \\
\text { 1. ASA } 1 \text { or } 2 \\
\text { 2. Scheduled for total abdominal hysterectomy with or without bilateral salpingo-oophorectomy } \\
\text { Exclusion criteria } \\
\text { 1. Known alcohol or drug abuse } \\
\text { 2. History of chronic pain } \\
\text { 3. Current treatment with NSAIDs } \\
\text { 4. Previous psychiatric history }\end{array}$ \\
\hline
\end{tabular}

Pre-emptive and preventive opioids for postoperative pain in adults undergoing all types of surgery (Review) 
Mansfield 1994 (Continued)
5. History of liver disease
6. Allergy to opioids

Interventions

Group A (30 participants): intravenous alfentanil $7.5 \mathrm{mcg} / \mathrm{kg}$ at induction and 90 seconds before incision $(15 \mathrm{mcg} / \mathrm{kg}$ total dose)

Group B (30 participants): intravenous $15 \mathrm{mcg} / \mathrm{kg}$ alfentanil 10 minutes after incision

\begin{tabular}{|c|c|c|}
\hline Outcomes & \multicolumn{2}{|c|}{$\begin{array}{l}\text { 1. Postoperative pain (0-to-100-millimetre VAS at } 2,6 \text {, and } 24 \text { hours) } \\
\text { 2. Morphine consumption (mg at } 2,6 \text {, and } 24 \text { hours) } \\
\text { 3. Intraoperative bradycardia (incidence and dose of atropine in } \mathrm{mcg} \text { ) }\end{array}$} \\
\hline Notes & $\begin{array}{l}\text { Funding: not reported } \\
\text { Declarations of intere } \\
\text { Authors contacted: we } \\
\text { Other: data reported }\end{array}$ & $\begin{array}{l}\text { : not reported } \\
\text { contacted authors for further information but received no response. } \\
\text { median, so included in narrative synthesis. }\end{array}$ \\
\hline \multicolumn{3}{|l|}{ Risk of bias } \\
\hline Bias & Authors' judgement & Support for judgement \\
\hline $\begin{array}{l}\text { Random sequence genera- } \\
\text { tion (selection bias) }\end{array}$ & Unclear risk & $\begin{array}{l}\text { No details. Quote: "after the pre-operative visit participants were allocated } \\
\text { randomly to either the study or control group" }\end{array}$ \\
\hline $\begin{array}{l}\text { Allocation concealment } \\
\text { (selection bias) }\end{array}$ & Unclear risk & No mention \\
\hline $\begin{array}{l}\text { Blinding of participants } \\
\text { and personnel (perfor- } \\
\text { mance bias) } \\
\text { All outcomes }\end{array}$ & High risk & No placebo. Quote: "were recruited into this single-blind, randomised study" \\
\hline $\begin{array}{l}\text { Blinding of outcome as- } \\
\text { sessment (detection bias) } \\
\text { All outcomes }\end{array}$ & Low risk & $\begin{array}{l}\text { Blinded. Quote: "nurses were unaware of each participant's group allocation } \\
\text { and none of the investigators saw any participant postoperatively until the } \\
\text { end of the study period" }\end{array}$ \\
\hline $\begin{array}{l}\text { Incomplete outcome data } \\
\text { (attrition bias) } \\
\text { All outcomes }\end{array}$ & Low risk & $\begin{array}{l}\text { Unlikely to bias results due to low numbers. Quote: "one participant in the } \\
\text { control group was withdrawn because of excessive nausea and itch which was } \\
\text { attributed to morphine in the PCA. The data for one participant were lost" }\end{array}$ \\
\hline $\begin{array}{l}\text { Selective reporting (re- } \\
\text { porting bias) }\end{array}$ & Unclear risk & No protocol or trial registration \\
\hline Other bias & Low risk & Similar baseline characteristics. No industry funding \\
\hline
\end{tabular}

Mansfield 1996

Study design: parallel-group randomized controlled trial
Sample size: 66
Country: UK
Setting: secondary care hospital


Mansfield 1996 (Continued)

Dates conducted: not reported

Postoperative opioid used and delivery: PCA morphine

Pain score collection: not reported

Concurrent postoperative analgesics: none reported in first 24 hours

Participants
$\begin{aligned} & \text { Inclusion criteria } \\ & \text { 2. Females undergoing total abdom } 1 \text { or } 2 \\ & \text { 3. Aged } 18 \text { to } 70 \text { years } \\ & \text { 4. Weighing } 45 \mathrm{~kg} \text { to } 100 \mathrm{~kg} \\ & \text { Exclusion criteria } \\ & \text { 1. If individual requested exclusion } \\ & \text { 2. Organ dysfunction } \\ & \text { 3. Chronic pain } \\ & \text { 4. Regular opioids } \\ & \text { 5. NSAIDs } \\ & \text { 6. Drug/alcohol abuse } \\ & \text { 7. Psychiatric disorder }\end{aligned}$

Interventions

Group Pre-low (22 participants): intravenous morphine $0.15 \mathrm{mg} / \mathrm{kg}$ given during induction and placebo at peritoneal closure

Group Pre-high (20 participants): intravenous morphine $0.3 \mathrm{mg} / \mathrm{kg}$ given during induction and placebo at peritoneal closure

Group Post (18 participants): placebo at induction and $0.15 \mathrm{mg} / \mathrm{kg}$ at peritoneal closure

1. Postoperative pain (1, 2, 4, 24, and 48 hours on 0-to-100-millimetre VAS and 0-to-8 VRS at rest and
movement)
$\begin{aligned} & \text { 2. Morphine consumption (mg at } 24 \text { and } 48 \text { hours) } \\ & \text { 3. Nausea, vomiting, and antiemetic requirement (all yes/no at } 24 \text { hours) }\end{aligned}$

Notes

Funding: not reported

Declarations of interest: not reported

Authors contacted: we contacted authors for further information but received no response.

Other: results reported as median so included in narrative synthesis. Pain data extracted from graph using computer software.

\section{Risk of bias}

\begin{tabular}{lll}
\hline Bias & Authors' judgement & Support for judgement \\
\hline $\begin{array}{l}\text { Random sequence genera- } \\
\text { tion (selection bias) }\end{array}$ & Unclear risk & No details \\
\hline $\begin{array}{l}\text { Allocation concealment } \\
\text { (selection bias) }\end{array}$ & Low risk & $\begin{array}{l}\text { Pharmacy controlled. Quote: "pharmacy prepared 10ml colourless solutions } \\
\text { which were sequentially numbered" }\end{array}$ \\
\hline $\begin{array}{l}\text { Blinding of participants } \\
\text { and personnel (perfor- } \\
\text { mance bias) }\end{array}$ & Low risk & $\begin{array}{l}\text { Double-dummy used. Quote: "pharmacy prepared 10ml colourless solutions } \\
\text { which were sequentially numbered" }\end{array}$ \\
\hline
\end{tabular}

Pre-emptive and preventive opioids for postoperative pain in adults undergoing all types of surgery (Review) 
Mansfield 1996 (Continued)

All outcomes

$\begin{array}{ll}\text { Blinding of outcome as- } & \text { Low risk } \\ \text { sessment (detection bias) } & \text { Blinded based on above information. Quote: "all investigators were blinded to } \\ \text { All outcomes } & \text { the contents of the pair of ampoules" }\end{array}$

All outcomes

\begin{tabular}{|c|c|c|}
\hline $\begin{array}{l}\text { Incomplete outcome data } \\
\text { (attrition bias) }\end{array}$ & Low risk & $\begin{array}{l}\text { Dropouts unlikely to bias results. } 1 \text { participant from } 1 \text { group excluded due to } \\
\text { severe anxiety, but number too small to affect results. }\end{array}$ \\
\hline
\end{tabular}

All outcomes severe anxiety, but number too small to affect results.

\begin{tabular}{lll}
\hline $\begin{array}{l}\text { Selective reporting (re- } \\
\text { porting bias) }\end{array}$ & Unclear risk & No protocol or trial registration \\
\hline Other bias & Low risk & Similar baseline characteristics \\
\hline
\end{tabular}

\section{Millar 1998}

Study design: parallel-group randomized controlled trial
Sample size: 68
Country: UK
Setting: secondary care hospital
Dates conducted: not reported
Postoperative opioid used and delivery: PCA morphine
Pain score collection: not reported
Concurrent postoperative analgesics: no other analgesics given during 24 hours after surgery

\begin{tabular}{ll}
\hline Participants & Inclusion criteria \\
1. ASA 1 and 2 individuals \\
2. Aged under 60 years old \\
3. Undergoing hysterectomy with or without salpingo-oophorectomy
\end{tabular}

\section{Exclusion criteria}

1. Chronic pain

2. Alcohol or drug abuse

3. Psychiatric history

Interventions

Group Induction (30 participants): intravenous morphine $0.3 \mathrm{mg} / \mathrm{kg}$ at induction and intravenous saline at incision

Group Incision (30 participants): intravenous saline at induction and intravenous morphine $0.3 \mathrm{mg} /$ $\mathrm{kg}$ at incision
Outcomes
1. Morphine consumption ( $\mathrm{mg}$ in recovery and at $1,2,4$, and 24 hours)
2. Postoperative pain (0-to-100-millimetre VAS and VRS at 1, 2, 4, 24, and 48 hours)
3. Nausea and vomiting (yes/no at 1, 2, 4, 24, and 48 hours)

$\begin{array}{ll}\text { Notes } & \text { Funding: not reported } \\ & \text { Declarations of interest: not reported }\end{array}$


Authors contacted: we contacted authors for further information and received a response, however no further data were available.

Other: data reported as median so included in narrative synthesis. Nausea and vomiting not reported.

Could not use pain score data as graphs have contradictory legends on and below the graph.

\section{Risk of bias}

\begin{tabular}{|c|c|c|}
\hline Bias & Authors' judgement & Support for judgement \\
\hline $\begin{array}{l}\text { Random sequence genera- } \\
\text { tion (selection bias) }\end{array}$ & Unclear risk & No details \\
\hline $\begin{array}{l}\text { Allocation concealment } \\
\text { (selection bias) }\end{array}$ & Low risk & Pharmacy controlled. Quote: "the hospital pharmacy prepared" \\
\hline $\begin{array}{l}\text { Blinding of participants } \\
\text { and personnel (perfor- } \\
\text { mance bias) } \\
\text { All outcomes }\end{array}$ & Low risk & $\begin{array}{l}\text { Double-dummy placebo that sounds similar in appearance. Quote: "and ran- } \\
\text { domized them so that the investigator did not know if the morphine was given } \\
\text { at induction or incision" }\end{array}$ \\
\hline $\begin{array}{l}\text { Blinding of outcome as- } \\
\text { sessment (detection bias) } \\
\text { All outcomes }\end{array}$ & Unclear risk & Not enough detail to assess \\
\hline $\begin{array}{l}\text { Incomplete outcome data } \\
\text { (attrition bias) } \\
\text { All outcomes }\end{array}$ & High risk & $\begin{array}{l}>10 \% \text { of participants lost to follow-up, and some for reasons that could have } \\
\text { influenced outcome. Quote: "one had a panic attack, one developed respirato- } \\
\text { ry depression" }\end{array}$ \\
\hline $\begin{array}{l}\text { Selective reporting (re- } \\
\text { porting bias) }\end{array}$ & High risk & Nausea and vomiting not reported \\
\hline Other bias & Low risk & Similar baseline characteristics. Quote: "patients were similar" \\
\hline
\end{tabular}

Pjevic 1999

Study design: parallel-group randomized controlled trial
Sample size: 30
Country: Croatia
Setting: secondary care hospital
Dates conducted: not reported
Postoperative opioid used and delivery: intramuscular piritramide
Pain score collection: not reported
Concurrent postoperative analgesics: intramuscular metamizole $2500 \mathrm{mg}$

Participants

\section{Inclusion criteria}

1. ASA 1 or 2 individuals undergoing open cholecystectomy

2. Aged 40 to 65 years old

\section{Exclusion criteria}


Pjevic 1999 (Continued)
1. On analgesics
2. Addicted to alcohol or drugs
3. Chronic pain
4. Liver disease

Interventions

Group 1 (15 participants): intravenous pethidine $1 \mathrm{mg} / \mathrm{kg} 5$ minutes before induction and equal volume of normal saline after peritoneal opening

Group 2 (15 participants): equal volume of normal saline 5 minutes before induction and intravenous pethidine $1 \mathrm{mg} / \mathrm{kg}$ after peritoneal opening

\begin{tabular}{ll}
\hline Outcomes & 1. Time to first analgesic request (minutes) \\
2. Piritramide and metamizole consumption (mg at 24 hours) \\
3. Postoperative pain (0-to-10-centimetre VAS before analgesia and at 4, 8, 12, and 24 hours) \\
\hline Fotes \\
Funding: not reported \\
Authors contacted: no \\
Other: participants also received metamizole for postoperative analgesia. Croatian article was translat- \\
ed before data extraction. Early acute pain scores included from 4 hours.
\end{tabular}

\section{Risk of bias}

\begin{tabular}{|c|c|c|}
\hline Bias & Authors' judgement & Support for judgement \\
\hline $\begin{array}{l}\text { Random sequence genera- } \\
\text { tion (selection bias) }\end{array}$ & Unclear risk & No details. Quote: "participants were divided into two groups" \\
\hline $\begin{array}{l}\text { Allocation concealment } \\
\text { (selection bias) }\end{array}$ & Unclear risk & No mention \\
\hline $\begin{array}{l}\text { Blinding of participants } \\
\text { and personnel (perfor- } \\
\text { mance bias) } \\
\text { All outcomes }\end{array}$ & Low risk & Similar double-dummy placebo \\
\hline $\begin{array}{l}\text { Blinding of outcome as- } \\
\text { sessment (detection bias) } \\
\text { All outcomes }\end{array}$ & Unclear risk & No mention \\
\hline $\begin{array}{l}\text { Incomplete outcome data } \\
\text { (attrition bias) } \\
\text { All outcomes }\end{array}$ & Low risk & No dropouts \\
\hline $\begin{array}{l}\text { Selective reporting (re- } \\
\text { porting bias) }\end{array}$ & Unclear risk & No protocol or trial registration \\
\hline Other bias & Low risk & Similar baseline characteristics \\
\hline
\end{tabular}

Methods Study design: parallel-group randomized controlled trial

Sample size: 60 
Pozos-Guillen 2007 (Continued)

Country: Mexico

Setting: secondary care hospital

Dates conducted: not reported

Postoperative opioid used and delivery: N/A

Pain score collection: in clinic-submitted pain evaluations

Concurrent postoperative analgesics: dexamethasone $4 \mathrm{mg}$ intramuscular before procedure, paracetamol $500 \mathrm{mg}$ to $1000 \mathrm{mg}$ or ketorolac $10 \mathrm{mg}$ (or intramuscular $30 \mathrm{mg}$ ) depending on pain

Inclusion criteria
$\begin{aligned} & \text { 1. Between the ages of } 19 \text { and } 27 \text { years } \\ & \text { 2. Undergoing elective removal of an impacted mands } \\ & \text { Exclusion criteria } \\ & \text { 1. Use of analgesics } 12 \text { hours before the treatment } \\ & \text { 2. History of seizure disorders } \\ & \text { 3. Pregnancy } \\ & \text { 4. Lactation }\end{aligned}$

Interventions

Group A (20 participants): intramuscular tramadol $100 \mathrm{mg} 1$ hour before surgery

Group B (20 participants): intramuscular tramadol 100 mg after surgery

Group C (20 participants): saline placebo

\begin{tabular}{ll}
\hline Outcomes & 1. Postoperative pain (0-to-10-centimetre VAS at 6 and 24 hours) \\
2. Relief of pain ( 0 -to- 4 scale at 24 hours) \\
3. Analgesic consumption (mg ketorolac and mg paracetamol at 24 hours)
\end{tabular}

Notes

Funding: funded by Universidad Autónoma San Luis Potosí; C0-FAI-04-3.4 and C04-FAI-10-10.53

Declarations of interest: not reported

Authors contacted: we contacted authors for further information but received no response.

Other: extracted from graphs using computer software. Unclear what errors bars represent

\section{Risk of bias}

\begin{tabular}{lll}
\hline Bias & Authors' judgement & Support for judgement \\
\hline $\begin{array}{l}\text { Random sequence genera- } \\
\text { tion (selection bias) }\end{array}$ & Unclear risk & Unclear details. Quote: "participants were randomized" \\
\hline $\begin{array}{l}\text { Allocation concealment } \\
\text { (selection bias) }\end{array}$ & Unclear risk & No mention \\
\hline $\begin{array}{l}\text { Blinding of participants } \\
\text { and personnel (perfor- } \\
\text { mance bias) } \\
\text { All outcomes }\end{array}$ & High risk & No double-dummy placebo \\
\hline
\end{tabular}

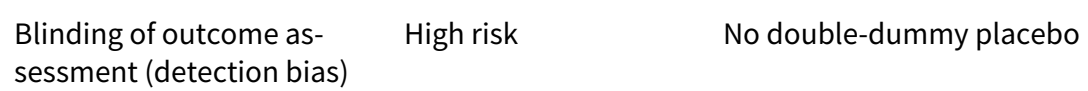


Pozos-Guillen 2007 (Continued)

All outcomes

Incomplete outcome data Low risk It appears that all participants were followed up.
(attrition bias)

(attrition bias)

All outcomes

\begin{tabular}{lll}
\hline $\begin{array}{l}\text { Selective reporting (re- } \\
\text { porting bias) }\end{array}$ & High risk & Adverse events not fully reported. \\
\hline Other bias & Low risk & $\begin{array}{l}\text { Similar groups and no industry funding. Quote: "demographic characteristics } \\
\text { of the sample were similar between groups for age and gender" }\end{array}$ \\
\hline
\end{tabular}

Richmond 1993

Study design: parallel-group randomized controlled trial
Sample size: 76
Country: UK
Setting: secondary care hospital
Dates conducted: not reported
Postoperative opioid used and delivery: PCA morphine
Pain score collection: not reported
Concurrent postoperative analgesics: none reported

Participants

Inclusion criteria

1. ASA 1 and 2
2. Undergoing elective total abdominal hysterectomy

\section{Exclusion criteria}

1. Chronic pain

2. Regular intake of analgesics

3. Psychiatric illness

Interventions

Group IV Pre (23 participants): intravenous morphine $10 \mathrm{mg}$ administered at induction

Group IV Post (21 participants): intravenous morphine $10 \mathrm{mg}$ administered at peritoneal closure

Also reports that saline placebo was used

Outcomes

1. Morphine consumption ( $\mathrm{mg}$ at 24 hours)

2. Pain sensitivity and postoperative pain (rest and movement on 0 -to-100-millimetre VAS at 4, 24, and 48 hours)

Notes

Funding: author recipient of Bristol-Myers Squibb research grant. Role in published study unclear

Declarations of interest: as above

Authors contacted: no 
Richmond 1993 (Continued)

Other: pain score data extracted from graph and standard deviations estimated. Study also included a further group who were administered intramuscular morphine but we did not include this group in review as different route of administration.

\section{Risk of bias}

\begin{tabular}{|c|c|c|}
\hline Bias & Authors' judgement & Support for judgement \\
\hline $\begin{array}{l}\text { Random sequence genera- } \\
\text { tion (selection bias) }\end{array}$ & Unclear risk & No mention. Quote: "patients were randomly allocated" \\
\hline $\begin{array}{l}\text { Allocation concealment } \\
\text { (selection bias) }\end{array}$ & Low risk & Performed by pharmacist. Quote: "were randomly allocated by a pharmacist" \\
\hline $\begin{array}{l}\text { Blinding of participants } \\
\text { and personnel (perfor- } \\
\text { mance bias) } \\
\text { All outcomes }\end{array}$ & Low risk & $\begin{array}{l}\text { Saline used as placebo. Pharmacy made up study medications blind. Quote: } \\
\text { "the study was double blind" }\end{array}$ \\
\hline $\begin{array}{l}\text { Blinding of outcome as- } \\
\text { sessment (detection bias) } \\
\text { All outcomes }\end{array}$ & Low risk & Reported as blinded. Quote: "the study was double blind" \\
\hline $\begin{array}{l}\text { Incomplete outcome data } \\
\text { (attrition bias) } \\
\text { All outcomes }\end{array}$ & High risk & $\begin{array}{l}\text { Number of participants who dropped out for the reasons listed and to which } \\
\text { groups they belonged is unclear from text. } 1 \text { reason for dropout was severe } \\
\text { nausea, which could bias outcome of morphine consumption. Quote: "16 were } \\
\text { excluded ... or severe nausea" }\end{array}$ \\
\hline $\begin{array}{l}\text { Selective reporting (re- } \\
\text { porting bias) }\end{array}$ & Unclear risk & No protocol or trial registration \\
\hline Other bias & Low risk & $\begin{array}{l}\text { Similar baseline characteristics. } 1 \text { of the investigators received industry fund- } \\
\text { ing, but it was unclear if the funding was specific to this study. Quote: "the } \\
\text { groups were not statistically different" }\end{array}$ \\
\hline
\end{tabular}

\section{Sarantopoulos 1996}

\begin{tabular}{ll}
\hline Methods & Study design: parallel-group randomized controlled trial \\
Sample size: 40 \\
Country: Greece \\
Setting: secondary care hospital \\
Dates conducted: not reported \\
Postoperative opioid used and delivery: pethidine $1 \mathrm{mg} / \mathrm{kg}$ (no PCA) \\
Pain score collection: blinded nurses \\
Concurrent postoperative analgesics: propoxyphene $75 \mathrm{mg}$ and paracetamol 600 mg intramuscularly if \\
pain insufficiently controlled \\
Inclusion criteria \\
$\begin{array}{l}\text { 1. ASA } 1 \text { or } 2 \\
\text { 2. Admitted for elective abdominal hysterectomy }\end{array}$
\end{tabular}


Sarantopoulos 1996 (Continued)

\section{Exclusion criteria}

1. Alcohol or drug abuse

2. History of chronic pain

3. Current treatment with analgesics

4. Psychiatric history

5. History of liver disease

Interventions

Group A (18 participants): intravenous sufentanil $1 \mathrm{mcg} / \mathrm{kg} 5$ minutes before induction and normal saline during round ligament ligation

Group B (21 participants): intravenous sufentanil $1 \mathrm{mcg} / \mathrm{kg}$ during round ligament ligation and normal saline before induction

Outcomes $\begin{aligned} & \text { 1. Analgesic consumption (mg pethidine and mg propoxyphene consumption at } 24 \text { hours) } \\ & \text { 2. Postoperative pain (0-to-10-centimetre VAS and 0-to- } 6 \text { NRS at analgesic request, } 4 \text { hourly for } 12 \text { hours } \\ & \text { then at } 24 \text { hours) } \\ & \text { 3. Time to first analgesic request (minutes) }\end{aligned}$

Notes

Funding: not reported

Declarations of interest: not reported

Authors contacted: no

Other: time to analgesic request not time to event. Analgesic consumption standard deviations estimated as means for both analgesics were combined. Early acute postoperative pain recorded from 4 hours postoperatively.

\section{Risk of bias}

\begin{tabular}{|c|c|c|}
\hline Bias & Authors' judgement & Support for judgement \\
\hline $\begin{array}{l}\text { Random sequence genera- } \\
\text { tion (selection bias) }\end{array}$ & Low risk & $\begin{array}{l}\text { Computer-generated random numbers. Quote: "using a computer-created ta- } \\
\text { ble of random numbers" }\end{array}$ \\
\hline $\begin{array}{l}\text { Allocation concealment } \\
\text { (selection bias) }\end{array}$ & Unclear risk & $\begin{array}{l}\text { Envelope used; no further details. Quote: "an investigator who was not in- } \\
\text { volved in administering the patient's anaesthesia or assessing postoperative } \\
\text { pain opened an envelope containing the group assignment for each prospec- } \\
\text { tive patient" }\end{array}$ \\
\hline $\begin{array}{l}\text { Blinding of participants } \\
\text { and personnel (perfor- } \\
\text { mance bias) } \\
\text { All outcomes }\end{array}$ & Low risk & $\begin{array}{l}\text { Double-dummy placebo used, which sounds similar. Quote: "the patient, } \\
\text { anaesthesiologists and nurses involved in anaesthesia, postoperative care, } \\
\text { and pain assessment were blinded to group assignment" }\end{array}$ \\
\hline $\begin{array}{l}\text { Blinding of outcome as- } \\
\text { sessment (detection bias) } \\
\text { All outcomes }\end{array}$ & Low risk & $\begin{array}{l}\text { Blinded. Quote: "the patient, anaesthesiologists and nurses involved in anaes- } \\
\text { thesia, postoperative care, and pain assessment were blinded to group assign- } \\
\text { ment" }\end{array}$ \\
\hline $\begin{array}{l}\text { Incomplete outcome data } \\
\text { (attrition bias) } \\
\text { All outcomes }\end{array}$ & Low risk & $\begin{array}{l}1 \text { participant withdrawn due to confusion, unlikely to bias. Quote: "one patient } \\
\text { assigned to the SA group was withdrawn from the study. This was due to men- } \\
\text { tal confusion and impaired cooperation" }\end{array}$ \\
\hline $\begin{array}{l}\text { Selective reporting (re- } \\
\text { porting bias) }\end{array}$ & Unclear risk & No protocol or trial registration \\
\hline Other bias & Low risk & $\begin{array}{l}\text { Similar baseline characteristics. Quote: "no significant differences were found } \\
\text { between the two groups" }\end{array}$ \\
\hline
\end{tabular}




Study design: parallel-group randomized controlled trial
Sample size: 50
Country: Turkey
Setting: secondary care hospital
Dates conducted: June 2009 to February 2010
Postoperative opioid used and delivery: PCA tramadol if VAS $>3$
Pain score collection: not reported
Concurrent postoperative analgesics: none reported

Participants

\section{Inclusion criteria}

1. ASA 1 or 2

2. Aged between 20 and 60 years

3. Scheduled for elective subtotal thyroidectomy or breast-conserving surgery

\section{Exclusion criteria}

1. Requiring radical neck dissection

2. Requiring axillary lymph node dissection

3. Receiving regular sedative or narcotic medications

4. Received systemic opioids within 48 hours of surgery

5. Significant history of cardiovascular, hepatic, or renal disease

6. Allergic to anaesthetics

Interventions

Group P (25 participants): intravenous pethidine $1 \mathrm{mg} / \mathrm{kg}$ before induction

Group I (25 participants): intravenous pethidine $1 \mathrm{mg} / \mathrm{kg} 20$ minutes before the end of surgery

Outcomes
1. Postoperative pain ( 30 minutes and $1,2,6,12$, and 24 hours on 0-to-10-centimetre VAS)
3. Time to first analgesic (minutes)
4. Side effects (intraoperative bradycardia, intraoperative hypotension, respiration depression, pruritus
and allergic reaction, yes/no at 24 hours)
5. Sedation (4-point scale up to 24 hours)

Notes

Funding: not reported

Declarations of interest: not reported

Authors contacted: we contacted authors for further information but received no response.

Other: unclear what average values represent on graph of postoperative pain scores. Time to first analgesic request not time to event. Sedation not used as ordinal scale. Results reported as median so included in narrative synthesis.

\section{Risk of bias}

\begin{tabular}{lll}
\hline Bias & Authors' judgement & Support for judgement \\
\hline $\begin{array}{l}\text { Random sequence genera- } \\
\text { tion (selection bias) }\end{array}$ & Low risk & $\begin{array}{l}\text { Computer-generated randomization. Quote: "the patients were randomly allo- } \\
\text { cated using a computer-generated randomization scheme to } 1 \text { of } 2 \text { groups" }\end{array}$ \\
\hline
\end{tabular}


Sert 2012 (Continued)

\begin{tabular}{|c|c|c|}
\hline $\begin{array}{l}\text { Allocation concealment } \\
\text { (selection bias) }\end{array}$ & Unclear risk & No mention \\
\hline $\begin{array}{l}\text { Blinding of participants } \\
\text { and personnel (perfor- } \\
\text { mance bias) } \\
\text { All outcomes }\end{array}$ & High risk & $\begin{array}{l}\text { No double-dummy placebo used. Quote: "an anesthesiologist who was not in- } \\
\text { volved in the data collection process prepared the study solutions" }\end{array}$ \\
\hline $\begin{array}{l}\text { Blinding of outcome as- } \\
\text { sessment (detection bias) } \\
\text { All outcomes }\end{array}$ & Unclear risk & $\begin{array}{l}\text { No mention of postoperative data collection. Quote: "another anesthesiolo- } \\
\text { gist, who was blinded to the treatment group allocation, collected the data } \\
\text { during the operations" }\end{array}$ \\
\hline $\begin{array}{l}\text { Incomplete outcome data } \\
\text { (attrition bias) } \\
\text { All outcomes }\end{array}$ & Low risk & $\begin{array}{l}\text { All participants analysed. Quote: "no patient was excluded from the study for } \\
\text { any reason" }\end{array}$ \\
\hline $\begin{array}{l}\text { Selective reporting (re- } \\
\text { porting bias) }\end{array}$ & Unclear risk & No protocol or trial registration \\
\hline Other bias & Low risk & $\begin{array}{l}\text { Similar baseline characteristics. Quote: "there were no statistically significant } \\
\text { differences between the } 2 \text { groups regarding sex, age, weight, height, ASA phys- } \\
\text { ical status, duration of anesthesia and surgery, or types of surgery" }\end{array}$ \\
\hline
\end{tabular}

\section{Shen 2008}

Methods

Study design: parallel-group randomized controlled trial

Sample size: 317

Country: China

Setting: secondary care hospital

Dates conducted: not reported

Postoperative opioid used and delivery: PCA morphine

Pain score collection: not reported

Concurrent postoperative analgesics: none

\section{Participants}

\section{Inclusion criteria}

1. ASA 1 or 2

2. Aged 18 to 65 years old

3. Underwent elective lumpectomy

\section{Exclusion criteria}
1. Allergy to opioids
2. History of use of centrally acting drugs
3. Chronic pain
4. Psychiatric disorders
5. Pregnancy
6. Not willing to take part
7. Individuals with a score under 6 out of 10 in PACU (measuring somnolence, respiration, movement, colour, and blood pressure on 0-to-2 scales) 
Shen 2008 (Continued)

8. Oxygen saturation was $92 \%$ or lower

9. Monoamine oxidase inhibitor use within 14 days

10.Alcohol abuse

11.Opioid-dependent individuals

Interventions

Group T1 (148 participants): intravenous tramadol $100 \mathrm{mg}$ in $10 \mathrm{~mL} 15$ minutes before surgery and the same volume of saline 15 minutes before the end of surgery

Group T2 (151 participants): $10 \mathrm{~mL}$ of saline was injected 15 minutes before surgery and the same volume of intravenous tramadol $100 \mathrm{mg} 15$ minutes before the end of surgery

Outcomes
1. Postoperative pain (0-to-100-millimetre VAS every hour between 1 and 12 hours then every 6 hours until 24 hours)

2. Morphine consumption ( $\mathrm{mg}$ at 24 hours)

3. Patient satisfaction (1-to-100-millimetre VAS at 24 hours)

4. Nausea, vomiting, dry mouth, dizziness, drowsiness, pruritus, sweating, constipation, urinary retention, respiratory depression, meiosis, and cognitive impairment (all yes/no at 24 hours)

\section{Notes \\ Funding: not reported \\ Declarations of interest: not reported \\ Authors contacted: we contacted authors for further information but received no response. \\ Other: morphine consumption reported as median so included in narrative synthesis. Pain data ex- tracted from graph using computer software.}

\section{Risk of bias}

\begin{tabular}{|c|c|c|}
\hline Bias & Authors' judgement & Support for judgement \\
\hline $\begin{array}{l}\text { Random sequence genera- } \\
\text { tion (selection bias) }\end{array}$ & Unclear risk & $\begin{array}{l}\text { Participants randomly assigned, although no details as to how this was } \\
\text { achieved. Quote: "all enrolled patients were randomly assigned into one of } \\
\text { two groups according to SNOSE way" }\end{array}$ \\
\hline $\begin{array}{l}\text { Allocation concealment } \\
\text { (selection bias) }\end{array}$ & Low risk & Sequentially numbered, opaque, sealed envelopes \\
\hline $\begin{array}{l}\text { Blinding of participants } \\
\text { and personnel (perfor- } \\
\text { mance bias) } \\
\text { All outcomes }\end{array}$ & Low risk & $\begin{array}{l}\text { Similar double-dummy placebo. Quote: "... and the same volume of saline be- } \\
\text { fore the end of operation" }\end{array}$ \\
\hline $\begin{array}{l}\text { Blinding of outcome as- } \\
\text { sessment (detection bias) } \\
\text { All outcomes }\end{array}$ & Low risk & $\begin{array}{l}\text { Likely blinded based on information above. Quote: "all research staff, data col- } \\
\text { lection doctors and nurses and drug delivery personnel were kept away from } \\
\text { the contents of the syringe" }\end{array}$ \\
\hline $\begin{array}{l}\text { Incomplete outcome data } \\
\text { (attrition bias) } \\
\text { All outcomes }\end{array}$ & Low risk & Similar dropouts, and reasons unlikely to bias \\
\hline
\end{tabular}

Selective reporting (re- Unclear risk No protocol or trial registration
porting bias)

Other bias Low risk

Similar baseline characteristics. Quote: "the demographic, background, surgical, anesthesia and intraoperative management data, baseline vital signs (all were within the physiological ranges throughout the anesthesia and surgical process) were not significantly different between the two groups" 
Wilson 1994

Study design: parallel-group randomized controlled trial
Sample size: 40
Country: UK
Setting: secondary care hospital
Dates conducted: not reported
Postoperative opioid used and delivery: 2 mg morphine boluses in recovery then PCA morphine
Pain score collection: no mention
Concurrent postoperative analgesics: no other analgesia
Inclusion criteria
$\begin{aligned} & \text { 1. Undergoing elective total abdominal hysterectomy via a transverse lower abdominal incision } \\ & \text { 2. ASA } 1 \text { or } 2 \\ & \text { 3. Aged between } 25 \text { and } 65 \text { years } \\ & \text { 4. Weighed between } 45 \mathrm{~kg} \text { and } 100 \mathrm{~kg}\end{aligned}$

Interventions

Group A (assumed 20 participants): IV $40 \mathrm{mcg} / \mathrm{kg}$ alfentanil on induction and $0.9 \%$ saline 1 minute after incision

Group B (assumed 20 participants): IV $40 \mathrm{mcg} / \mathrm{kg}$ alfentanil 1 minute after incision and $0.9 \%$ saline on induction

$\begin{array}{ll}\text { Outcomes } & \text { Morphine consumption (mg in recovery and } 4,8,12,16,20 \text {, and } 24 \text { hours postoperatively) } \\ \text { 2. Postoperative pain (0-to-100-millimetre VAS at } 24 \text { hours) }\end{array}$

Notes Funding: not reported

Declarations of interest: not reported

Authors contacted: we contacted authors for further information and received a response, however no further data were available.

Other: pain reported as median so included in narrative synthesis.

\section{Risk of bias}

\begin{tabular}{|c|c|c|}
\hline Bias & Authors' judgement & Support for judgement \\
\hline $\begin{array}{l}\text { Random sequence genera- } \\
\text { tion (selection bias) }\end{array}$ & Unclear risk & No details. Quote: 'participants were randomly allocated to one of two groups' \\
\hline $\begin{array}{l}\text { Allocation concealment } \\
\text { (selection bias) }\end{array}$ & Unclear risk & No mention \\
\hline $\begin{array}{l}\text { Blinding of participants } \\
\text { and personnel (perfor- } \\
\text { mance bias) } \\
\text { All outcomes }\end{array}$ & Low risk & $\begin{array}{l}\text { Double-dummy placebo used and methods state: "the anaesthetist, partici- } \\
\text { pant and the assessor were blind to the participant's group allocation" }\end{array}$ \\
\hline
\end{tabular}


Wilson 1994 (Continued)

Blinding of outcome as- Low risk Blinded as above. Quote: "the anaesthetist, participant and the assessor were sessment (detection bias) blind to the participant's group allocation" and "Recovery staff were blind to All outcomes the patient's group allocation"

\begin{tabular}{lll}
$\begin{array}{l}\text { Incomplete outcome data } \\
\text { (attrition bias) } \\
\text { All outcomes }\end{array}$ & Unclear risk & No mention \\
\hline $\begin{array}{l}\text { Selective reporting (re- } \\
\text { porting bias) }\end{array}$ & Unclear risk & No protocol or trial registration \\
\hline Other bias & Low risk & $\begin{array}{l}\text { Similar baseline characteristics. Quote: "there were no differences between } \\
\text { the groups in the mean age, weight, time from induction to incision and length } \\
\text { of operation" }\end{array}$
\end{tabular}

Wordliczek 2002

Study design: parallel-group randomized controlled trial
Sample size: 90
Country: Poland
Setting: secondary care hospital
Dates conducted: not reported
Postoperative opioid used and delivery: PCA tramadol
Pain score collection: not reported
Concurrent postoperative analgesics: none reported

\section{Participants}

\section{Inclusion criteria}

1. Scheduled for elective colon surgery (hemicolectomy)

\section{Exclusion criteria}

1. Severe hepatic, renal, cardiovascular, or psychological disorders

2. Unable to rate the VAS score

3. Unable to use the PCA pump

Interventions

Group I (30 participants): $100 \mathrm{mg}$ IV tramadol 15 minutes before induction

Group II (30 participants): $100 \mathrm{mg}$ IV tramadol after peritoneal closure

Group Control (30 participants): $100 \mathrm{mg}$ IV tramadol immediately after operation

\begin{tabular}{ll}
\hline Outcomes & $\begin{array}{l}\text { 1. Tramadol consumption (mg in early postoperative period) } \\
\text { 2. Postoperative pain (VAS on initial activation of PCA device, } 2,4,8,12 \text { hours postoperatively, and the } \\
\text { morning of the day following surgery) }\end{array}$ \\
3. Time to analgesia (minutes) \\
$\begin{array}{ll}\text { 4. Drowsiness/sedation (yes/no postoperatively) } \\
\text { 5. Nausea and vomiting (yes/no postoperatively) }\end{array}$ \\
\hline Fotes \\
Polanding: supported by grant WL/241/KL/L from Collegium Medicum Jagiellonian University, Kraków,
\end{tabular}


Wordliczek 2002 (Continued)

Declarations of interest: none reported

Authors contacted: we contacted authors for further information but received no response.

Other: only results from Group I (preventive) and control group compared. Sedation not analysed as dichotomous outcome. Time to analgesic request standard deviations estimated as unclear from graph.

\section{Risk of bias}

\begin{tabular}{lll}
\hline Bias & Authors' judgement & Support for judgement \\
\hline $\begin{array}{l}\text { Random sequence genera- } \\
\text { tion (selection bias) }\end{array}$ & Unclear risk & No details. Quote: "participants were randomly allocated into three groups" \\
\hline $\begin{array}{l}\text { Allocation concealment } \\
\text { (selection bias) }\end{array}$ & Unclear risk & No mention \\
\hline $\begin{array}{l}\text { Blinding of participants } \\
\text { and personnel (perfor- } \\
\text { mance bias) }\end{array}$ & High risk & $\begin{array}{l}\text { Interventions given at different times. Quote: "30 patients (I group) were ad- } \\
\text { ministered } 100 \text { mg of tramadol iv } 15 \text { minutes before induction of general anes- } \\
\text { thesia. The patients of Il group were administered } 100 \text { mg of tramadol iv im- } \\
\text { mediately after peritoneal closure. In order to determine the influence of the } \\
\text { inhibition of phase II (inflammatory response in the postoperative period) on } \\
\text { nociceptive stimulation, patients in control group (30 patients) received } 100 \\
\text { mg of tramadol iv immediately after operation" }\end{array}$ \\
\hline
\end{tabular}

Blinding of outcome as- High risk Likely unblinded based on above information
sessment (detection bias) All outcomes

\begin{tabular}{lll}
\hline $\begin{array}{l}\text { Incomplete outcome data } \\
\text { (attrition bias) } \\
\text { All outcomes }\end{array}$ & Unclear risk & No mention of any dropouts \\
\hline $\begin{array}{l}\text { Selective reporting (re- } \\
\text { porting bias) }\end{array}$ & Unclear risk & No protocol or trial registration \\
\hline Other bias & Low risk & Similar baseline characteristics and no reported conflicts of interest \\
\hline
\end{tabular}

\section{Zand 2012}

\section{Methods}

Study design: parallel-group randomized controlled trial

Sample size: 60

Country: Iran

Setting: secondary care hospital

Dates conducted: not reported

Postoperative opioid used and delivery: $1 \mathrm{mg}$ morphine boluses in recovery then PCA morphine

Pain score collection: blinded nurse

Concurrent postoperative analgesics: no other analgesics

\section{Participants}

\section{Inclusion criteria}

1. Aged 40 to 70 years old 
Zand 2012 (Continued)

2. ASA 1 or 2

3. Scheduled to undergo elective open unilateral nephrolithotomy

\section{Exclusion criteria}

1. History of acute or chronic kidney injury

2. Drug abuse

3. Received any analgesic medications during the previous 48 hours

4. Unable to use a PCA device

Interventions

Group E (30 participants): intravenous morphine $0.1 \mathrm{mg} / \mathrm{kg}$ immediately after intubation

Group L (30 participants): intravenous morphine $0.1 \mathrm{mg} / \mathrm{kg} 20$ to 30 minutes before the end of surgery

\begin{tabular}{ll}
\hline Outcomes & $\begin{array}{l}\text { 1. Postoperative pain (in recovery then } 4 \text { hourly until } 24 \text { hours on a 0-to-10 NRS) } \\
\text { 2. Morphine consumption (mg at } 24 \text { hours) }\end{array}$ \\
\hline Fotes & Funding: not reported \\
Declarations of interest: not reported \\
Authors contacted: we contacted authors for further information but received no response. \\
Other: graph for pain did not include median for 24 hours. Standard deviations estimated for 24 -hour \\
morphine consumption and are calculated by adding PACU morphine to morphine consumption on the \\
ward.
\end{tabular}

\section{Risk of bias}

\begin{tabular}{|c|c|c|}
\hline Bias & Authors' judgement & Support for judgement \\
\hline $\begin{array}{l}\text { Random sequence genera- } \\
\text { tion (selection bias) }\end{array}$ & Low risk & $\begin{array}{l}\text { Computer-generated random numbers. Quote: "randomization of the subjects } \\
\text { using a computer generated random numbers" }\end{array}$ \\
\hline $\begin{array}{l}\text { Allocation concealment } \\
\text { (selection bias) }\end{array}$ & Unclear risk & No mention \\
\hline $\begin{array}{l}\text { Blinding of participants } \\
\text { and personnel (perfor- } \\
\text { mance bias) } \\
\text { All outcomes }\end{array}$ & High risk & $\begin{array}{l}\text { No double-dummy placebo used. Quote: "both groups received } 0.1 \mathrm{mg} / \mathrm{kg} \\
\text { morphine intravenously diluted in normal saline to a concentration of } 1 \mathrm{mg} / \\
\mathrm{ml} \text { at } 2 \text { different times; in the first group (group E) immediately after intubation } \\
\text { and in the second group (group L) 20-30 min before the anticipated end of op- } \\
\text { eration" }\end{array}$ \\
\hline $\begin{array}{l}\text { Blinding of outcome as- } \\
\text { sessment (detection bias) } \\
\text { All outcomes }\end{array}$ & Low risk & $\begin{array}{l}\text { Blinded outcome assessment. Quote: "the pain score was recorded according } \\
\text { to numerical rating scale by a nurse, who was blinded to the patient study as- } \\
\text { signments" }\end{array}$ \\
\hline $\begin{array}{l}\text { Incomplete outcome data } \\
\text { (attrition bias) } \\
\text { All outcomes }\end{array}$ & Low risk & Quote: "all 60 participants completed the study" \\
\hline $\begin{array}{l}\text { Selective reporting (re- } \\
\text { porting bias) }\end{array}$ & Low risk & ACTRN: 12609000570280. Outcomes pre-stated and fully reported. \\
\hline Other bias & Low risk & $\begin{array}{l}\text { Similar baseline characteristics. Quote: "both groups were similar with respect } \\
\text { to age, weight, gender, duration of anesthesia, and surgery and hemodynamic } \\
\text { variables during the operation" }\end{array}$ \\
\hline
\end{tabular}


IV: intravenous

N/A: not applicable

NRS: numeric rating scale

NSAIDs: non-steroidal anti-inflammatory drugs

PACU: postanaesthesia care unit

PCA: patient-controlled analgesia

VAS: visual analogue scale

VRS: verbal rating scale

Characteristics of excluded studies [ordered by study ID]

Study Reason for exclusion

Part of the postincision dose was given before incision.

Characteristics of studies awaiting assessment [ordered by study ID]

Espi 2004

Methods Study design: parallel-group randomized controlled trial

Sample size: 20

Country: not reported

Setting: not reported

Dates conducted: not reported

Participants Inclusion criteria

1. ASA 1 or 2 women undergoing total abdominal hysterectomy

Interventions Group A: morphine $0.2 \mathrm{mg} / \mathrm{kg}$ at induction

Group B: morphine $0.2 \mathrm{mg} / \mathrm{kg}$ on removal of the uterus

1. Time to eye opening
2. Time to extubation
3. Time to first words
4. Postoperative pain (0-to-100-millimetre VAS)
5. Morphine consumption (unclear time points)
6. Sedation (Ramsey sedation scale)
7. Time to first analgesic request (minutes)
8. Adverse events

Notes

Funding: not reported

Declarations of interest: not reported

Authors contacted: we contacted authors for further information but received no response.

Other: conference abstract. Insufficient information from abstract to include study in review. 
Nagasaka 1996

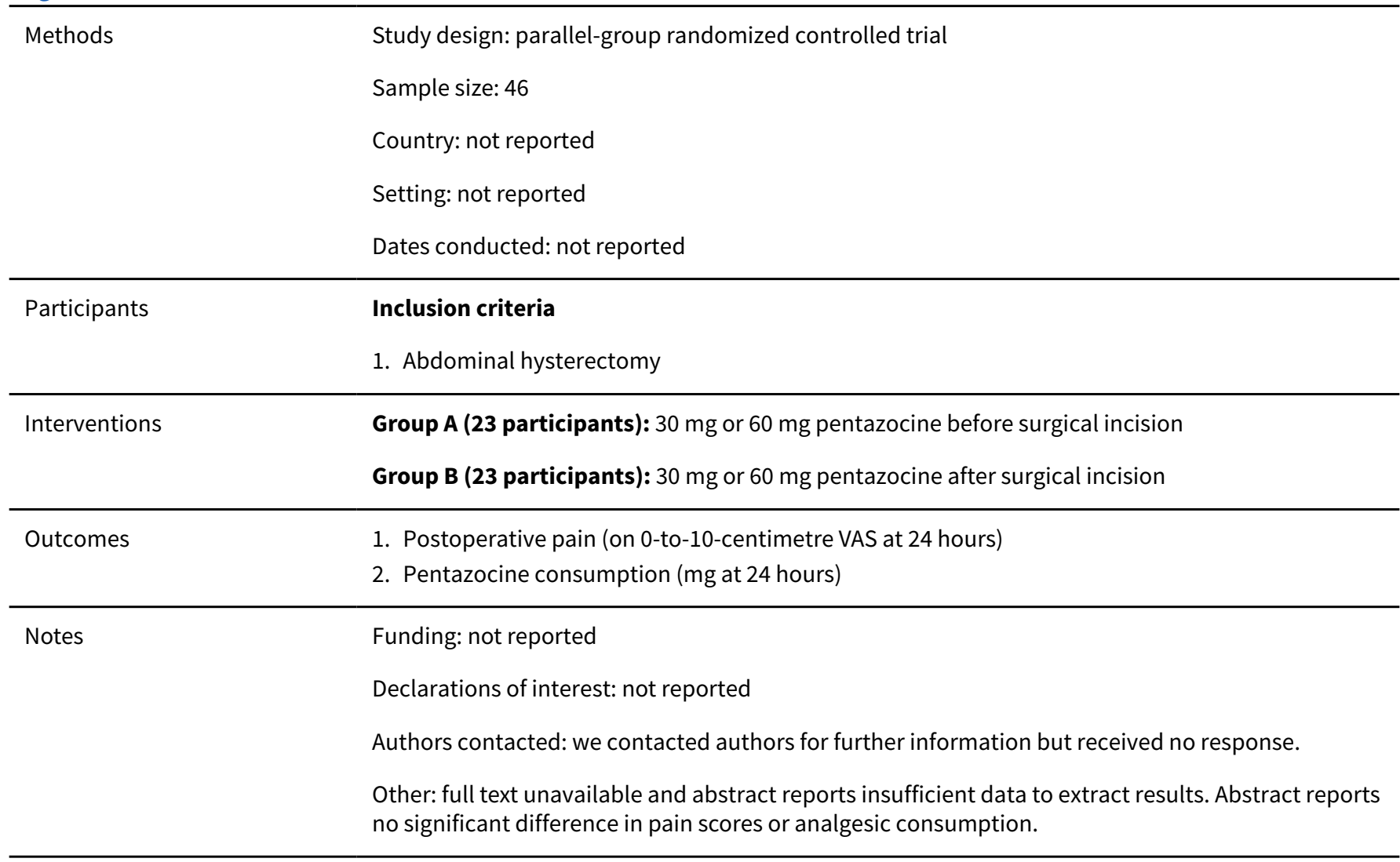

ASA: American Society of Anesthesiologists

VAS: visual analogue scale

\section{DATA AND ANALYSES}

\section{Comparison 1. Preventive versus postincision opioids for postoperative pain}

\begin{tabular}{lllll}
\hline Outcome or subgroup title & No. of studies & $\begin{array}{l}\text { No. of partici- } \\
\text { pants }\end{array}$ & Statistical method & Effect size \\
\hline $\begin{array}{l}1 \text { Early acute postoperative pain } \\
\text { (within 6 hours postoperatively) }\end{array}$ & 10 & 706 & $\begin{array}{l}\text { Mean Difference (IV, Random, } \\
95 \% \mathrm{Cl})\end{array}$ & $0.11[-0.32,0.53]$ \\
\hline 2 Nausea and vomiting (long term) & 3 & 121 & $\begin{array}{l}\text { Risk Ratio (M-H, Random, 95\% } \\
\text { Cl) }\end{array}$ & $0.90[0.58,1.39]$ \\
\hline $\begin{array}{l}3 \text { Late acute postoperative pain (24 } \\
\text { to 48 hours postoperatively) }\end{array}$ & 9 & 668 & $\begin{array}{l}\text { Mean Difference (IV, Random, } \\
95 \% \text { Cl) }\end{array}$ & $-0.06[-0.13,0.01]$ \\
\hline $\begin{array}{l}4 \text { 24-hour morphine consumption } \\
\text { (mg) }\end{array}$ & 11 & 526 & $\begin{array}{l}\text { Mean Difference (IV, Random, } \\
95 \% \text { Cl) }\end{array}$ & $-4.91[-9.39,-0.44]$ \\
\hline $\begin{array}{l}5 \text { Time to first analgesic request } \\
\text { (minutes) }\end{array}$ & 6 & 298 & $\begin{array}{l}\text { Mean Difference (IV, Random, } \\
95 \% \text { Cl) }\end{array}$ & $-8.15[-19.45,3.14]$ \\
\hline
\end{tabular}




\begin{tabular}{lllll}
\hline Outcome or subgroup title & No. of studies & $\begin{array}{l}\text { No. of partici- } \\
\text { pants }\end{array}$ & Statistical method & Effect size \\
\hline 6 Pruritus (long term) & 3 & 383 & $\begin{array}{l}\text { Risk Ratio (M-H, Random, 95\% } \\
\text { Cl) }\end{array}$ & $0.75[0.40,1.43]$ \\
\hline 7 Bradycardia (incidence) & 2 & 112 & $\begin{array}{l}\text { Risk Ratio (M-H, Random, 95\% } \\
\text { Cl) }\end{array}$ & 0.33 [0.01, 7.88] \\
\hline $\begin{array}{l}8 \text { Bradycardia (mean dose of } \\
\text { chronotrope in mcg) }\end{array}$ & 2 & 112 & Mean Difference (IV, Random, & $-9.68[-28.65,9.29]$ \\
\hline 9 Hypotension (incidence) & 2 & 88 & $95 \%$ Cl) & $\begin{array}{l}\text { Risk Ratio (M-H, Random, 95\% } \\
\text { Cl) }\end{array}$ \\
\hline
\end{tabular}

Analysis 1.1. Comparison 1 Preventive versus postincision opioids for postoperative pain, Outcome 1 Early acute postoperative pain (within 6 hours postoperatively).

\begin{tabular}{|c|c|c|c|c|c|c|c|}
\hline \multirow{3}{*}{$\begin{array}{l}\text { Study or subgroup } \\
\text { Fassoulaki } 1995\end{array}$} & \multicolumn{2}{|c|}{ Preventive } & \multicolumn{2}{|c|}{ Post-incision } & \multirow{2}{*}{$\begin{array}{l}\text { Mean Difference } \\
\text { Random, } 95 \% \mathrm{Cl}\end{array}$} & \multirow[t]{2}{*}{ Weight } & \multirow{2}{*}{$\begin{array}{l}\text { Mean Difference } \\
\text { Random, } 95 \% \mathrm{Cl}\end{array}$} \\
\hline & $\mathbf{N}$ & Mean(SD) & $\mathbf{N}$ & $\operatorname{Mean}(S D)$ & & & \\
\hline & 25 & $6.2(2)$ & 38 & $4.2(2.4)$ & $\longrightarrow$ & $9.08 \%$ & $1.99[0.92,3.06]$ \\
\hline Gerlach 2003 & 32 & $6.5(4.4)$ & 15 & $6.1(2)$ & + & $4.37 \%$ & $0.42[-1.4,2.24]$ \\
\hline Griffin 1997 & 18 & $4.4(1.8)$ & 16 & $3.8(1.8)$ & $-"$ & $7.83 \%$ & $0.6[-0.61,1.81]$ \\
\hline Kiliçkan 2001 & 20 & $3.9(1.8)$ & 20 & $4.9(1.8)$ & - & $8.68 \%$ & $-1[-2.12,0.12]$ \\
\hline Koprulu 2015 & 25 & $3.4(0.9)$ & 25 & $3.2(1.1)$ & + & $15.72 \%$ & $0.2[-0.36,0.76]$ \\
\hline Richmond 1993 & 23 & $3.6(0.9)$ & 21 & $3.8(1.8)$ & $\longrightarrow$ & $11.53 \%$ & $-0.18[-1.03,0.67]$ \\
\hline Sarantopoulos 1996 & 18 & $6.7(2.5)$ & 21 & $5.8(2.5)$ & $\longrightarrow$ & $5.45 \%$ & $0.9[-0.67,2.47]$ \\
\hline Shen 2008 & 148 & $1(0.6)$ & 151 & $1.2(0.4)$ & * & $21.19 \%$ & $-0.17[-0.29,-0.05]$ \\
\hline Wordliczek 2002 & 30 & $5.5(2.5)$ & 30 & $5.8(2.5)$ & $\longrightarrow$ & $7.41 \%$ & $-0.3[-1.57,0.97]$ \\
\hline Total $\star \star \star ~$ & 354 & & 352 & & & $100 \%$ & $0.11[-0.32,0.53]$ \\
\hline Test for overall effect: & & & & & & & \\
\hline
\end{tabular}

Analysis 1.2. Comparison 1 Preventive versus postincision opioids for postoperative pain, Outcome 2 Nausea and vomiting (long term).

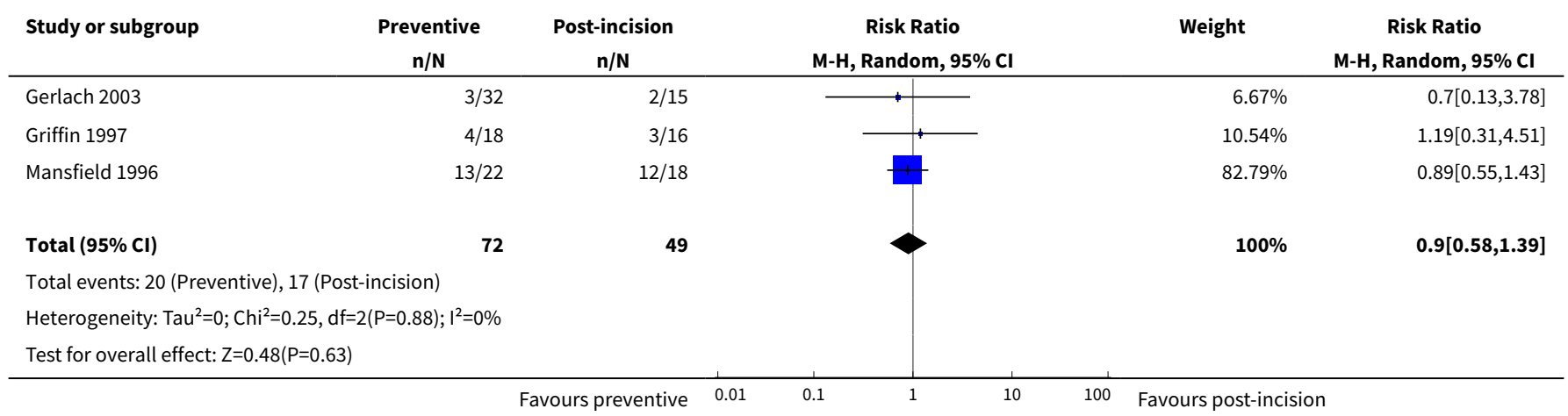


Analysis 1.3. Comparison 1 Preventive versus postincision opioids for postoperative pain, Outcome 3 Late acute postoperative pain (24 to 48 hours postoperatively).

\begin{tabular}{|c|c|c|c|c|c|c|c|}
\hline \multirow[t]{2}{*}{ Study or subgroup } & \multicolumn{2}{|c|}{ Preventive } & \multicolumn{2}{|c|}{ Post-incision } & \multirow{2}{*}{$\begin{array}{l}\text { Mean Difference } \\
\text { Random, } 95 \% \mathrm{Cl}\end{array}$} & \multirow[t]{2}{*}{ Weight } & \multirow{2}{*}{$\begin{array}{l}\text { Mean Difference } \\
\text { Random, } 95 \% \mathrm{CI}\end{array}$} \\
\hline & $\mathbf{N}$ & Mean(SD) & $\mathbf{N}$ & Mean(SD) & & & \\
\hline Fassoulaki 1995 & 34 & $3.9(2)$ & 51 & $3.8(2)$ & 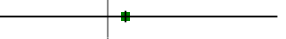 & $0.65 \%$ & $0.1[-0.75,0.95]$ \\
\hline Gerlach 2003 & 32 & $2.3(2.4)$ & 15 & $3.4(3.8)$ & & $0.11 \%$ & $-1.12[-3.2,0.96]$ \\
\hline Griffin 1997 & 18 & $3(2.2)$ & 16 & $3(2.2)$ & & $0.21 \%$ & $0[-1.48,1.48]$ \\
\hline Kiliçkan 2001 & 20 & $0.9(0.6)$ & 20 & $0.9(0.6)$ & & $3.41 \%$ & $0[-0.37,0.37]$ \\
\hline Koprulu 2015 & 25 & $1.8(1.1)$ & 25 & $1.7(0.9)$ & & $1.52 \%$ & $0.1[-0.46,0.66]$ \\
\hline Richmond 1993 & 23 & $3.1(1.9)$ & 21 & $2.6(2)$ & & $0.35 \%$ & $0.58[-0.58,1.74]$ \\
\hline Sarantopoulos 1996 & 18 & $3.1(1.9)$ & 21 & $2.5(2)$ & & $0.31 \%$ & $0.6[-0.63,1.83]$ \\
\hline Shen 2008 & 148 & $0.3(0.2)$ & 151 & $0.4(0.4)$ & & $92.35 \%$ & $-0.07[-0.14,0]$ \\
\hline 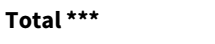 & 333 & & 335 & & $\gamma$ & $100 \%$ & $-0.06[-0.13,0.01]$ \\
\hline \multicolumn{8}{|c|}{ Heterogeneity: $\operatorname{Tau}^{2}=0 ; \mathrm{Chi}^{2}=3.96, \mathrm{df}=8(\mathrm{P}=0.86) ; \mathrm{I}^{2}=0 \%$} \\
\hline
\end{tabular}

Analysis 1.4. Comparison 1 Preventive versus postincision opioids for postoperative pain, Outcome 4 24-hour morphine consumption (mg).

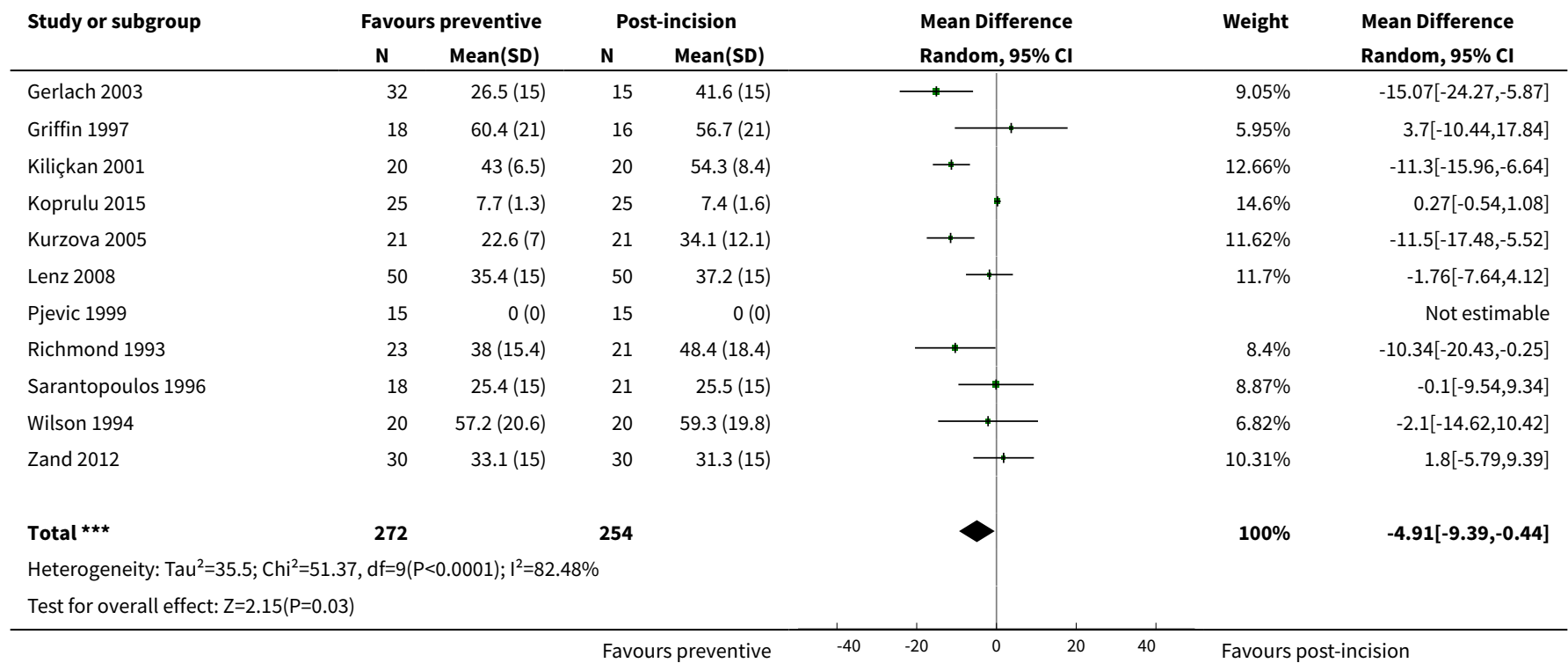


Analysis 1.5. Comparison 1 Preventive versus postincision opioids for postoperative pain, Outcome 5 Time to first analgesic request (minutes).

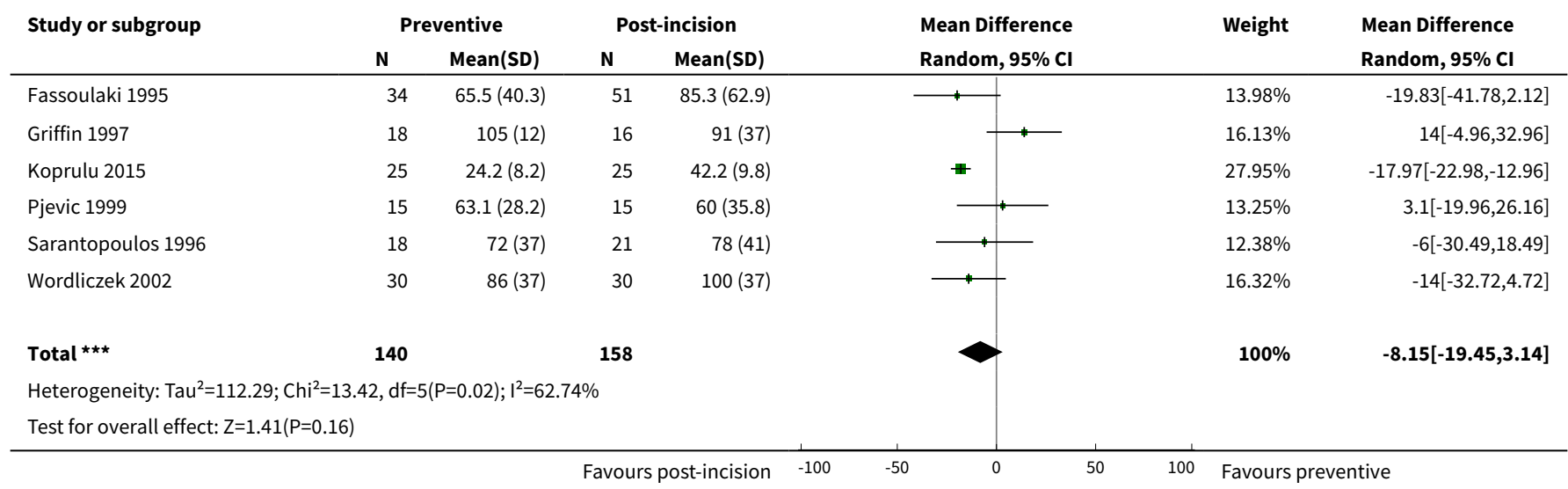

Analysis 1.6. Comparison 1 Preventive versus postincision opioids for postoperative pain, Outcome 6 Pruritus (long term).

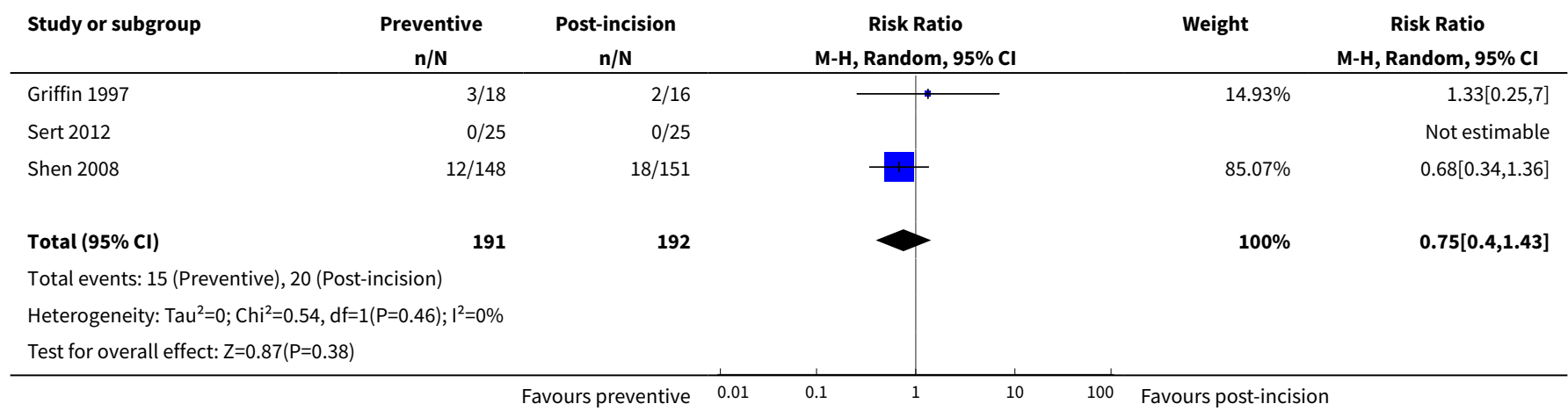

Analysis 1.7. Comparison 1 Preventive versus postincision opioids for postoperative pain, Outcome 7 Bradycardia (incidence).

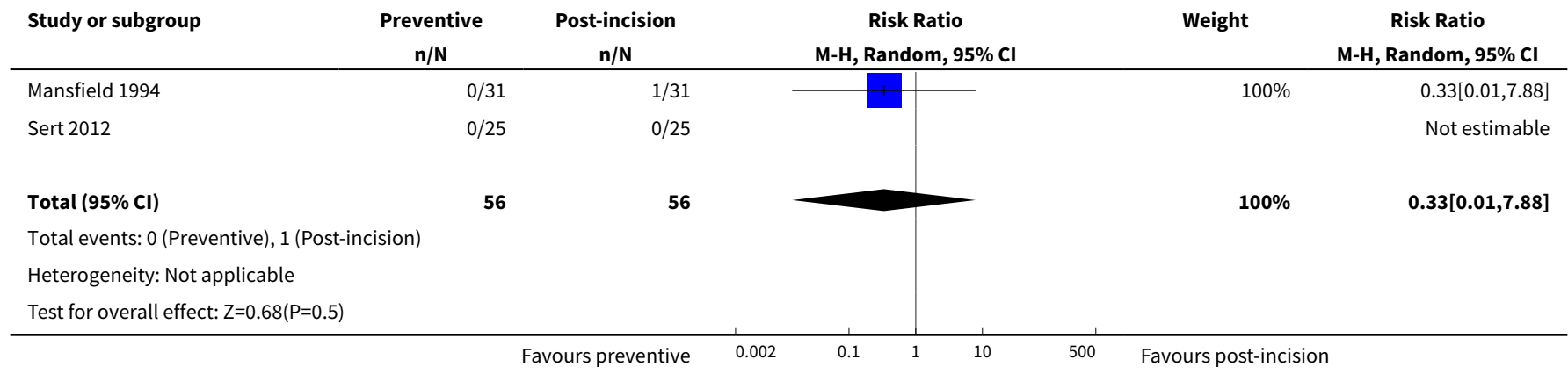


Analysis 1.8. Comparison 1 Preventive versus postincision opioids for postoperative pain, Outcome 8 Bradycardia (mean dose of chronotrope in $\mathbf{m c g}$ ).

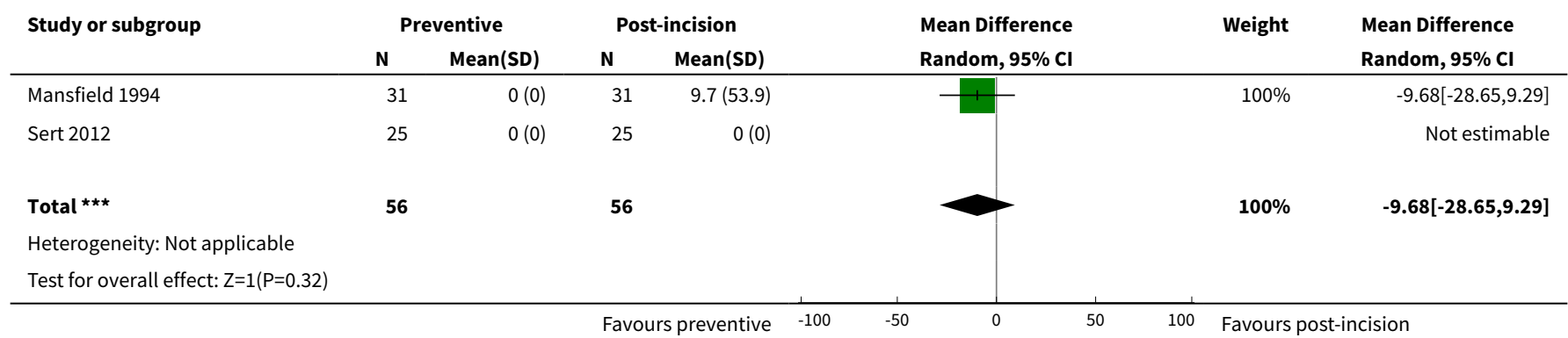

Analysis 1.9. Comparison 1 Preventive versus postincision opioids for postoperative pain, Outcome 9 Hypotension (incidence).

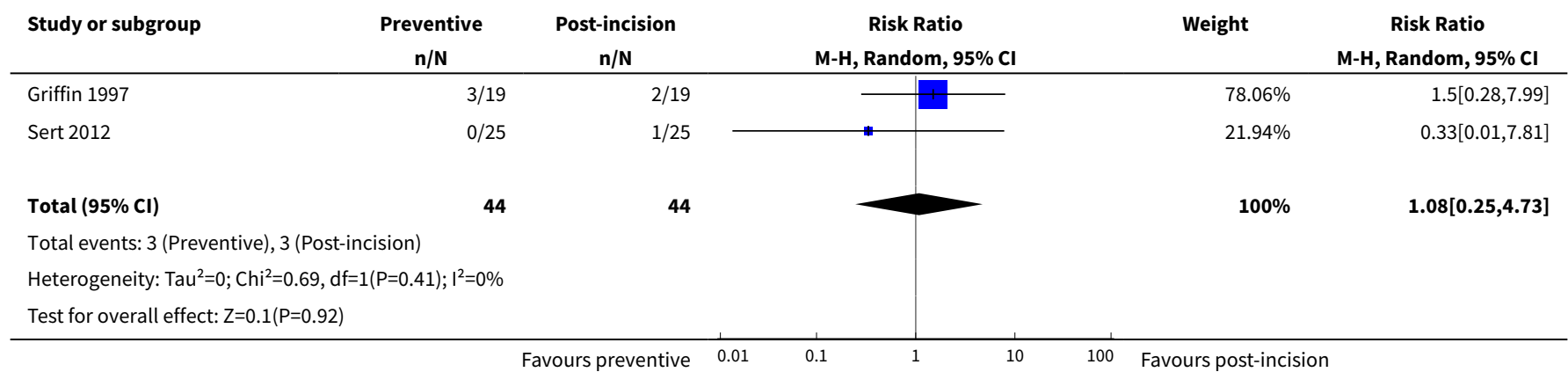

\section{ADDITIONAL TABLES}

Table 1. Morphine equivalent conversion factors

\begin{tabular}{ll}
\hline Opioid & Conversion factor \\
\hline Oral morphine & $3: 1$ \\
\hline Pethidine/meperidine & $10: 1$ \\
\hline Ketobemidone & $1: 1$ \\
\hline Tramadol & $20: 1$ \\
\hline Fentanyl & $1: 100$ \\
\hline Remifentanil & $1: 100$ \\
\hline Piritramide & $1: 0.75$ \\
\hline Intravenous hydromorphone & $1: 3$ \\
\hline Oral hydrocodone & $2: 1$ \\
\hline
\end{tabular}


Table 1. Morphine equivalent conversion factors (Continued)

\begin{tabular}{ll} 
Intravenous oxycodone & $1: 1.5$ \\
\hline Oral oxycodone & $2.5: 1$ \\
\hline Papaveretum & $1.5: 1$ \\
\hline Meptazinol & $5: 1$ \\
\hline Nalbuphine & $1: 1$ \\
\hline Propoxyphene & $10: 1$ \\
\hline Sublingual buprenorphine & $1: 25$ \\
\hline Trimeperidine & $2: 1$
\end{tabular}

Table 2. Pre-emptive versus postincision opioids: other outcomes

\begin{tabular}{llll}
\hline Study & Outcome & Effect estimate & Participants \\
\hline Pozos-Guillen 2007 & Early acute postoperative pain & MD - $1.20,95 \% \mathrm{Cl}-1.75$ to -0.65 & 40 \\
\hline Pozos-Guillen 2007 & Late acute postoperative pain & MD -2.10, 95\% Cl -2.57 to - 1.63 & 40 \\
\hline
\end{tabular}

$\mathrm{Cl}$ : confidence interval

MD: mean difference

Table 3. Preventive versus postincision opioids: other outcomes

\begin{tabular}{|c|c|c|c|}
\hline Study & Outcome & Effect estimate & Participants \\
\hline Sert 2012 & $\begin{array}{l}\text { Hypotension (mean dose of inotrope/va- } \\
\text { sopressor in } \mathrm{mg} \text { ) }\end{array}$ & $\mathrm{MD}-0.20,95 \% \mathrm{Cl}-0.59$ to 0.19 & 50 \\
\hline Kiliçkan 2001 & Sedation (short term) & MD $0.60,95 \% \mathrm{Cl}-2.22$ to 3.42 & 40 \\
\hline Kiliçkan 2001 & Sedation (long term) & MD $1.40,95 \% \mathrm{Cl}-3.19$ to 5.99 & 40 \\
\hline Shen 2008 & Patient satisfaction (long term) & MD $-0.22,95 \% \mathrm{Cl}-0.53$ to 0.09 & 299 \\
\hline
\end{tabular}

$\mathrm{Cl}$ : confidence interval

MD: mean difference

\section{A P P E N D I C E S}

\section{Appendix 1. MEDLINE search strategy}

1. preemptive analgesia [ti.ab]

2. postoperative pain [ti.ab]

3. preventive analgesia [ti.ab]

Pre-emptive and preventive opioids for postoperative pain in adults undergoing all types of surgery (Review) 

4. preincision* ${ }^{*}$ ti.ab]
5. exp PAIN, POSTOPERATIVE/
6. 1 OR 2 OR 3 OR 4 OR 5
7. opioid ${ }^{\star}$ or opiate $^{\star}[$ ti.ab]
8. morphine OR diamorphine OR fentanyl OR remifentanil OR alfentanil OR meperidine OR pethidine OR tramadol OR ketobemidone [ti.ab]
9. 7 OR 8

10. 6 AND 9

11. randomi?ed controlled trial [pt]

12. controlled clinical trial [pt]

13. randomi?ed [ti.ab]

14. placebo [ti.ab]

15. drug therapy [sh]

17. randomly [ti.ab]

18. trial [ti.ab]

19. groups [ti.ab]

20. 11 OR 12 OR 13 OR 14 OR 15 OR 16 OR 17 OR 18

21. 10 AND 20

22. 21 [Limit to: (Age group Young Adult or Adult or Middle aged or Aged or Aged, 80 and over) and Humans]

\section{Appendix 2. Embase and CINAHL search strategy}

1. preemptive $[\mathrm{ti}, \mathrm{ab}]$

2. preventive [ti,ab]

3. 1 OR 2

4. exp 'POSTOPERATIVE PAIN'/

5. surgery $[\mathrm{ti}, \mathrm{ab}]$

6. pain $[\mathrm{ti}, \mathrm{ab}]$

7. 4 OR 5 OR 6

8. 3 AND 7

9. opioid ${ }^{\star}$ OR opiate* $[\mathrm{ti}, \mathrm{ab}]$

10. morphine OR diamorphine OR fentanyl OR remifentanil OR alfentanil OR meperidine OR pethidine OR tramadol OR ketobemidone [ti,ab]

11. 9 OR 10

12. 8 AND 11

Pre-emptive and preventive opioids for postoperative pain in adults undergoing all types of surgery (Review) 


\section{Appendix 3. AMED search strategy}

1. preemptive [ti,ab]

2. preventive [ti,ab]

3. 1 OR 2

4. surgery [ti,ab]

5. pain $[t i, a b]$

6. 4 OR 5

7. 3 AND 6

8. opioid ${ }^{\star}$ OR opiate ${ }^{\star}[\mathrm{ti}, \mathrm{ab}]$

9. morphine OR diamorphine OR fentanyl OR remifentanil OR alfentanil OR meperidine OR pethidine OR tramadol OR ketobemidone [ti,ab]

10.8 OR 9

11. 7 AND 10

\section{Appendix 4. 'Risk of bias' tool}

\section{Random sequence generation}

Selection bias (biased allocation to interventions) due to inadequate generation of a randomized sequence.

\section{Criteria for a judgement of 'low risk' of bias}

The investigators describe a random component in the sequence generation process such as:

1. referring to a random number table;

2. using a computer random number generator;

3. coin tossing;

4. shuffling cards or envelopes;

5. throwing dice;

6. drawing of lots;

7. minimization.*

*Minimization may be implemented without a random element and is considered to be the equivalent of random.

\section{Criteria for a judgement of 'high risk' of bias}

The investigators describe a non-random component in the sequence generation process. Usually, the description would involve some systematic, non-random approach, for example:

1. sequence generated by odd or even date of birth;

2. sequence generated by some rule based on date (or day) of admission;

3. sequence generated by some rule based on hospital or clinic record number.

Other non-random approaches occur much less frequently than the systematic approaches mentioned above and tend to be obvious. They usually involve judgement or some method of non-random categorization of participants, for example:

1. allocation by judgement of the clinician;

2. allocation by preference of the participant;

3. allocation based on the results of a laboratory test or a series of tests;

4. allocation by availability of the intervention.

\section{Criteria for a judgement of 'unclear risk' of bias}

Insufficient information about the sequence generation process to permit judgement of 'low risk' or 'high risk'. 


\section{Allocation concealment}

Selection bias (biased allocation to interventions) due to inadequate concealment of allocations prior to assignment.

\section{Criteria for a judgement of 'low risk' of bias}

Participants and investigators enrolling participants could not foresee assignment because one of the following, or an equivalent method, was used to conceal allocation:

1. central allocation (including telephone, web-based, and pharmacy-controlled randomization);

2. sequentially numbered drug containers of identical appearance;

3. sequentially numbered, opaque, sealed envelopes.

\section{Criteria for a judgement of 'high risk' of bias}

Participants or investigators enrolling participants could possibly foresee assignments and thus introduce selection bias, such as allocation based on:

1. using an open random allocation schedule (e.g. a list of random numbers);

2. assignment envelopes used without appropriate safeguards (e.g. if envelopes were unsealed or nonopaque or not sequentially numbered);

3. alternation or rotation;

4. date of birth;

5. case record number;

6. any other explicitly unconcealed procedure.

\section{Criteria for a judgement of 'unclear risk' of bias}

Insufficient information to permit judgement of 'low risk' or 'high risk'. This is usually the case if the method of concealment is not described or not described in sufficient detail to allow a definitive judgement, for example if the use of assignment envelopes is described, but it remains unclear whether envelopes were sequentially numbered, opaque, and sealed.

\section{Blinding of participants and personnel}

Performance bias due to knowledge of the allocated interventions by participants and personnel during the study.

\section{Criteria for a judgement of 'low risk' of bias}

Any one of the following:

1. no blinding or incomplete blinding, but the review authors judge that the outcome is not likely to be influenced by lack of blinding;

2. blinding of participants and key study personnel ensured, and unlikely that the blinding could have been broken.

\section{Criteria for a judgement of 'high risk' of bias}

Any one of the following:

1. no blinding or incomplete blinding, and the outcome is likely to be influenced by lack of blinding;

2. blinding of key study participants and personnel attempted, but likely that the blinding could have been broken, and the outcome is likely to be influenced by lack of blinding.

\section{Criteria for a judgement of 'unclear risk' of bias}

Any one of the following:

1. insufficient information to permit judgement of 'low risk' or 'high risk';

2. the study did not address this outcome.

\section{Blinding of outcome assessment}

Detection bias due to knowledge of the allocated interventions by outcome assessors.

\section{Criteria for a judgement of 'low risk' of bias}

Any one of the following:

1. no blinding of outcome assessment, but the review authors judge that the outcome measurement is not likely to be influenced by lack of blinding;

Pre-emptive and preventive opioids for postoperative pain in adults undergoing all types of surgery (Review) 
2. blinding of outcome assessment ensured, and unlikely that the blinding could have been broken.

\section{Criteria for a judgement of 'high risk' of bias}

Any one of the following:

1. no blinding of outcome assessment, and the outcome measurement is likely to be influenced by lack of blinding;

2. blinding of outcome assessment, but likely that the blinding could have been broken, and the outcome measurement is likely to be influenced by lack of blinding.

\section{Criteria for a judgement of 'unclear risk' of bias}

Any one of the following:

1. insufficient information to permit judgement of 'low risk' or 'high risk';

2. the study did not address this outcome.

\section{Incomplete outcome data}

Attrition bias due to the amount, nature, or handling of incomplete outcome data.

\section{Criteria for a judgement of 'low risk' of bias}

Any one of the following:

1. no missing outcome data;

2. reasons for missing outcome data unlikely to be related to true outcome (for survival data, censoring unlikely to introduce bias);

3. missing outcome data balanced in numbers across intervention groups, with similar reasons for missing data across groups;

4. for dichotomous outcome data, the proportion of missing outcomes compared with observed event risk not enough to have a clinically relevant impact on the intervention effect estimate;

5. for continuous outcome data, plausible effect size (difference in means or standardized difference in means) among missing outcomes not enough to have a clinically relevant impact on observed effect size;

6. missing data have been imputed using appropriate methods.

\section{Criteria for a judgement of 'high risk' of bias}

Any one of the following:

1. reason for missing outcome data likely to be related to true outcome, with either imbalance in numbers or reasons for missing data across intervention groups;

2. for dichotomous outcome data, the proportion of missing outcomes compared with observed event risk enough to induce clinically relevant bias in intervention effect estimate;

3. for continuous outcome data, plausible effect size (difference in means or standardized difference in means) among missing outcomes enough to induce clinically relevant bias in observed effect size;

4. 'as-treated' analysis done with substantial departure of the intervention received from that assigned at randomization;

5. potentially inappropriate application of simple imputation.

\section{Criteria for a judgement of 'unclear risk' of bias}

Any one of the following:

1. insufficient reporting of attrition/exclusions to permit judgement of 'low risk' or 'high risk' (e.g. number randomized not stated, no reasons for missing data provided);

2. the study did not address this outcome.

\section{Selective reporting}

Reporting bias due to selective outcome reporting.

\section{Criteria for a judgement of 'low risk' of bias}

Any of the following:

1. the study protocol is available and all of the study's prespecified (primary and secondary) outcomes that are of interest in the review have been reported in the prespecified way; 
2. the study protocol is not available but it is clear that the published reports include all expected outcomes, including those that were prespecified (convincing text of this nature may be uncommon).

\section{Criteria for a judgement of 'high risk' of bias}

Any one of the following:

1. not all of the study's prespecified primary outcomes have been reported;

2. one or more primary outcomes is reported using measurements, analysis methods, or subsets of the data (e.g. subscales) that were not prespecified;

3. one or more reported primary outcomes were not prespecified (unless clear justification for their reporting is provided, such as an unexpected adverse effect);

4. one or more outcomes of interest in the review are reported incompletely so that they cannot be entered in a meta-analysis;

5. the study report fails to include results for a key outcome that would be expected to have been reported for such a study.

\section{Criteria for a judgement of 'unclear risk' of bias}

Insufficient information to permit judgement of 'low risk' or 'high risk'. It is likely that the majority of studies will fall into this category.

\section{Other bias}

Bias due to problems not covered elsewhere in the table.

\section{Criteria for a judgement of 'low risk' of bias}

The study appears to be free of other sources of bias.

\section{Criteria for a judgement of 'high risk' of bias}

There is at least one important risk of bias. For example, the study:

1. had a potential source of bias related to the specific study design used;

2. has been claimed to have been fraudulent; or

3. had some other problem.

\section{Criteria for a judgement of 'unclear risk' of bias}

There may be a risk of bias, but there is either:

1. insufficient information to assess whether an important risk of bias exists; or

2. insufficient rationale or evidence that an identified problem will introduce bias.

\section{Appendix 5. Data extraction form}

\section{Review title or ID}

Study ID (surname of first author and year first full report of study was published e.g. Smith 2001)

Report IDs of other reports of this study (e.g. duplicate publications, follow-up studies) 


\section{Notes:}

\section{General information}

Date form completed (dd/mm/yyyy)

\section{Name/ID of person extracting data}

\section{Report title}

(title of paper/abstract/report that data are extracted from)

\section{Report ID}

(ID for this paper/abstract/report)

\section{Reference details}

\section{Report author contact details}

\section{Publication type}

(e.g. full report, abstract, letter)

\section{Study funding sources}

(including role of funders)

\section{Possible conflicts of interest}

(for study authors)

\section{Notes:}

\section{Study eligibility}

\begin{tabular}{|c|c|c|c|c|c|}
\hline Study characteristics & $\begin{array}{l}\text { Eligibility criteria } \\
\text { (Insert eligibility criteria for each character- } \\
\text { istic as defined in the Protocol) }\end{array}$ & Yes & No & Unclear & $\begin{array}{l}\text { Location in } \\
\text { text } \\
(p g \& q / f i g / \\
\text { table) }\end{array}$ \\
\hline \multirow[t]{2}{*}{ Type of study } & Randomized controlled trial & & & & \\
\hline & Controlled clinical trial & & & & \\
\hline
\end{tabular}




\section{Participants}

\section{Types of intervention}

\section{Types of outcome mea-}

sures

INCLUDE EXCLUDE

\section{Reason for exclusion}

Notes:

DO NOT PROCEED IF STUDY EXCLUDED FROM REVIEW

\section{Population and setting}

\section{Description}

Include comparative information for each group (i.e. intervention and controls) if available
Location in text

(pg \& $\mathbf{q} /$ fig/table)

\section{Population description \\ (from which study participants are drawn)}

\section{Setting}

(including location and social context)

Inclusion criteria

\section{Exclusion criteria}

Method/s of recruitment of participants

Informed consent obtained $\quad$ Yes No Unclear

\section{Notes:}

\section{Methods}




\section{Aim of study}

Design (e.g. parallel, cross-over, cluster)

\section{Unit of allocation}

(by individuals, cluster/groups or body parts)

\section{Start date}

\section{End date}

\section{Total study duration}

\section{Ethical approval needed/obtained for study}

Notes:

\section{5. 'Risk of bias' assessment}

See Chapter 8 of the Cochrane Handbook

\begin{tabular}{|c|c|c|c|c|c|}
\hline \multirow[t]{2}{*}{ Domain } & \multicolumn{3}{|c|}{ Risk of bias } & \multirow{2}{*}{$\begin{array}{l}\text { Support for } \\
\text { judgement }\end{array}$} & \multirow{2}{*}{$\begin{array}{l}\text { Location in } \\
\text { text } \\
(p g \& q / f i g / t a- \\
\text { ble) }\end{array}$} \\
\hline & Low risk & High risk & Unclear & & \\
\hline
\end{tabular}

\section{Random sequence generation}

(selection bias)

\section{Allocation concealment}

(selection bias)

\section{Blinding of participants and personnel}

(performance bias)

Outcome group:

All]

\begin{tabular}{ll} 
(if required) & Outcome group: \\
\hline Blinding of outcome assessment & Outcome group: \\
(detection bias) & All/
\end{tabular}

\section{Incomplete outcome data}

(attrition bias) 
(Continued)

\section{Selective outcome reporting?}

(reporting bias)

\section{Other bias}

\section{Notes:}

\section{Participants}

Provide overall data and, if available, comparative data for each intervention or comparison group.

Description as stated Location in text
in report/paper

\section{Total no. randomized}

\section{Baseline imbalances}

\section{Withdrawals and exclusions}

(if not provided below by outcome)

Age

Other treatment received (additional to study intervention)

\section{Subgroups measured}

\section{Subgroups reported}

\section{Notes:}

\section{Intervention groups}

Copy and paste table for each intervention and comparison group

\section{Intervention Group 1}

\section{Group name}

\section{No. randomized to group}


(Continued)

Description (include sufficient detail for replication, e.g. content, dose, components)

\section{Duration of treatment period}

Timing (e.g. how long before surgery?)

Delivery (e.g. intravenous, oral or intra-muscular)

\section{Co-interventions}

\section{Notes:}

\section{Outcomes}

Copy and paste table for each outcome.

\section{Outcome 1}

\section{Description as stated in report/paper}

Location in text

(pg \& $/ /$ fig/table)

\section{Outcome name}

\section{Time points measured}

\section{Time points reported}

Outcome definition (with diagnostic criteria if relevant)

\section{Person measuring/reporting}

\section{Unit of measurement}

(if relevant)

\section{Is outcome/tool validated?}

Yes No Unclear

\section{Notes:}

\section{Results}

Copy and paste the appropriate table for each outcome, including additional tables for each time point and subgroup as required.

\section{Dichotomous outcome}




\section{Comparison}

\section{Outcome}

\section{Subgroup}

\section{Time point}

(specify whether from start or end of inter-

vention)

\begin{tabular}{|c|c|c|c|c|}
\hline \multirow[t]{2}{*}{ Results } & \multicolumn{2}{|c|}{ Intervention } & \multicolumn{2}{|c|}{ Comparison } \\
\hline & No. events & No. participants & No. events & $\begin{array}{l}\text { No. partici- } \\
\text { pants }\end{array}$ \\
\hline
\end{tabular}

\section{No. missing participants and reasons}

\section{No. participants moved from other} group and reasons

\section{Any other results reported}

\begin{tabular}{ll}
\hline Reanalysis required? (specify) & Yes No Unclear \\
\hline Reanalysis possible? & Yes No Unclear \\
\hline
\end{tabular}

\section{Reanalysed results}

\section{Notes:}

\section{Continuous outcome}




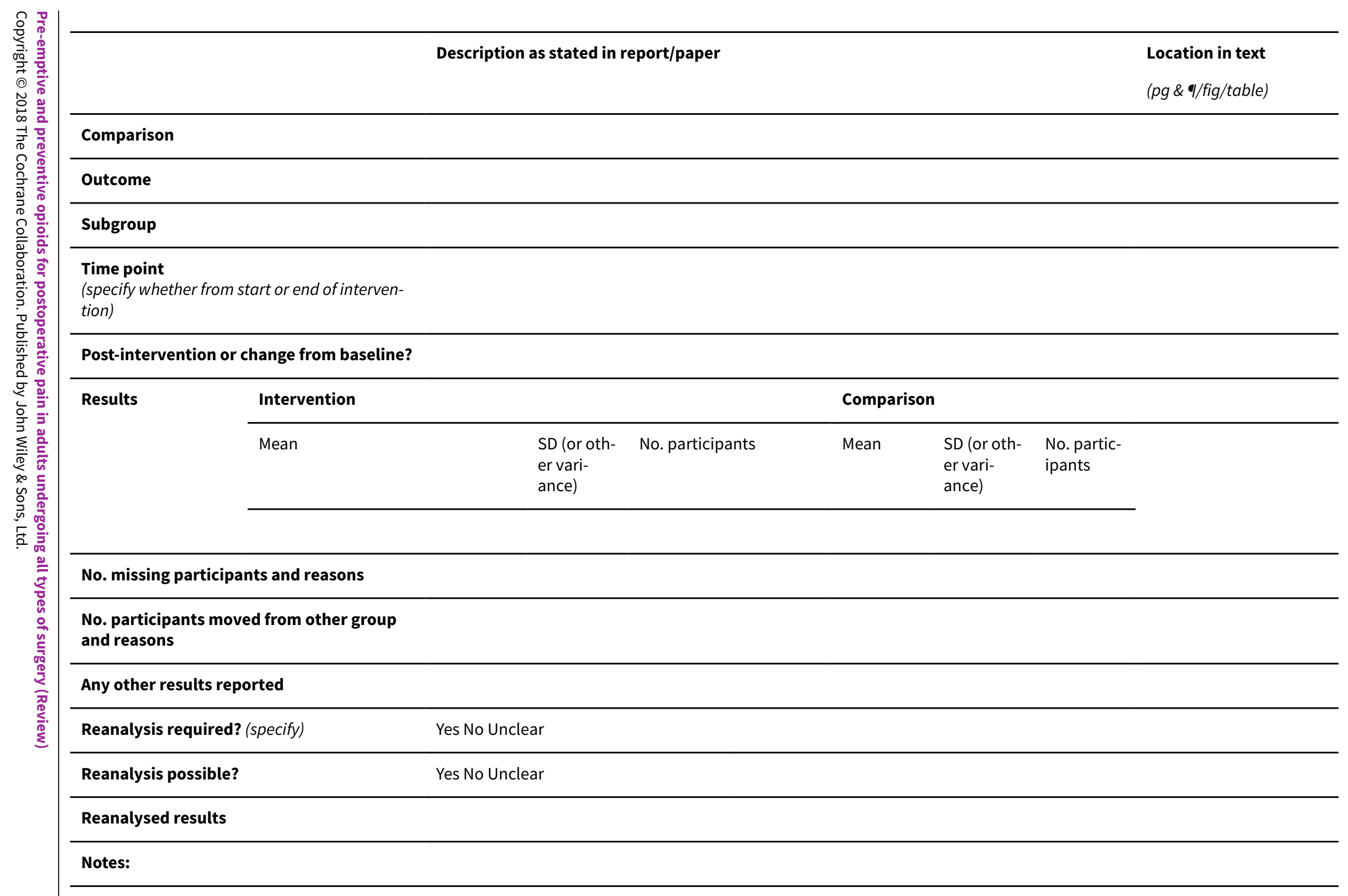




\section{Applicability}

\begin{tabular}{l} 
Have important populations been excluded from the study? (consider disadvantaged popula- \\
tions, and possible differences in the intervention effect) \\
\hline Is the intervention likely to be aimed at disadvantaged groups? (e.g. lower socioeconomic
\end{tabular}

Notes:

\section{Other information}

Description as stated in report/paper

\section{Location in text}

(pg \& ฯ/fig/table)

\section{Key conclusions of study authors}

\section{References to other relevant studies}

\section{Correspondence required for further study information (from whom, what} and when)

\section{Notes:}

\section{CONTRIBUTIONS OF AUTHORS}

Brett Doleman (BD), Jo Leonardi-Bee (JLB), Thomas Heinink (TH), Debamita Bhattacharjee (DB), Jon Lund (JL), John P Williams (JPW).

Conceiving the review: BD, JPW

Co-ordinating the review: $\mathrm{BD}, \mathrm{JPW}, \mathrm{JL}, \mathrm{JLB}, \mathrm{TH}, \mathrm{DB}$

Undertaking manual searches: BD

Screening search results: BD

Organizing retrieval of papers: BD

Screening retrieved papers against inclusion criteria: BD, JPW, TH

Appraising the quality of papers: BD, JPW, TH, JLB

Abstracting data from papers: $\mathrm{BD}, \mathrm{JPW}, \mathrm{TH}$

Writing to authors of papers for additional information: BD

Providing additional data about papers: BD

Obtaining and screening data on unpublished studies: BD

Data management for the review: BD, JPW, DB, JL 
Entering data into Review Manager 5: BD, JPW

Review Manager 5 statistical data: BD, JPW

Other statistical analysis not using Review Manager 5: BD

Interpretation of data: BD, JPW, JLB

Statistical inferences: BD, JPW, JLB

Writing the review: $\mathrm{BD}$, JPW, JLB, TH

Securing funding for the review: N/A

Performing previous work that was the foundation of the present study: BD, JPW, JL, TH

Guarantor for the review (one author): BD

Person responsible for reading and checking review before submission: BD, JL, JPW, JLB, TH, DB

\section{DECLARATIONSOF INTEREST}

Brett Doleman: received a grant in 2015 from the Association of Anaesthetists of Great Britain and Ireland (AAGBI) (free from industry support) for a randomized controlled trial of preventive paracetamol and has previously undertaken meta-analyses of preventive paracetamol and gabapentin (Doleman 2015a; Doleman 2015b).

Jo Leonardi-Bee: no declarations of interest.

Thomas Heinink: no declarations of interest.

Debamita Bhattacharjee: no declarations of interest.

Jon Lund: received a grant in 2015 from AAGBI (free from industry support) for a randomized controlled trial of preventive paracetamol and has previously undertaken meta-analyses of preventive paracetamol and gabapentin (Doleman 2015a; Doleman 2015b).

John P Williams: received a grant in 2015 from AAGBI (free from industry support) for a randomized controlled trial of preventive paracetamol and has previously undertaken meta-analyses of preventive paracetamol and gabapentin (Doleman 2015a; Doleman 2015b).

\section{DIFFERENCES BETWEEN PROTOCOLANDREVIEW}

We made the following changes from the published protocol (Doleman 2017b).

1. We changed the title to more accurately reflect the content of the review.

2. We added a new author (DB) to assist with data collection.

3. We only reported number needed to treat for an additional beneficial/harmful outcome (NNTB/NNTH) if we found significant differences on analysis, as this information would not add further information to the already reported effect estimates.

4. We changed the outcomes reported in the 'Summary of findings' tables so as to not exceed the maximum recommended. We included our primary outcomes and adverse events as well as outcomes of importance for analgesic trials, and removed nausea and vomiting, time to analgesic request, and chronic pain.

5. We removed the specific measurement scale 'Ramsey sedation scale' from the sedation outcome to be more inclusive.

6. Following advice from the review statistician, we changed some language in the Data synthesis section regarding inputting data for continuous outcomes.

7. We added information on specific opioid agents that were assigned to each subgroup category for clarity (see Subgroup analysis and investigation of heterogeneity).

\section{IN DEX TERMS}

\section{Medical Subject Headings (MeSH)}

*Surgical Procedures, Operative; Acute Pain [prevention \& control]; Analgesics, Opioid [ ${ }^{\star}$ therapeutic use]; Bradycardia [epidemiology]; Hypotension [epidemiology]; Hysterectomy [adverse effects] [methods]; Morphine [therapeutic use]; Pain, Postoperative [diagnosis] [ ${ }^{\star}$ prevention \& control]; Pain, Procedural [* prevention \& control]; Randomized Controlled Trials as Topic

\section{MeSH check words}

Adult; Humans

Pre-emptive and preventive opioids for postoperative pain in adults undergoing all types of surgery (Review)

Copyright (c) 2018 The Cochrane Collaboration. Published by John Wiley \& Sons, Ltd. 